\title{
Do Online Voter Guides Empower Citizens? Evidence from a Field Experiment with Digital Trace Data*
}

\author{
Simon Munzert, Hertie School ${ }^{\dagger}$ \\ Pablo Barberá, University of Southern California \\ Andrew Guess, Princeton University \\ JungHwan Yang, University of Illinois at Urbana-Champaign
}

\section{Accepted for publication at Public Opinion Quarterly}

\begin{abstract}
Voting Advice Applications (VAAs), which provide citizens with information on the party that best represents their political preferences, are often cited as evidence of the empowering capabilities of digital tools. Aside from the informational benefits of these voter guides, observational studies have suggested a strong effect on political participation and vote choice. However, existing impact evaluations have been limited by a reliance on convenience samples, lack of random assignment, or both. This raises questions about self-selection and the precise mechanisms underlying how voters learn about politics. Here, we provide evidence from a field experiment with survey outcomes conducted with a sample of over 1,000 German citizens in the 2017 federal election campaign. Using linked panel survey and digital trace data combined with a randomized encouragement to complete a VAA, we are able to assess respondents' compliance with treatment as well as to observe how the use of this tool affects political behavior, attitudes, media consumption, political knowledge, and even social media activity. Our findings reveal that the overwhelming consensus in favor of positive effects on turnout and vote choice should be treated with caution, as we find no such effects. Rather, we show that the actual virtue of VAAs in a complex online information environment is in increasing knowledge about parties' positions on issues - exactly the kind of information these tools were designed to provide.
\end{abstract}

Keywords. voting advice applications, field experiment, encouragement design, Germany, digital trace data, political knowledge

*This research was generously funded by a grant from the Volkswagen Foundation Computational Social Science Initiative, reference 92 143. This study was approved by the Princeton University Institutional Review Board (\#8327, 10014, 10041). We thank Toma Pavlov, Sebastian Ramirez Ruiz, and Jona Ronen for helpful research assistance.

${ }^{\dagger}$ Corresponding author. Hertie School, Friedrichstr. 180, 10117 Berlin, Germany. Email: munzert@hertieschool.org. 


\section{Introduction}

In dynamic electoral systems with multiple parties and shifting coalitions, even the most attentive voters can have trouble keeping track of platforms and campaign promises. This concern motivates civic interventions designed to boost knowledge about the positions of political candidates and how they relate to citizens' own preferences. A prominent and much-studied example is the use of online voter guides, or Voting Advice Applications (VAAs), that quiz users on their positions and provide information about the parties and candidates whose policies most closely match them (Schultze, 2014; Westle, Begemann and Rütter, 2014; Kamoen et al., 2015; van de Pol, 2016). Often deployed in cooperation with major media organizations, public broadcasters, and online platforms, these voter guides are widely used - and shared via social media - in many countries. Proponents argue that by providing useful information, VAAs can boost turnout and better align users' voting behavior with their preferred political positions. With a seemingly endless amount of content online available to consume and competing demands on people's attention, do voter guides help the citizens who could benefit from them the most?

To answer this question, we deployed a field experiment in a nationally representative online panel survey in Germany in which respondents were randomly incentivized to use a VAA shortly before the 2017 federal elections. The challenge in evaluating behavioral and informational effects of VAAs is that self-selection patterns generally observed in media consumption (e.g., Arceneaux and Johnson 2013) are likely to be present in the use of voter guides as well. If people who are interested in politics and tend to vote in elections are already likely to use VAAs, then these tools' effectiveness in reducing inequalities in knowledge and turnout may be limited. ${ }^{1}$ And crucially from the standpoint of research design, observational analysis may lead to inappropriate inferences that mistake these selection dynamics for causal effects. Randomly encouraging panelists to use the VAA allows us to identify local treatment effects among compliers. Furthermore, to avoid well-known problems with self-reported measures of VAA usage, we are able to track use of the application with digital trace data linked to individual respondents.

Challenging the consensus in existing research, we find no evidence that VAAs are effective in motivating citizens to vote or alter their vote preferences. Instead, we show that VAAs succeed in significantly increasing knowledge about parties' positions on issues - exactly the kind of benefit these tools are designed to provide.

\section{The use and popularity of voting advice applications}

A Voting Advice Application (VAA) is an online tool, either a website or a mobile app, that guides voters' choices by showing them how their positions on issues correspond to those of each party competing in the election (see, e.g., Garzia and Marschall, 2012). When voters open this tool, they are first asked to complete a series of items to indicate their agreement with policy statements on salient political, social, and economic issues. VAAs compile party positions on this exact same set of issues by either asking them directly or inferring them from public statements such as manifestos, press releases, and speeches. This allows the VAA to compute the overlap between a voter's and each party's position and make a recommendation to the voter regarding which party best represents his or her opinion. This

\footnotetext{
${ }^{1}$ Perhaps in response to such concerns, Facebook has implemented features intended to inform users about parties' positions on issues: https://de.newsroom.fb.com/news/2017/09/update-zu-den-wahlen/. Last accessed: April 9, 2020.
} 
information is then displayed to the voter as a ranked list of parties or a graph that visualizes how their positions compare to those of the parties. The tool thus matches voters with parties and also provides them with information about the issue positions of parties. ${ }^{2}$

Over the past decade, VAAs have become extremely popular, particularly in European countries with multi-party systems such as Netherlands, Belgium, Germany and Switzerland, and also during second-order elections, such as the elections to the European Parliament. ${ }^{3}$ Although VAAs tend to be developed by governmental agencies or private companies in partnership with academics, they are often advertised by the most prominent media outlets in each country, which contributes to their visibility. More recently, Facebook deployed its own variant in countries including Germany and the United States, where it offered a "Vote Planner" for the 2016 election with information about where candidates at all levels of government stood on relevant political issues. ${ }^{4}$

\section{On the search for effects of voting advice applications}

A large number of studies has examined the potential effects of VAAs on voters' political behavior at the individual level, with at times contradictory findings. These studies usually focus on one or more of the following outcomes of interest: the decision to turn out out to vote, whom to vote for in the election, a boost in knowledge about related issues, and activation in terms of information seeking during the campaign.

Our study likewise adopts these outcomes of interest. To be able to contrast our results with those presented in previous research, we conducted a systematic review of VAA effects studies. All in all, we identified 25 studies (61 unique effects) that were designed to identify attitudinal and behavioral effects of VAA usage. ${ }^{5}$

\footnotetext{
${ }^{2}$ See Section C in the Online Appendix for screenshots from the German VAA "Wahl-O-Mat" as implemented for the German Federal Election 2017, which is the tool under study here.

${ }^{3}$ Such tools have not gained as much traction in the United States. During the 2016 election campaign, a partnership between a Canadian VAA provider and a U.S. online news organization yielded approximately 70,000 responses. See https://www.vox.com/policy-and-politics/2016/10/25/13345184/trump-voters-more-liberal-chart, last accessed: April 9, 2020. A related tool, iSideWith, has garnered tens of millions of uses since 2012, although whether it should be classified as a VAA rather than a viral quiz made primarily for instructional purposes is debatable. See https://www.washingtonpost.com/news/the-intersect/wp/2016/11/07/ thousands-of-people-have-changed-their-votes-after-taking-this-quiz-will-you/, last accessed: April 9, $2020 . \quad$ Future research should explore the origins of VAAs' distinctive use pattern in the United States, although we suspect that one reason may be related to a coordination problem: Aside from the Vote Compass effort mentioned here, at least four major news organizations - including CNN and USA Today - sponsored separate online voter guides in 2016.

${ }^{4}$ See https://newsroom.fb.com/news/2016/10/preparing-for-the-us-election-2016/, last accessed: April 9, 2020.

${ }^{5}$ In order to identify research on attitudinal and behavioral effects of VAAs, we proceeded as follows: First, we looked through the work listed on the pages of the ECPR Research Network on Voting Advice Applications, which provides a curated bibliography on research related to VAAs in general (see http://vaa-research.net/?page_id=18). Second, we did a research on Google Scholar using the keywords "voting advice application" and "effect". Third, using all studies we had identified until then, we screened their bibliographies for further relevant studies. Fourth, we contacted authors of the collected papers and asked them to identify further studies that we had not collected yet. Next, we classified the effects reported in studies by the outcomes they studied using the broad categories turnout behavior, voting behavior, political knowledge, and information seeking. Duplicate studies as well as such that did not focus on any of these outcomes were excluded. Furthermore, we excluded studies that implemented a design which did not offer a plausible control group of VAA usage, in particular studies exclusively looking at VAA user samples without a before-after measure. In each study, we then identified effects of interest. If multiple model specifications were presented, we relied on the model the authors regarded as the most relevant one.
} 
Table 1: Overview of VAA effects studies by study design and outcome of interest.

\begin{tabular}{|c|c|c|c|c|}
\hline \multirow[b]{2}{*}{ Article } & \multicolumn{4}{|c|}{ Effect tendency for outcome } \\
\hline & Turnout & Vote choice & $\begin{array}{c}\text { Political } \\
\text { knowledge }\end{array}$ & $\begin{array}{c}\text { Information } \\
\text { seeking }\end{array}$ \\
\hline \multicolumn{5}{|l|}{ Observational - no panel } \\
\hline Garzia and Angelis (2014) & + & & & \\
\hline Garzia, Trechsel and De Angelis (2017) & + & & & \\
\hline Marschall and Schultze (2012) & + & & & \\
\hline Mykkänen and Moring (2006) & + & & & \\
\hline Schultze (2014) & \multicolumn{4}{|c|}{+} \\
\hline \multicolumn{5}{|l|}{ Observational - panel } \\
\hline Andreadis and Wall (2014) & & + & & \multirow{5}{*}{+} \\
\hline Gemenis and Rosema (2014) & + & & & \\
\hline Heinsohn et al. (2016) & + & & + & \\
\hline Klein Kranenburg (2015) & & + & & \\
\hline Kleinnijenhuis et al. (2017) & & + & & \\
\hline Manavopoulos et al. (2018) & & & & \multirow[t]{4}{*}{+} \\
\hline Ruusuvirta and Rosema (2009) & + & + & & \\
\hline Walgrave, Van Aelst and Nuytemans (2008) & & 0 & & \\
\hline Westle, Begemann and Rütter (2014) & & & 0 & \\
\hline \multicolumn{5}{|l|}{ Observational - selection models } \\
\hline Gemenis (2018) & 0 & & & \multirow{6}{*}{+} \\
\hline Germann and Gemenis (2019) & + & & & \\
\hline Heinsohn et al. (2019) & + & & 0 & \\
\hline Pianzola $(2014 a)$ & & + & & \\
\hline Pianzola $(2014 b)$ & & + & & \\
\hline van de Pol (2016) & & & - & \\
\hline \multicolumn{5}{|l|}{ Experimental } \\
\hline Enyedi (2016) & 0 & 0 & & \multirow{5}{*}{0} \\
\hline Mahéo (2016) & & 0 & & \\
\hline Mahéo (2017) & 0 & & & \\
\hline Pianzola et al. (2019) & & 0 & & \\
\hline Vassil (2011) & + & 0 & & \\
\hline \multicolumn{5}{|c|}{$\begin{array}{l}\text { Note: Reported effect tendencies indicate positive (+) or negative (-) effects significant at the } 5 \% \text { level and null effects (0). Studies were classified as } \\
\text { follows: (1) Observational - no panel when VAA usage is not manipulated and the outcome is measured in a singular observation (post VAA usage) } \\
\text { without a pre-VAA baseline, (2) Observational - panel when the outcome is measured before and after VAA use allowing to identify changes, (3) } \\
\text { Observational - selection models when authors estimate the effect through a two-equation structure, where selection into VAA use is explicitly modeled, } \\
\text { and (4) Experimental when VAA usage is randomly manipulated. }\end{array}$} \\
\hline
\end{tabular}

The reported effects we identified are indicated in Table 1 and summarized in Figure $1 .^{6}$ Studies are sorted by research design type (see discussion in the following section). As can be seen, the questions of whether VAAs affect turnout and vote choice are at the core of the VAA effects research program. With regards to turnout, the vast majority of effects reported in the literature are positive, and most imply a significant boost in turnout among VAA users compared to VAA non-users. Substantively, the magnitude of the reported effects varies widely. Gemenis (2018) estimates an effect on the probability of voting in the May (June) 2012 Greek parliamentary election of 9.5 (6.2) percentage points (but no

\footnotetext{
${ }^{6}$ Some studies report effects for multiple outcomes or elections, which is why the number of effects is higher than the number of studies.
} 
Figure 1: Summary of VAA effects studies (see Table 1 for an overview). Reported effects by outcomes, direction, and significance (at $p<0.05$ ).

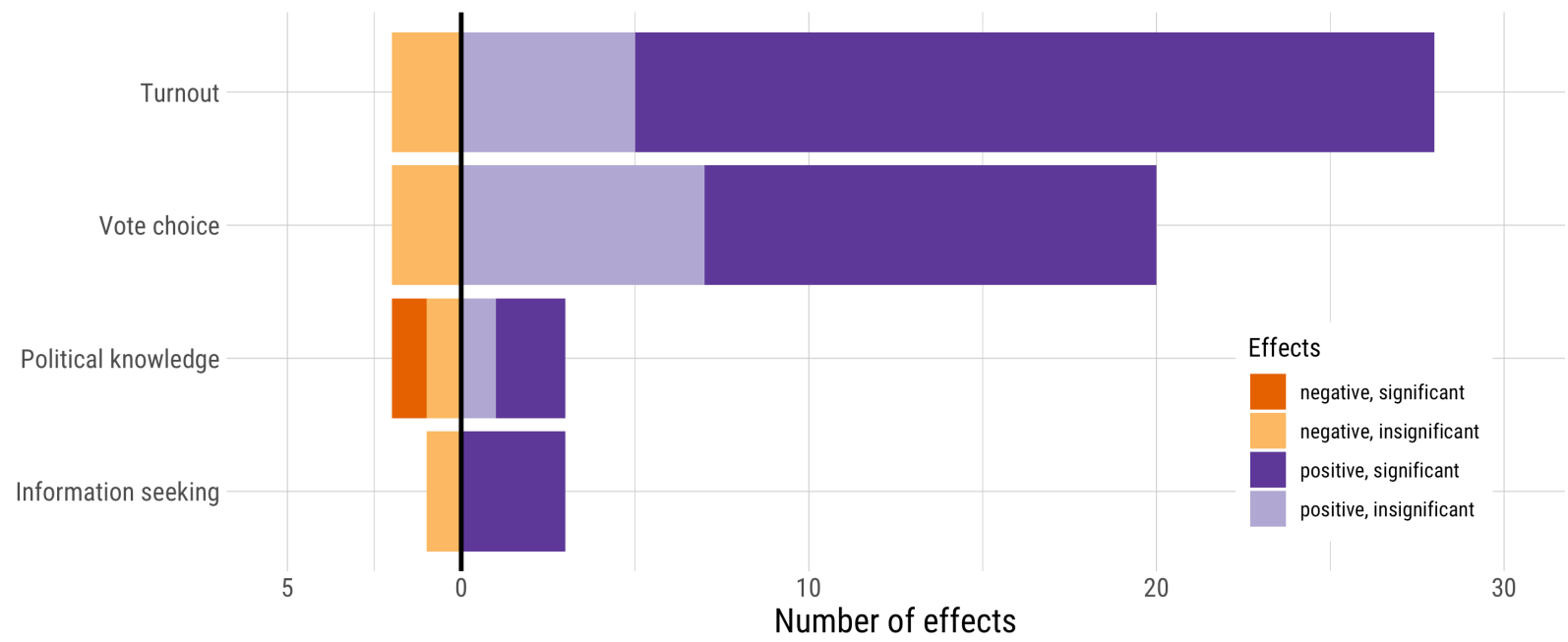

significant effects at later elections). Ruusuvirta and Rosema (2009) report a difference associated with VAA usage of 24 percentage points for those who were a priori uncertain about their intention to vote. On the other hand, neither Mahéo (2017) nor Enyedi (2016), who study the effect in the context of experiments where VAA usage is randomly assigned, find significant effects on electoral participation.

The second major outcome that is studied in VAA effects research is vote choice (sometimes operationalized as vote switching). Again, the majority of studies identifies positive and significant effects of VAA usage on people's inclination to adapt their voting behavior. A major comparative study by Andreadis and Wall (2014) reports vote switches between 19 and 44 percentage points at various national elections in European countries and concludes that VAA use had a significant impact on switching in a majority of these settings. However, existing experimental studies consistently fail to uncover significant effects.

Finally, an obvious but understudied question is whether these tools, which first and foremost provide information about parties' policy positions, foster knowledge about these positions or even motivate them to look for further information on vote options. This mechanism is fundamental for downstream effects on actual changes in voting behavior. The research on such immediate cognitive and behavioral consequences, however, is limited. When measuring levels of political knowledge about party positions using (independent) German samples, both Schultze (2014) and Heinsohn et al. (2016) find moderate positive effects of VAA usage, while van de Pol (2016) even reports negative effects in a Dutch sample. Conversely, Heinsohn et al. (2019) do not find robust changes on a similar measure, but report increased interested in the campaign. Mahéo (2017) is the first to provide evidence on the impact on VAA usage on campaign-related information seeking behavior, finding no substantive effects. On the other hand, Manavopoulos et al. (2018) report a surplus of politics-related media consumption among VAA users. 


\section{Methodological issues in research on VAA effects}

Our discussion of the literature indicates that, while the reported effects vary substantially and are at times difficult to compare, they are often large, positive, and — if VAA usage was not randomly encouraged - significant. So why keep studying these questions? The seeming consensus in the literature is, in our view, largely due to key methodological decisions that limit our ability to make valid inferences about these important questions. These issues are related to two areas: sampling and measurement.

As highlighted in Table 1, most previous studies rely on observational data that suffers from selfselection into the treatment and into the sample, which leads to endogeneity issues that are likely to inflate the estimated effects of VAA usage (Pianzola, 2014a). Despite their wide popularity across multiple countries, previous work has revealed important selection effects regarding who uses VAA tools, consistent with inequalities in other forms of online political engagement (Norris, 2001; Vaccari, 2013). Younger voters who are highly educated, politically interested, and politically knowledgeable are disproportionately more likely to use a VAA (Marschall and Schultze, 2014, 2015; Vassil, 2011). Other difficult-to-observe characteristics such as digital literacy might play a role as well.

Given the biases in usage as well as selection into taking the survey, early studies relying on crosssectional data suffer from lack of internal (causal) and external validity (generalizability). To counter these biases, designs have advanced over time, exploiting panel setups (e.g., Andreadis and Wall, 2014; Heinsohn et al., 2016; Walgrave, Van Aelst and Nuytemans, 2008) and implementing various forms of selection and matching methods (e.g., Gemenis, 2018; Pianzola, 2014a). More recently, a set of pioneering studies has adopted an experimental approach to identify VAA effects by randomly assigning VAA use (e.g., Enyedi, 2016; Mahéo, 2016; Vassil, 2011; Pianzola et al., 2019). A limitation of the experimental approach is that these well-designed studies tend to rely on small sample sizes and lack compliance indicators. The former is problematic when expected effect sizes are small, providing the designs with too little power. The latter is important for identifying the effect of VAA use among "compliers" - those who use it as a result of treatment assignment (Gerber and Green, 2012). This is key in contexts where VAAs are relatively popular and participants assigned to the control group make use of the tool anyway. Likewise, respondents assigned to the treatment group may not take the VAA (Germann and Gemenis, 2019).

A second set of issues relates to measurement of treatment and outcome variables. Cross-sectional studies that use post-election surveys rely on self-reported measures of VAA usage, which could suffer from over-reporting due to social desirability bias or under-reporting if the survey is administered weeks after respondents use the tool. Surveys embedded within VAAs themselves do not suffer from this issue, but they do lack a control group of non-VAA users (which is why we excluded them from our discussion of the literature). Common to both designs is the lack of both pre- and post-treatment measures of the relevant outcome variables, such as levels of political knowledge or vote choice. In the absence of this longitudinal component, it is hard to overcome the selection issues discussed above. On the other hand, while panel setups allow the study of change on outcomes and mitigate the confounding influence of time-constant respondent characteristics, they are no panacea to the selection issue, since VAA usage could in part be driven by time-varying factors, such as campaign-induced interest in parties or policies. Furthermore, panel conditioning might affect measures on both sides of the equation (Warren and Halpern-Manners, 2012). 


\section{Methods}

Our goal is to study the real-world effects of a VAA on a set of substantively meaningful outcomes. In particular, we address the core questions asked in the rich literature on VAA effects: Does VAA usage encourage people to vote? Does it induce changes in vote choice? Does it affect people's knowledge on parties' issue positions? And does it have downstream effects on information search behavior?

At the same time, we aim to approximate the ideal empirical study to estimate these effects, tackling methodological issues that have plagued a fair share of the existing research: To sidestep concerns about selection, building on the latest generation of VAA effects research we randomly assign VAA usage to a sample of the voting population that potentially gets exposed to the VAA and measure the relevant outcome variables before and after the administration of the treatment. Furthermore, we monitor compliance with the treatment by directly observing whether the survey respondents completed the VAA, limiting the problems of over- and underreporting of VAA usage.

\section{Experimental design}

Our experimental design is built on a randomized encouragement to use the German VAA (Wahl-OMat) during the field period between two survey waves. The Wahl-O-Mat is the most popular VAA in Germany. It was deployed for the first time in advance of the 2002 Federal Election and, with all its various editions (many of the state-level elections had their own version of the Wahl-O-Mat, too), has been used over 70 million times since then (Bundeszentrale für politische Bildung, 2018). It was used more than 15 million times for the 2017 Federal Election alone, compared to an electorate of about 60 million. ${ }^{7}$ A significant share of the attention the tool has received is often attributed to the fact that it was promoted by over 60 media partners (mostly online news outlets), some of which embedded the tool on their webpages. Further, a smartphone and tablet app was available for Android and iOS.

A randomly chosen subset of the survey respondents (60\%) received an encouragement in the form of a request to use the Wahl-O-Mat before the next survey wave. Figure 2 provides the encouragement shown to the randomly selected subset of survey respondents. ${ }^{8}$ Note that the respondents had three options: (1) agree to use the Wahl-O-Mat and at the same time disclose that they have not used it yet, (2) agree to use the Wahl-O-Mat and disclose that they have already used it, and (3) decline to use

it. Given that we could neither prevent respondents from using the tool if they did not receive the encouragement (or had used it before the encouragement was delivered) nor force non-users to use it, our design produces two types of non-compliance:

(a) Respondent is encouraged to use VAA but does not ("never-takers");

(b) Respondent is not encouraged to use VAA but nevertheless does ("always-takers").

The challenge in addressing two-sided non-compliance in designs lacking a placebo group is that we cannot observe membership in the "always-taker" or "never-taker" groups (Gerber and Green, 2012). This is because subjects in the control group who do not use the VAA could either be "complying" with non-encouragement or they could be never-takers who would also not have used the VAA had they been assigned to the treatment group. Similarly, those in the treatment group who use the VAA could be compliers or always-takers.

${ }^{7}$ This figure represents uses, not unique users, so the actual fraction of Wahl-O-Mat users in the electorate is likely to be lower than $25 \%$.

${ }^{8}$ See Section $\mathrm{C}$ in the Online Appendix for screenshots of the actual implementation. 
Figure 2: Representation of the encouragement item in the survey (translated from German).

In the next survey, we would like to ask you some questions on positions of parties as well as your own attitudes towards certain political topics. For this purpose, we would like to ask you to use the voting advice application "Wahl-O-Mat", offered by the Federal Agency for Civic Education [Bundeszentrale für Politische Bildung] at www.wahl-o-mat.de before the next wave. Would you be willing to use this tool before the next survey, which will take place in about two weeks?

Please note: If you agree, we would remind you of using the tool by e-mail before the next survey starts. In compensation of your consent, you would be reimbursed with 50 YouGov points.

Yes, I am willing to use the Wahl-O-Mat before the next survey, and I have not used it so far.

Yes, I am willing to use the Wahl-O-Mat before the next survey, and I have already used it.

No, I am not willing to use the Wahl-O-Mat.

The typical resolution to this issue is to compute the Complier Average Causal Effect (CACE), an estimand equivalent to the treatment effect among compliers (Angrist, Imbens and Rubin, 1996). The CACE (sometimes referred to as the LATE, or Local Average Treatment Effect) is estimated by using treatment assignment as an instrument for actual treatment, scaling the Intent to Treat (ITT) by the share of compliers in the treatment group. This is identified because, while we do not know the precise identity of the compliers in both treatment and control groups, randomization guarantees that in expectation the proportion of compliers in both is equal. In interpreting the CACE, it is important to remember that estimates are local: specific to compliers, or subjects who use the VAA if and only if encouraged to do so.

In our presentation of results, in addition to the CACE estimates we will also offer ITT as an estimand gauging the impact of treatment assignment. ITT speaks to the causal effect of randomly encouraging people in the population to make use of the VAA, which is a relevant quantity of interest from a policy intervention perspective. Furthermore, we will report the effect solely based on observed VAA usage, irrespective of treatment. This is an estimand much more vulnerable to selection bias and therefore potentially closer to many of the effects reported in earlier literature. Instrumenting VAA usage with assignment, we estimate the CACE for all outcomes reported in the paper via Two Stage Least Squares regression with robust standard errors ( $\mathrm{HC} 2$ ) and adjusting using the pre-treatment covariates gender, age, education, household income, political interest, and left-right ideology. For the ITT, treatment assignment is used along with the same set of covariates.

\section{Survey}

The experiment was embedded in an online panel survey initially fielded to 1,500 respondents recruited for the German YouGov Pulse panel, which enables passive metering of individuals' web usage on desktop and mobile devices. This allows us to observe every URL that respondents visited and the apps they used during our period of study. The Pulse panel is a subset of YouGov's standard survey respondent pool. 
Table 2: Descriptive statistics of respondent characteristics, by subgroup. Percentages within characteristics reported.

\begin{tabular}{|c|c|c|c|c|c|c|}
\hline \multirow[b]{3}{*}{ Respondent characteristic } & \multirow{3}{*}{$\begin{array}{l}\text { b4p'17 } \\
\text { Index }\end{array}$} & \multirow{3}{*}{$\begin{array}{r}\text { Full } \\
\text { sample }\end{array}$} & \multicolumn{4}{|c|}{ Wahl-O-Mat... } \\
\hline & & & \multicolumn{2}{|c|}{ Encouragement } & \multicolumn{2}{|c|}{ Usage } \\
\hline & & & No & Yes & No & Yes \\
\hline \multicolumn{7}{|l|}{ Gender } \\
\hline -Male & 53 & 52 & 57 & 52 & 52 & 53 \\
\hline -Female & 47 & 48 & 43 & 48 & 48 & 47 \\
\hline \multicolumn{7}{|l|}{ Age } \\
\hline$-18-34$ & 28 & 28 & 23 & 23 & 26 & 26 \\
\hline$-35-44$ & 17 & 18 & 19 & 20 & 19 & 18 \\
\hline$-45-54$ & 23 & 24 & 26 & 24 & 24 & 24 \\
\hline$-55+$ & 32 & 30 & 32 & 33 & 31 & 32 \\
\hline \multicolumn{7}{|l|}{ Education } \\
\hline -No graduation & 1 & 1 & 0 & 1 & 1 & 1 \\
\hline -Lower secondary school & 27 & 15 & 18 & 15 & 18 & 15 \\
\hline -Middle school & 35 & 39 & 40 & 41 & 47 & 35 \\
\hline -High school & 37 & 44 & 42 & 43 & 34 & 49 \\
\hline
\end{tabular}

The survey launched on July 13, 2017, about ten weeks before election date and just before the more intensive campaign phase. The first four waves were fielded before the election, the last wave after the election. The encouragement was issued in Wave 3, which was fielded between September 4 and 13, or three weeks before election date. The Wahl-O-Mat launched on August 30, 2017, which gave respondents the opportunity to use it before receiving the encouragement treatment in the survey. For the analysis presented here, we subset our sample, only using respondents who took part in Waves 3 , 4 , and 5, which are the waves in which most of the outcomes of interest are measured. Accounting for item non-response on pre-treatment variables that go into the models, this reduces our sample size to 979 respondents. ${ }^{9}$

Table 2 reports a comparison of respondent characteristics on core demographic variables in the full sample (wave 1) as well as by encouragement assignment and VAA use, together with distributional information from the Best for Planning study (Best for Planning, 2017), a high-quality face-to-face study that was used to identify target marginals of the German population that used the internet as a sampling frame, which were then employed by YouGov for quota-based recruitment. It is evident that the target distributions are mostly well matched by the full sample, with the only exception being that people in the upper two quartiles on the education variable are slightly overrepresented. While the treatment and control groups are balanced reasonably well, actual use (which was partly encouraged) is more prevalent among highly educated people (those with a high school degree) than people of lower formal education (degree from a lower secondary school or middle school). ${ }^{10}$

\footnotetext{
${ }^{9}$ More information on the survey setup, the recruitment and enticement of survey respondents, and the deployment of the passive metering software is reported in Online Appendix A.

${ }^{10}$ It is likely that these differences would have been even larger had we not randomly encouraged a subset of the sample to use the tool.
} 


\section{Measuring VAA usage with digital trace data}

A core advantage of our setup is that we can draw on two complementary indicators of VAA usage. First, we have a conventional survey-based measure that asks about VAA use in Wave 4 (posttreatment). While this item helps uncover treatment status for both groups, it should not be used naïvely, as it might suffer from social desirability bias: Respondents who originally agreed to using the tool-and were incentivized to do so regardless of actual usage-might feel obliged to report compliance. Furthermore, respondents from the control group might more generally feel that using this tool is socially desirable, especially in the context of a study that is clearly focused on political matters. Moreover, they might confuse their usage of the VAA for previous elections with the currently available tool, although we try to guard against such misunderstandings by asking for usage for this particular election.

Unlike previous field experiments of media effects, which have relied on self-reported measures of compliance collected via post-treatment surveys (e.g., Pianzola et al., 2019; Vassil, 2011), we are able to at least partly overcome this shortcoming by exploiting comprehensive individual-level data on web usage. This allows us to directly observe whether a respondent used (and, making some assumptions, did not use) the VAA. To that end, we compared subjects' complete available browsing histories with URLs that led to the Wahl-O-Mat. ${ }^{11}$ If any of these URLs was found in a person's browsing history, we coded this as a valid case of usage of the VAA. In addition, we tracked whether the person had installed the VAA app on her mobile device. If yes, we also coded this as VAA usage.

While the tracking-based measure is certainly an improvement over previous accounts of compliance, it is not perfect. Respondents in the panel are not always online and using the passive metering software. In our case, web visit data was missing for $22 \%$ of our respondents in the period under study. For those, we imputed VAA use with the self-reported measure. Comparing both measures of compliance, we find that while they are fairly strongly correlated, there is disagreement for a substantive fraction of respondents. $47 \%$ of those for which we could not identify VAA usage in the tracking data they provided stated that they used the Wahl-O-Mat (see Table 3). Disaggregating this by encouragement assignment group shows that measurement error in the tracking software is probably not the main culprit for this mismatch: While $34 \%$ of those identified by tracking as non-users in the control group reported using the tool, $63 \%$ did so in the encouragement group. This is a strong indication of socially desirable answering behavior. At the same time, the share of respondents who were identified as having used the VAA but reported not doing so is substantively smaller (10\%). We take this as evidence in favor of using the tracking data as a more robust compliance measure. ${ }^{12}$

\section{Political outcomes}

In line with what has been studied by the majority of the VAA effects literature, we start by focusing on three core potential effects on citizen empowerment: increasing turnout, changing vote choice, and acquiring political (issue) knowledge. In addition, we make use of the unique behavioral data available

\footnotetext{
${ }^{11}$ In addition to the official landing page of the Federal Agency for Civic Education, https://www.wahl-o-mat.de/ bundestagswahl2017/, we collected 30 more URLs from media partners who embedded the tool on their page. For instance, the popular mainstream news outlet SPIEGEL ONLINE hosted the Wahl-O-Mat at http://wahlomat.spiegel.de/ 2017bundw/, while the webpage of the flagship TV news program of the public service broadcaster ARD, the Tagesschau, featured it at http://wahl-o-mat.tagesschau.de/. For a complete list of the URLs used, see Table B8 in the Online Appendix.

${ }^{12}$ As a robustness check, the 147 respondents with missing tracking data and reported VAA usage were discarded from the analysis. The results remained virtually identical; see Figure B7 in the Online Appendix.
} 
Table 3: VAA use, survey-based vs. tracking-based measure

\begin{tabular}{llcccc}
\hline & \multicolumn{5}{c}{ VAA use, reported } \\
\hline & & No & Yes & Missing & Total \\
& No & 233 & 203 & 0 & 436 \\
VAA use, tracked & Yes & 39 & 344 & 0 & 383 \\
& Missing & 84 & 147 & 0 & 231 \\
& Total & 356 & 694 & 0 & 1050 \\
\hline
\end{tabular}

for many of the respondents to shed light on the effect of VAA use on online news consumption and social media interactions. Although these are arguably preconditions for downstream consequences on political behavior, these potential effects of VAA use have barely been studied. The measures are operationalized as follows: ${ }^{13}$

Turnout. Lacking validated information about voting behavior, we rest on the reported turnout variable ("Did you vote at the Federal election on September 24?"), measured in wave 5, to assess whether a person voted or not.

Switched vote choice. Respondents were asked in all waves about their vote intention for the upcoming federal election ("You have two votes at the federal election in September 2017. The first is for a candidate in your constituency, the second for a party. What will you choose on the ballot (second vote)?"). We identify changes in vote intention using the immediate pre- and post-treatment measures of waves 3 and 4.

Issue knowledge. In order to measure respondents' knowledge about parties' positions on policy items that were the subject of the tool, we reproduced six of the original 38 Wahl-O-Mat items and asked respondents to select, for each item, the parties that agree with the corresponding statement ("What do you think, which parties agree with the following statements, i.e. support the corresponding statement in the campaign? "). ${ }^{14}$ Comparing these judgments with the party positions as reported in the tool, we then computed the fraction of correctly perceived positions.

News consumption and political exchanges. We approximated respondents' exposure to political information by observing how many visits they made to the online portals of news outlets. To that end, we matched the web tracking data with a list of 309 major and regional media websites and then measured news consumption (in log counts) between wave 4 and Election Day.

Another possible behavioral manifestation of increased interest in politics resulting from VAA completion is a greater number of political posts on social media. As part of our study, we also asked our

\footnotetext{
${ }^{13}$ The untranslated question wordings used for these variables as well as those used for adjustment in the regression setup are documented in Section D in the Online Appendix. Descriptive statistics of the outcome measures by encouragement group and compliance and VAA usage are reported in Figures B3 to B6 in the Online Appendix.

${ }^{14}$ Due to time and budget constraints, we could not replicate the entire set of items in the survey.
} 
Figure 3: Experiment compliance: VAA use by encouragement group.

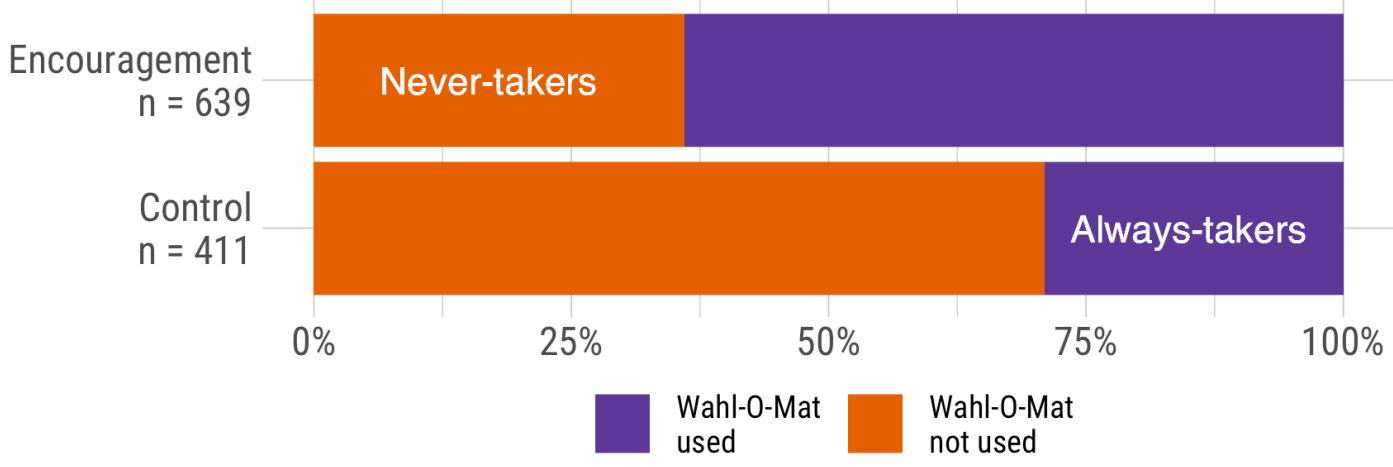

respondents to provide voluntary access to their Twitter and Facebook feeds. Of the 74\% of respondents with a Facebook account, $79 \%$ agreed to share their posts; of the $26 \%$ with a Twitter account, $49 \%$ gave their permission. We then used a dictionary of keywords and hashtags related to politics and the election as a simple classification method to detect how frequently our respondents post political messages on their profiles. Given the sparsity of the data (only 10\% of Facebook users and 28\% of Twitter users ever posted about politics), our outcome variable is simply whether they posted at least one tweet or profile update mentioning one of these keywords during the period after the initial VAA intervention and before the election.

\section{Results}

\section{Compliance}

Before we turn to the main results, we explore the effectiveness of the encouragement. Overall, the encouragement worked very well. Figure 3 provides compliance statistics for both the encouragement and the control group. Using the combined measure (i.e. tracking-based indicator with imputed survey reports), we find that $65 \%$ of those who received the encouragement actually used the VAA, whereas $71 \%$ of those who did not receive the encouragement also did not use it. These figures imply substantive two-sided non-compliance, with 35\% never-takers in the encouragement group and 29\% always-takers in the control group.

To identify the causal effect among compliers, we instrument VAA use with treatment assignment. The first-stage results indicate the strength of the instrument $(F$-test for weak instrument in first stage $=131.53) .{ }^{15}$ Once the encouragement treatment is taken into account, none of the pre-treatment covariates, with the exception of education, seems to have had an impact on VAA use.

To further learn about the subsample that complied with the encouragement, we implement the profiling method suggested by Marbach and Hangartner (2020) for the principal strata. Figure 4 reports point estimates along with $83 \% / 95 \%$ bootstrap confidence intervals on various covariates for the entire sample, compliers, always-takers, and never-takers. Compared to the entire sample, compliers tend to have lower levels of education but report higher likelihoods to vote and vote certainty (all pre-treatment). Levels of political interest and civic knowledge are close to the sample averages. These

\footnotetext{
${ }^{15}$ Table B1 in the Online Appendix reports the complete first-stage results.
} 
Figure 4: Descriptive statistics (mean and 83\%/95\% bootstrap confidence intervals) on various covariates for the principle strata, following the profiling method by Marbach and Hangartner (2020).

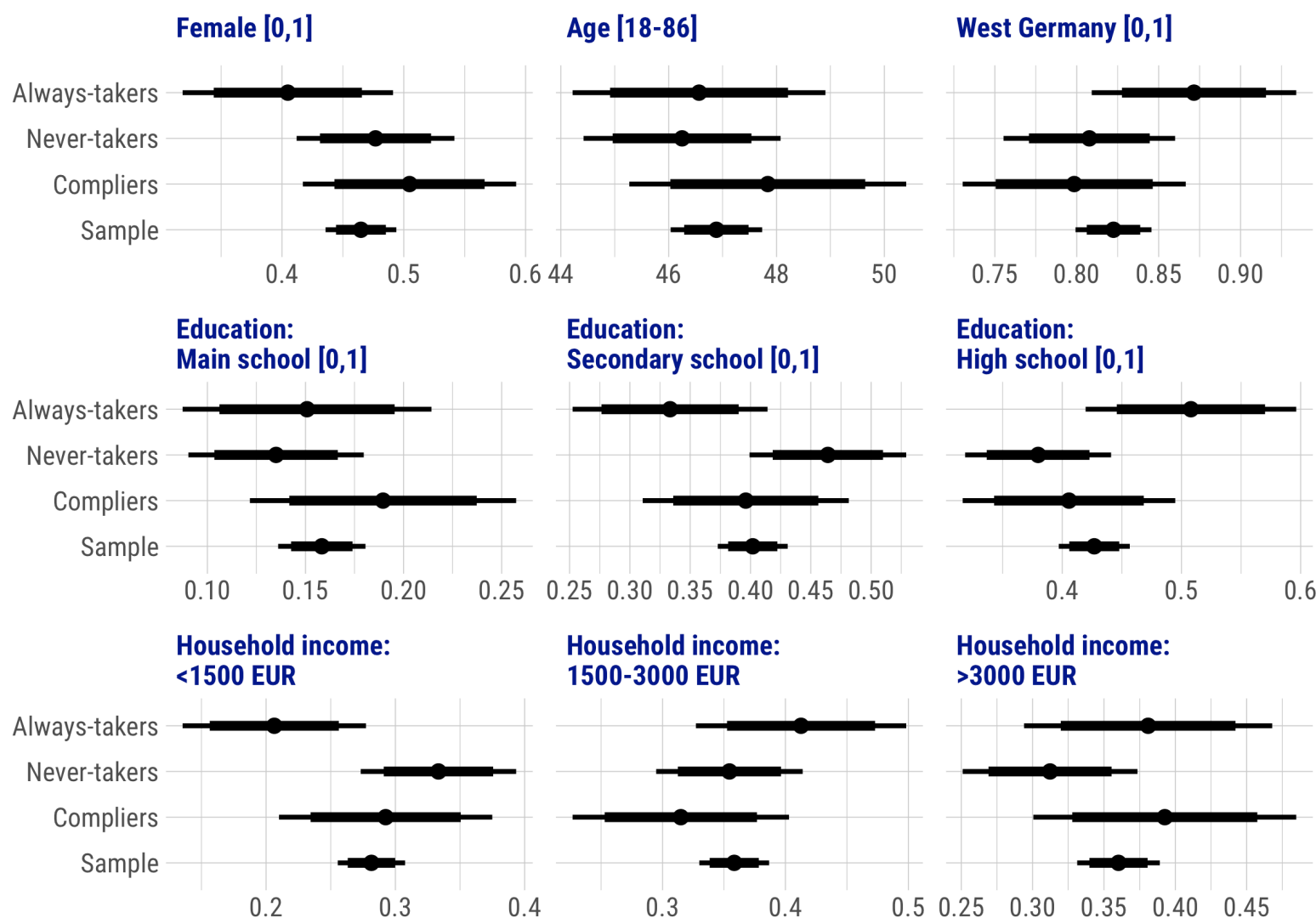

Political interest $[1,5]$

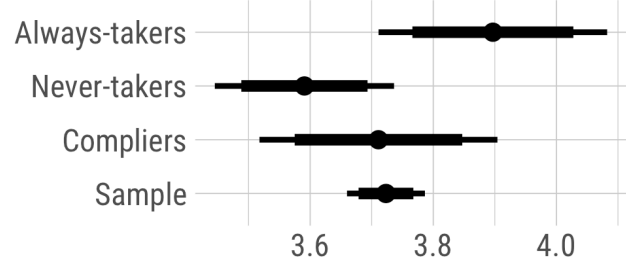

Voted $2013[0,1]$

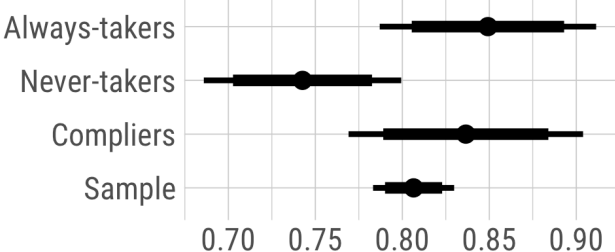

Civic knowledge [0,2]

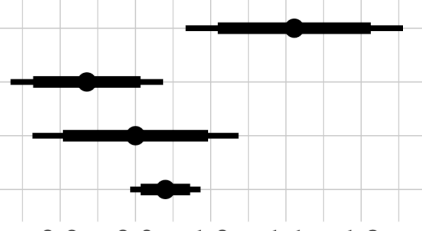

$\begin{array}{lllll}0.8 & 0.9 & 1.0 & 1.1 & 1.2\end{array}$

Likelihood to vote $[1,10]$

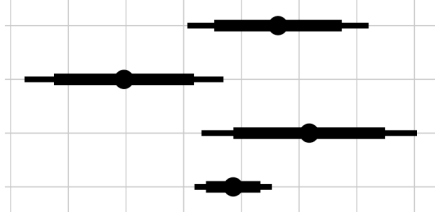

8.4
Political ideology $[1,11]$

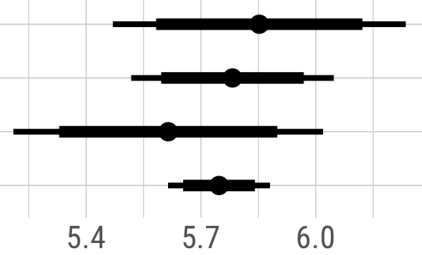

Vote certainty $[1,10]$

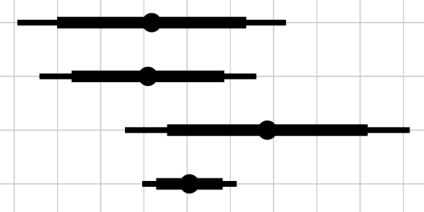

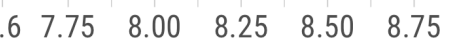

Mean and $83 \% / 95 \%$ confidence intervals

findings are important to keep in mind when putting the estimated local treatment effects into context. In particular, the fact that compliers report, on average, higher likelihoods to vote and certainty whom 
to vote for should limit the potential of the VAA to affect political behavior in this group. Moreover, it becomes visible that never-takers score substantively lower on political interest civic knowledge, previous turnout and likelihood to vote. This is further evidence of the limited potential of the VAA to empower those who are least likely to become politically engaged - they decline to use the tool despite of being financially compensated for it.

\section{Political outcomes}

The first panel on Figure 5 summarizes our results on the impact of the Wahl-O-Mat on turnout, along with $83 \%$ and $95 \%$ confidence intervals. ${ }^{16}$ When we simply compare respondents who completed the VAA with those who did not in an observational analysis - ignoring the randomized component of our design and mirroring early practice in VAA effects research - we do find that VAA use is associated with a 5-percentage-point increase in turnout. However, this difference, which is consistent with the average result in past studies, appears to be due almost entirely to selection bias. The causally identified estimate in our randomized experiment shows that the effect on turnout is not statistically different from zero.

The second panel in this figure displays results on whether respondents switched vote choice between waves. To provide some context for this finding, we compared each respondent's reported VAA recommendation (the party for which the tool reported the highest overlap with the respondent's issue positions; reported in Wave 4) with her pre-treatment vote intention and found that the preferred party was recommended by the app in less than a third of the cases (see Figure B1 in the Online Appendix for the distributions of recommendations and anti-recommendations by party preferences). While these mismatches between preferences and recommendations could conceivably induce users to adapt their vote choices, we find no such evidence in the data using either of the estimands. None of them is statistically different from zero.

It is important to note that switching vote choice is a rather high benchmark. VAAs cannot only convert but also reinforce attitudes, i.e., by increasing vote certainty, likelihood to vote, or simply change a user's sympathy towards particular parties. Just measuring reported changes in vote intentions thus might lead to underestimating attitudinal effects. While we do not find any meaningful effects on the change in either likelihood to vote or vote certainty, we do observe noteworthy (though not significant at the 95\% level) changes among compliers in sympathy towards the Conservatives (CDU/CSU; +0.4 points [95\% CI: $-0.17 ; 1.0$ ] on 11 -point scale, more than for any other party (see Figure B8 in the Online Appendix). This is consistent with the observation that the Conservatives were by far the most popular VAA match in our sample (see again Figure B1). ${ }^{17}$

Finally, did the additional information that respondents obtained by completing the Wahl-O-Mat actually translate into better knowledge of where parties stand? The last panel on Figure 5 displays the change in knowledge about parties' issue positions from before to after the completion of the VAA tool. Here, we do find a significant and positive causal effect: among compliers, the increase in the percentage of issue positions respondents are able to recognize is around 3 percentage points, from

\footnotetext{
${ }^{16}$ In Tables B2 to B7 in the Online Appendix we provide the full regression results of the models summarized here.

${ }^{17}$ Furthermore, it is plausible to expect lower propensities to switch vote choice and, at the same time, increasing vote certainty among those for which preferences and VAA recommendations match and vice versa if preferences and recommendations do not match (Alvarez et al., 2014). However, such effects are very difficult to identify even under random treatment encouragement because the recommendation itself as a mediator was not randomized and the local sequential ignorability assumption is unlikely to hold (Imai, Tingley and Yamamoto, 2013).
} 
Figure 5: Effects of VAA use on self-reported turnout, change in vote choice, and knowledge on parties' issue positions. Observed = VAA users vs. VAA non-users, ITT = Intent-to-Treat, CACE $=$ Complier Average Causal Effect. Bars represent 83\% and 95\% confidence intervals using HC2 standard errors.
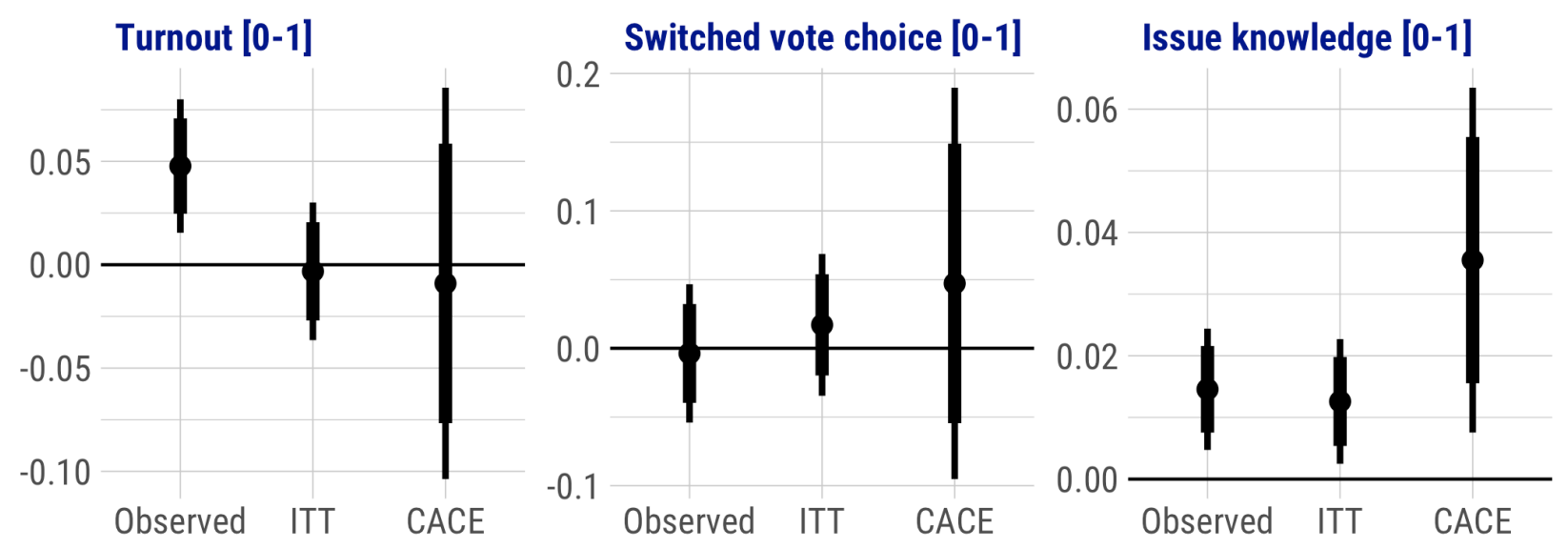

roughly $63 \%$ to $66 \%$. The substantive magnitude of this effect is fairly large: It is similar to the gap in political knowledge between respondents who report moderate political interest and high political interest, and $50 \%$ of the gap in political knowledge between low and high political interest. In other words, completing the Wahl-O-Mat can increase respondents' knowledge from the level of a person who is only somewhat interested in the campaign to someone who is very interested. ${ }^{18}$

In addition to this core set of measures, we employ numerous alternative measures and outcomes, including mobilization to vote between elections, change in political efficacy, and other forms of political knowledge (change in civic knowledge, change in candidate recognition using pictures, and knowledge about recent news events). The corresponding results are presented in Figures B8 and B9 in the Online Appendix. In sum, the results match the main findings above: We do not find evidence for attitudinal or behavioral CACE effects. For knowledge outcomes other than those about parties' issue positions, we also do not find any effects, which seems plausible given the specific, issue-based knowledge that is communicated by the VAA.

\section{Information search and social media activity}

Completing a VAA could potentially have effects beyond an increase in citizens' level of political knowledge or their likelihood to turn out to vote; it may also affect their propensity to consume or produce political information (Mahéo, 2017). Being more familiar with the structure of political competition could boost interest in the election, leading to an increase in visits to news websites; or it may even encourage the sharing of political positions on social media (Fischer et al., 2017).

Contrary to these expectations, however, here we also find null effects (see Figure 6). Even though individuals who complete the VAA visit news websites more than $50 \%$ more often than those who do not, once we account for self-selection, we do not find any significant effects. The pattern for posting

\footnotetext{
${ }^{18}$ In Figure B10 in the Online Appendix, we report effects separated by item and find substantive variation. However, it has to remain speculative as to why knowledge on parties' positions on health care, diesel taxes, and renewable energies increased whereas it did not on fake news regulation, asylum limits, and housing.
} 
Figure 6: Effects of VAA use on news consumption and political posts on Facebook and Twitter. Observed $=$ VAA users vs. VAA non-users, ITT $=$ Intent-to-Treat, CACE $=$ Complier Average Causal Effect. Bars represent $83 \%$ and $95 \%$ confidence intervals using HC2 standard errors.

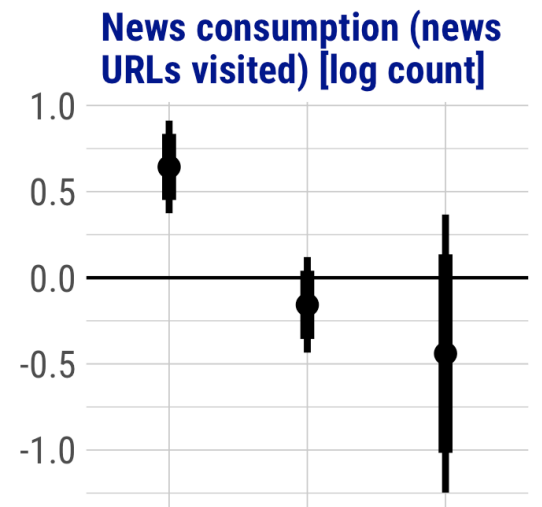

Observed ITT CACE

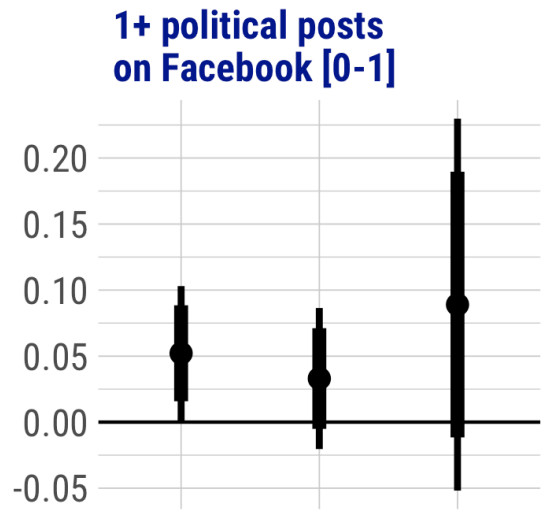

Observed ITT CACE

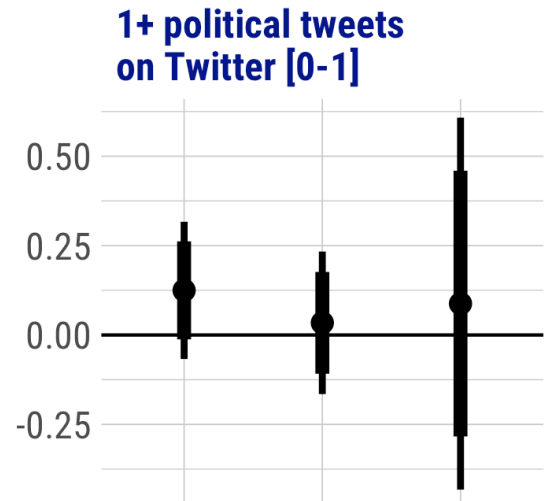

Observed ITT CACE

about politics on Facebook and Twitter is similar: The naïve estimates are in the expected direction (although not statistically significant at conventional levels), but the effects are indistinguishable from zero among compliers.

\section{Heterogeneity}

Even among those who visit VAA websites, there may be considerable effect heterogeneity. If VAAs only reach voters with high levels of knowledge, as Mummolo and Peterson (2017) show in the U.S. context, they may exacerbate participation differences if they impede alternative outreach efforts by media organizations and civic groups, with similar effects as get-out-the-vote campaigns that only mobilize individuals with a high pre-existing propensity to vote (Enos, Fowler and Vavreck, 2013).

Past work has identified heterogeneity of effects along characteristics such as education (Mahéo, 2017), political interest (Alvarez et al., 2014), socio-economic status, and gender (Mykkänen and Moring, 2006). The sample size and compliance rates of our experiments limits our ability to explore subgroup differences in effects. Nevertheless, Figures B11 to B18 in the Online Appendix provide CACE estimates on the core set of outcomes by age, education, gender, political ideology, political interest, civic knowledge, candidate recognition, and party preference (all measured pre-treatment). Even setting aside the enlarged standard errors due to subgroup analysis, we find little evidence of trends in heterogeneity, with few exceptions: The effect on knowledge of parties' issue positions seems to be concentrated among the 46-60-year-old respondents, those with lower levels of formal education, and high levels of civic knowledge. On the one hand, this is partly in line with previous findings by Mahéo (2017), indicating that the VAA can offer important benefits to educationally disadvantaged citizens, albeit they tend to be less likely to use VAAs in the first place (Marschall and Schultze, 2014, 2015; Vassil, 2011). On the other hand, those with already higher levels of civic knowledge benefit from most from the tool, limiting VAAs' effectiveness in reducing inequalities. 


\section{Discussion and Conclusion}

Do voter guides empower citizens? Focusing on whether they provide the resources voters need to make informed decisions, the answer is yes: encouraging citizens to use VAAs causes a measurable and nontrivial increase in political knowledge. More specifically, this result is driven by an increase in exactly the kind of information these tools are designed to provide-knowledge about parties' positions on issues. Judged according to its stated goals, then, the Wahl-O-Mat is arguably a success.

When we define empowerment more broadly, however, the limitations of voter guides become apparent. Taking an online quiz and receiving informative feedback may help those with less engagement in politics to quickly bring themselves up to speed with details of policy debates and partisan competition. This can be especially useful for the citizens of multi-party-system countries like Germany, where policy debates can be more complex. But we find little evidence of downstream effects on political behaviors such as turning out to vote, seeking out new information, or changing self-reported vote choice. Voter guides can help to reduce inequalities in political knowledge-to expand the currency of citizenship-but that may not be sufficient to carry over into more concrete civic obligations such as voting. At the same time, we can rule out potentially negative consequences of widespread VAA dissemination such as confusion or demobilization.

These mixed findings suggest that designers of VAAs should focus on the core problem the tools were designed to solve: insufficient levels of basic political knowledge in the mass public. This is an important normative goal in itself, core to theories of democratic competence and representation. Given that the currency of citizenship is not evenly distributed, voter guides can also play an important equalizing role in the provision of policy-relevant information. Our encouragement partially closed the educational gap in voter guide use, suggesting that intensive targeting efforts aimed at specific subgroups could similarly boost usage among people with lower levels of interest in politics, further reducing inequalities in knowledge. However, we also showed that those with particularly low levels of political interest, engagement, and civic knowledge are least likely to be motivated to use VAAs.

Our study's design provides a template for rigorously quantifying the effects of online media use on both behavioral and survey-based outcomes. We deploy a randomized encouragement within an online survey panel and embed our post-treatment measures within an ostensibly unrelated survey (Broockman, Kalla and Sekhon, 2017). Recruiting subjects who simultaneously share web consumption data enables two further advantages. First, we unobtrusively measure whether or not a subject takes up the treatment, allowing us to estimate the effect on compliers - those who use the VAA if and only if encouraged to do so. This limits the need to rely on self-reported measures of online behavior, which are subject to well-known distortions and biases (Guess, 2015; Guess et al., 2018). Second, we can observe downstream web consumption behavior to test hypotheses about habit formation and information seeking.

We emphasize that the divergence between our findings and those in much of the literature on VAA use illustrates the challenges of estimating causal effects in the presence of self-selection. This difficulty directly parallels debates in the media effects literature over whether, for instance, media choice exacerbates or attenuates polarization (Levendusky, 2013; Arceneaux, 2008). We present evidence that political interest and educational attainment are correlated with Wahl-O-Mat use, but controlling for these factors is not sufficient to correct for the bias in our naive estimates of the effects on turnout and vote choice as compared to our experimental benchmark. Even if existing theory and evidence are clear about these known predictors of VAA use, any additional unobserved confounders correlated with both treatment and the outcome will continue to bias estimates. 
Of course, our study has limitations of its own. Though we recruited our subjects from a high-quality online panel balanced on key demographic and political variables, such samples have been shown to be somewhat more knowledgeable than the population (Ansolabehere and Schaffner, 2014). It is also possible that the additional step of selecting into the Pulse panel may have resulted in the under- or over-representation of participants with particular characteristics. We still recover unbiased sample average treatment effects, but in making inferences to the population we implicitly assume that selection into our sample is unrelated to potential outcomes.

We hope future research will incorporate similar design innovations to evaluate the effectiveness of other VAA tools, both within and beyond Germany. Are some types of VAAs more effective than others? How do effects vary across different national and political contexts? Additional research can also explore how best to encourage the use of voter guides among those least likely to do so. This could build on the real-world strategies attempted by VAA sponsors as well as insights from the literature on voter turnout and social pressure. Finally, given the increasing importance of social media as an information source, maximizing the likelihood of encountering voter information online will be a crucial task for platforms and civil society alike. 


\section{References}

Alvarez, R Michael, Ines Levin, Peter Mair and Alexander Trechsel. 2014. "Party preferences in the digital age: The impact of voting advice applications.” Party Politics 20(2):227-236.

Andreadis, Ioannis and Matthew Wall. 2014. "The impact of voting advice applications on vote choice.” Matching Voters with Parties and Candidates. Voting Advice Applications in Comparative Perspective pp. 115-128.

Angrist, Joshua D, Guido W Imbens and Donald B Rubin. 1996. "Identification of causal effects using instrumental variables." Journal of the American Statistical Association 91(434):444-455.

Ansolabehere, Stephen and Brian F Schaffner. 2014. "Does survey mode still matter? Findings from a 2010 multi-mode comparison." Political Analysis 22(3):285-303.

Arceneaux, Kevin. 2008. “Can Partisan Cues Diminish Democratic Accountability?” Political Behavior 30:139-160.

Arceneaux, Kevin and Martin Johnson. 2013. Changing Minds or Changing Channels? Partisan News in an Age of Choice. University of Chicago Press.

Best for Planning. 2017. Berichtsband b4p 2017. Gesellschaft für integrierte Kommunikationsforschung.

Broockman, David E, Joshua L Kalla and Jasjeet S Sekhon. 2017. "The design of field experiments with survey outcomes: A framework for selecting more efficient, robust, and ethical designs." Political Analysis 25(4):435-464.

Bundeszentrale für politische Bildung. 2018. "Wahl-O-Mat Archiv: Nutzungen des Wahl-O-Mat." https://www.bpb.de/politik/wahlen/wahl-o-mat/45484/archiv.

Enos, Ryan D, Anthony Fowler and Lynn Vavreck. 2013. "Increasing inequality: The effect of GOTV mobilization on the composition of the electorate." The Journal of Politics 76(1):273-288.

Enyedi, Zsolt. 2016. “The Influence of Voting Advice Applications on Preferences, Loyalties and Turnout: An Experimental Study." Political Studies 64(4):1000-1015.

Fischer, Moritz Valentin, Philipp Tschochohei, Laura Anders, Kimberly Dana Breuer, Alejandro Hermida Carrillo and Sarah Diefenbach. 2017. "Exploring the Social Media Impact of Voting Advice Apps: A Case Study on the Representation of the Wahl-O-Mat on Twitter." i-com 16(3):279-285.

Garzia, Diego, Alexander H Trechsel and Andrea De Angelis. 2017. "Voting advice applications and electoral participation: a multi-method study." Political Communication 34(3):424-443.

Garzia, Diego and Andrea De Angelis. 2014. The Impact of Voting Advice Applications on Electoral Participation. In Matching Voters with Parties and Candidates. Voting Advice Applications in a Comparative Perspective, ed. Diego Garzia and Stefan Marschall. ECPR Press chapter 8, pp. 105-114.

Garzia, Diego and Stefan Marschall. 2012. "Voting Advice Applications under review: the state of research." International Journal of Electronic Governance 5(3-4):203-222. 
Gemenis, Kostas. 2018. "The Impact of Voting Advice Applications on Electoral Turnout: Evidence from Greece." Statistics, Politics, and Policy 0(0):1-19.

Gemenis, Kostas and Martin Rosema. 2014. "Voting advice applications and electoral turnout.” Electoral studies 36:281-289.

Gerber, Alan S and Donald P Green. 2012. Field experiments: Design, analysis, and interpretation. WW Norton.

Germann, Micha and Kostas Gemenis. 2019. “Getting Out the Vote With Voting Advice Applications.” Political Communication 36(1):149-170.

Guess, Andrew, Kevin Munger, Jonathan Nagler and Joshua Tucker. 2018. "How Accurate Are Survey Responses on Social Media and Politics?” Political Communication pp. 1-18.

Guess, Andrew M. 2015. "Measure for Measure: An Experimental Test of Online Political Media Exposure.” Political Analysis 23(1):59-75.

Heinsohn, Till, Jonas Israel, Stefan Marschall and Martin Schultze. 2016. "Online-Wahlhilfen in Wahlkämpfen.” Zeitschrift für Politikwissenschaft 26(3):253-277.

Heinsohn, Till, Matthias Fatke, Jonas Israel, Stefan Marschall and Martin Schultze. 2019. "Effects of voting advice applications during election campaigns. Evidence from a panel study at the 2014 European elections." Journal of Information Technology er Politics 16(3):250-264.

Imai, Kosuke, Dustin Tingley and Teppei Yamamoto. 2013. "Experimental designs for identifying causal mechanisms." Journal of the Royal Statistical Society: Series A (Statistics in Society) 176(1):5-51.

Kamoen, Naomi, Bregje Holleman, André Krouwel, Jasper Van de Pol and Claes De Vreese. 2015. “The effect of voting advice applications on political knowledge and vote choice." Irish Political Studies 30(4):595-618.

Klein Kranenburg, Laurens. 2015. The impact of voting advice applications on party choice in Dutch national and provincial elections. Master's thesis University of Twente.

Kleinnijenhuis, Jan, Jasper van de Pol, Anita MJ van Hoof and André PM Krouwel. 2017. "Genuine effects of vote advice applications on party choice: Filtering out factors that affect both the advice obtained and the vote." Party Politics p. 1354068817713121.

Levendusky, Matthew S. 2013. "Why do partisan media polarize viewers?” American Journal of Political Science 57(3):611-623.

Mahéo, Valérie-Anne. 2016. "The Impact of Voting Advice Applications on Electoral Preferences: A Field Experiment in the 2014 Quebec Election.” Policy \& Internet 8(4):391-411.

Mahéo, Valérie-Anne. 2017. "Information Campaigns and(Under) Privileged Citizens: An Experiment on the Differential Effects of a Voting Advice Application." Political Communication 34(4):511-529. 
Manavopoulos, Vasilis, Vasiliki Triga, Stefan Marschall and Lucas Constantin Wurthmann. 2018. "The Impact of VAAs on (non-Voting) Aspects of Political Participation: Insights from Panel Data Collected During the 2017 German Federal Elections Campaign." Statistics, Politics and Policy 9(2):105134.

Marbach, Moritz and Dominik Hangartner. 2020. "Profiling Compliers and Noncompliers for Instrumental-Variable Analysis.” Political Analysis pp. 1-10.

Marschall, Stefan and Martin Schultze. 2012. "Voting Advice Applications and their effect on voter turnout: the case of the German Wahl-O-Mat." International Journal of Electronic Governance 5(34):349-366.

Marschall, Stefan and Martin Schultze. 2014. "German E-Campaigning and the Emergence of a 'Digital Voter’? An Analysis of the Users of the Wahl-O-Mat.” German Politics 24(4):525-541.

Marschall, Stefan and Martin Schultze. 2015. "German E-Campaigning and the Emergence of a 'Digital Voter'? An Analysis of the Users of the Wahl-O-Mat.” German Politics 24(4):525-541.

Mummolo, Jonathan and Erik Peterson. 2017. "How content preferences limit the reach of voting aids.” American Politics Research 45(2):159-185.

Mykkänen, Juri and Tom Moring. 2006. "Dealigned Politics Comes of Age? The Effects of Online Candidate Selectors on Finnish Voters." Paper presented at the Conference of Politics on the Internet: New Forms of Media for Political Action, Tampere, 24-25 November, 2006.

Norris, Pippa. 2001. Digital divide: Civic engagement, information poverty, and the Internet worldwide. Cambridge University Press.

Pianzola, Joëlle. 2014a. "Selection biases in voting advice application research." Electoral Studies $36: 272-280$.

Pianzola, Joëlle. 2014b. "Swing voting due to smartvote use? Evidence from the 2011 Swiss federal elections.” Swiss Political Science Review 20(4):651-677.

Pianzola, Joëlle, Alexander H Trechsel, Kristjan Vassil, Guido Schwerdt and R Michael Alvarez. 2019. "The impact of personalized information on vote intention: Evidence from a randomized field experiment." The Journal of Politics 81(3):000-000.

Ruusuvirta, Outi and Martin Rosema. 2009. Do online vote selectors influence electoral participation and the direction of the vote? In ECPR General Conference 2009, Potsdam. pp. 1-22.

Schultze, Martin. 2014. "Effects of voting advice applications (vaas) on political knowledge about party positions." Policy \& Internet 6(1):46-68.

Vaccari, Cristian. 2013. Digital politics in Western democracies: a comparative study. JHU Press.

van de Pol, Jasper. 2016. Voting wiser: The effect of Voting Advice Applications on political understanding. $\mathrm{PhD}$ Thesis University of Amsterdam. 
Vassil, Kristjan. 2011. Voting Smarter? The impact of voting advice applications on political behavior. European University Institute: $\mathrm{PhD}$ Thesis.

Walgrave, Stefaan, Peter Van Aelst and Michiel Nuytemans. 2008. “Do the vote test': the electoral effects of a popular vote advice application at the 2004 Belgian elections." Acta Politica 43(1):50-70.

Warren, John Robert and Andrew Halpern-Manners. 2012. "Panel Conditioning in Longitudinal Social Science Surveys." Sociological Methods \& Research 41(4):491-534.

Westle, Bettina, Christian Begemann and Astrid Rütter. 2014. "The "Wahl-O-Mat" in the course of the German Federal Election 2013-Effects of a German VAA on users' election-relevant political knowledge." Zeitschrift für Politikwissenschaft 24(4):389-426. 


\section{Do Online Voter Guides Empower Citizens? Evidence from a Field Experiment with Digital Trace Data*}

\section{Online Appendix}

Simon Munzert, Hertie School ${ }^{+}$

Pablo Barberá, University of Southern California

Andrew Guess, Princeton University

JungHwan Yang, University of Illinois at Urbana-Champaign

Accepted for publication at Public Opinion Quarterly

\section{Contents}

$\begin{array}{lr}\text { Appendices } & 1\end{array}$

Appendix A Information on the Survey and Tracking Data 2

Appendix B Supporting Tables and Figures $\quad 5$

$\begin{array}{lll}\text { Appendix C Wahl-O-Mat screenshots } & 20\end{array}$

$\begin{array}{ll}\text { Appendix D Questionnaire items } & 24\end{array}$

*This research was generously funded by a grant from the Volkswagen Foundation Computational Social Science Initiative, reference 92 143. This study was approved by the Princeton University Institutional Review Board (\#8327, 10014, 10041). We thank Toma Pavlov, Sebastian Ramirez Ruiz, and Jona Ronen for helpful research assistance.

${ }^{\dagger}$ Corresponding author. Hertie School, Friedrichstr. 180, 10117 Berlin, Germany. Email: munzert@hertieschool.org. 


\section{Appendix A Information on the Survey and Tracking Data}

\section{Sampling}

The survey was administrated by YouGov. Surveys run by YouGov combine purposive sampling with a multi-stage sample-matching and weighting procedure (Rivers, 2006). First, a target population is defined, which is the German online population for the data at hand. Based on information from highquality studies on demographic population marginals (i.e. gender, age and educational attainment), a sampling frame is defined. For the panel, data on marginals from Best for Planning (2017) were used, who conducted 30,000 face-to-face interviews to evaluate the German online population. A stratified sample is drawn from this frame and matched as closely as possible to YouGov's longstanding panel (with over a million members).

The resulting target sample constitutes a representative set of respondents in terms of traditional sampling theory. However, respondents might be hard to contact because they either have never reported their contact details or do not agree to the terms of the survey. Hence, multi-stage matching is applied, combining the representative target sample with YouGov's longstanding panel of reliable respondents. From this panel, a sample of individuals is selected that matches as closely as possible the distribution of the target sample and has opted in to provide website visit data (see below). Through this procedure, YouGov guarantees not only a minimum of 1,000 respondents in the survey, but also the inclusion of hard-to-reach population subgroups.

\section{Survey design and fielding}

All data was gathered by YouGov from July 1 to December 9, 2017. The panel was made up of five waves. Figure A1 provides a conceptual overview of the panel's timeline. The encouragement to use the VAA was randomly assigned in Wave 3, which was in the field between September 4 and September 13, 2017. The Wahl-O-Mat went online on August 30, 2017, i.e. shortly before the encouragement wave was launched. Wave 4 was in the field between September 18 and September 24, 2017 (just before the election took place). Wave 5 was in the field between September 25 and October 4, 2017 (just after the election took place).

The survey covered a wide range of topics such as people's political preferences, their general attitudes towards politics, opinions on particular parties, what people think of the election campaign (the federal elections were held on September 24, 2017), and evaluated respondents' political knowledge on several dimensions. It also included questions on media usage, social networks (online and offline) and involvement in popular social media services such as Facebook and Twitter. The follow-up surveys to the kick-off in July 2017 were rather short (about five to ten minutes completion time on average). Retention is reported in Table A1. Over the five waves, up to $20 \%$ respondents were lost, but about $89 \%$ took part again in the final wave.

\section{Passive metering technology}

Wakoopa, the tracking software used by YouGov in this study, runs in the background of panelists' devices and collects anonymized visit data. There are no technological limits to the types of websites that can be included in the data. Moreover, the software tracks web traffic (passwords and financial transactions are ignored) for all browsers installed on a user's computer. The technology does not slow 
Figure A1: Panel setup.

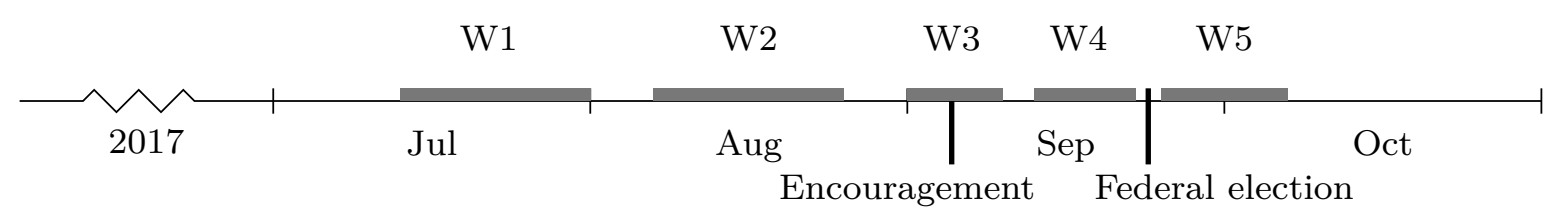

Table A1: Panel participation over time.

\begin{tabular}{ccc}
\hline Wave & Participants & Retention \\
\hline 1 & 1516 & - \\
2 & 1377 & 90.8 \\
3 & 1224 & 80.7 \\
4 & 1215 & 80.1 \\
5 & 1344 & 88.7 \\
\hline
\end{tabular}

the performance of users' computers and is transparent about the data that is being sent: Panelists can see a list of the last several captured URLs and can also pause tracking for 15 minutes. Of course, they can also uninstall the software at any time. YouGov encourages its panelists to install the software on as many devices as possible, including laptops, mobile phones, and tablets. The capabilities for mobile tracking are somewhat more limited for privacy reasons, but data on domain-level visits and app use are collected.

Panelists are recruited from YouGov's traditional participant pool via incentives. The company reports fairly strong incentives: 4,000 "points" for signing up and downloading the Wakoopa softwareroughly 8 times the number offered for a typical survey-and 1,000 additional points every month. Participants in online surveys can redeem these points for clothing, prepaid gift cards, and other merchandise. One consequence of this recruitment strategy is that YouGov Pulse users are a subset of the overall panel, making sampling somewhat more challenging.

\section{Collection of social media data}

Using an approved Facebook web application, we asked respondents if they would be willing to share information about their Facebook activity. We requested several data fields available to app developers, including public profile information, Timeline posts, and page likes. Respondents were given the opportunity to log into their Facebook account after a survey prompt, and if they did so they were asked what specific pieces of information they were willing to share. They could choose to share all of the information, selectively approve only some information, or share nothing. No data on News Feed content or subjects' friends was shared with researchers. We additionally used an approved Twitter app that, again with subjects' permission, collected publicly available information from their Twitter profiles. After collecting participants' Twitter IDs, we collected their own tweets for the duration of 
the project. We also periodically collect the list of friends and followers of participants' Twitter accounts.

\section{Privacy and ethical considerations of data}

Combining survey data and digital trace data of the same respondents has substantive merits to understand the effects of online exposure on people's attitudes and behavior. However, it entails challenging tasks for protecting the privacy of the respondents and raises ethical questions, as users may not be aware of how their data are being used. Even with the consent of the participants, it still could be problematic because the account names and meta-information of their social media accounts can be identifiable and linked to their survey responses (Stier et al., 2019). Thus, it is important to communicate these concerns as clearly as possible when collecting data (Menchen-Trevino, 2013). In every step of data collection, we informed participants about the scope of data collection, data management, confidentiality, and research purpose. We have an explicit and informed consent from the people whose data are collected.

Regarding the web-tracking data, YouGov received the consent from the panel that their social media data can be linked to other survey items they have participated. They highlighted that participants have complete control over which data they share for research purposes. Participants can choose which information they want to share, pause the tracking app when they want, and withdraw their consent anytime. After data collection, YouGov removed any personally identifying information (PII) and sensitive data (e.g., financial transaction) and stripped-out geocoding information that is too specific before delivering the data to researchers. The deliverables are de-identified and anonymized and fully comply with the EU's General Data Protection Regulation (GDPR) requirements.

Social media data were collected after getting additional informed consent during the survey. All collected social media data are stored in a separate secure location and can be linked with the survey data only through a key-matching information that is separately stored. These data will be deleted upon the completion of the project. 


\section{Appendix B Supporting Tables and Figures}

Figure B1: Summary of Wahl-O-Mat top matches of parties with voters. Distribution of recommended parties by pre-treatment party preferences.

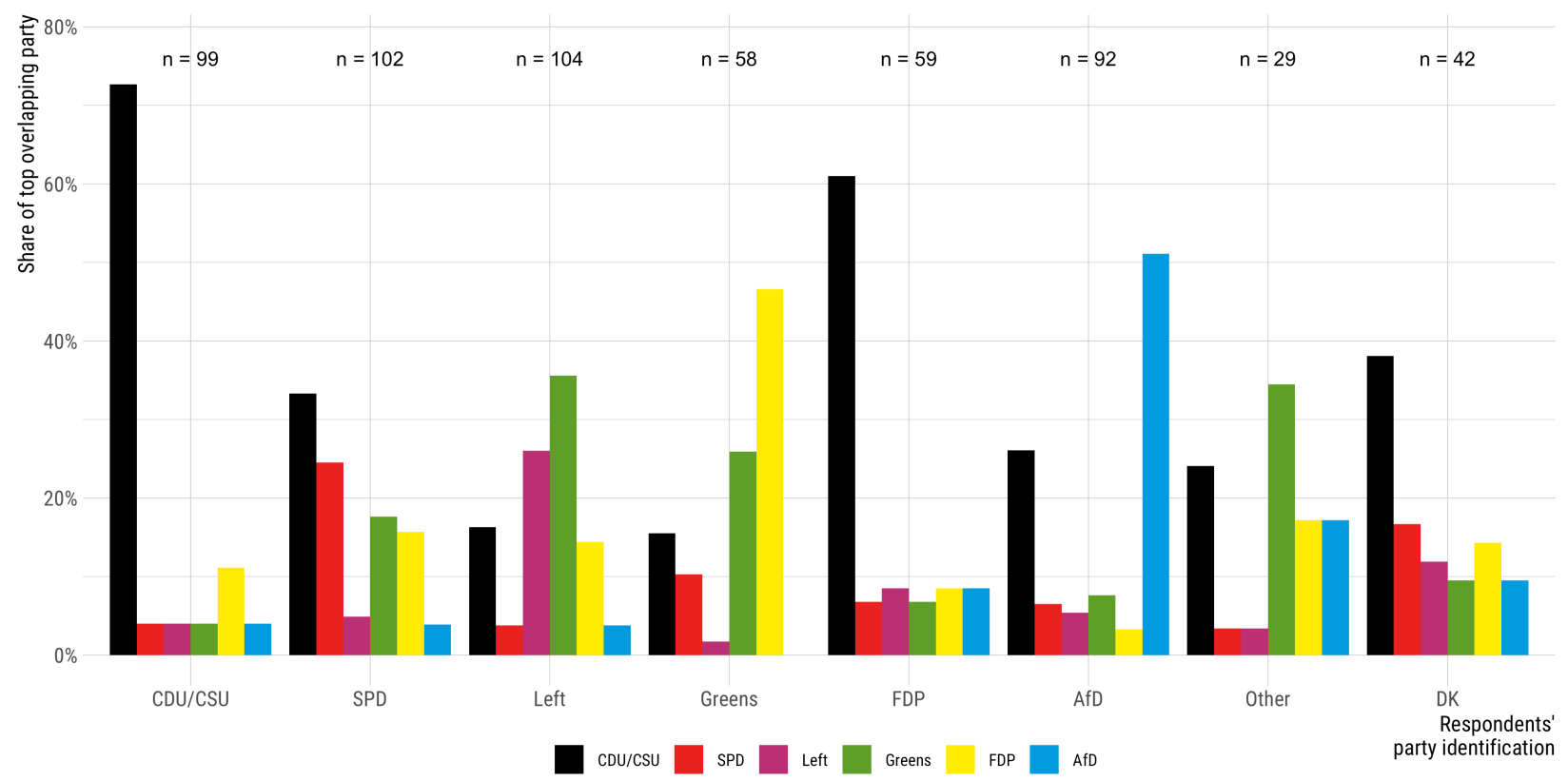

Figure B2: Summary of Wahl-O-Mat bottom matches of parties with voters. Distribution of leastrecommended parties by pre-treatment party preferences.

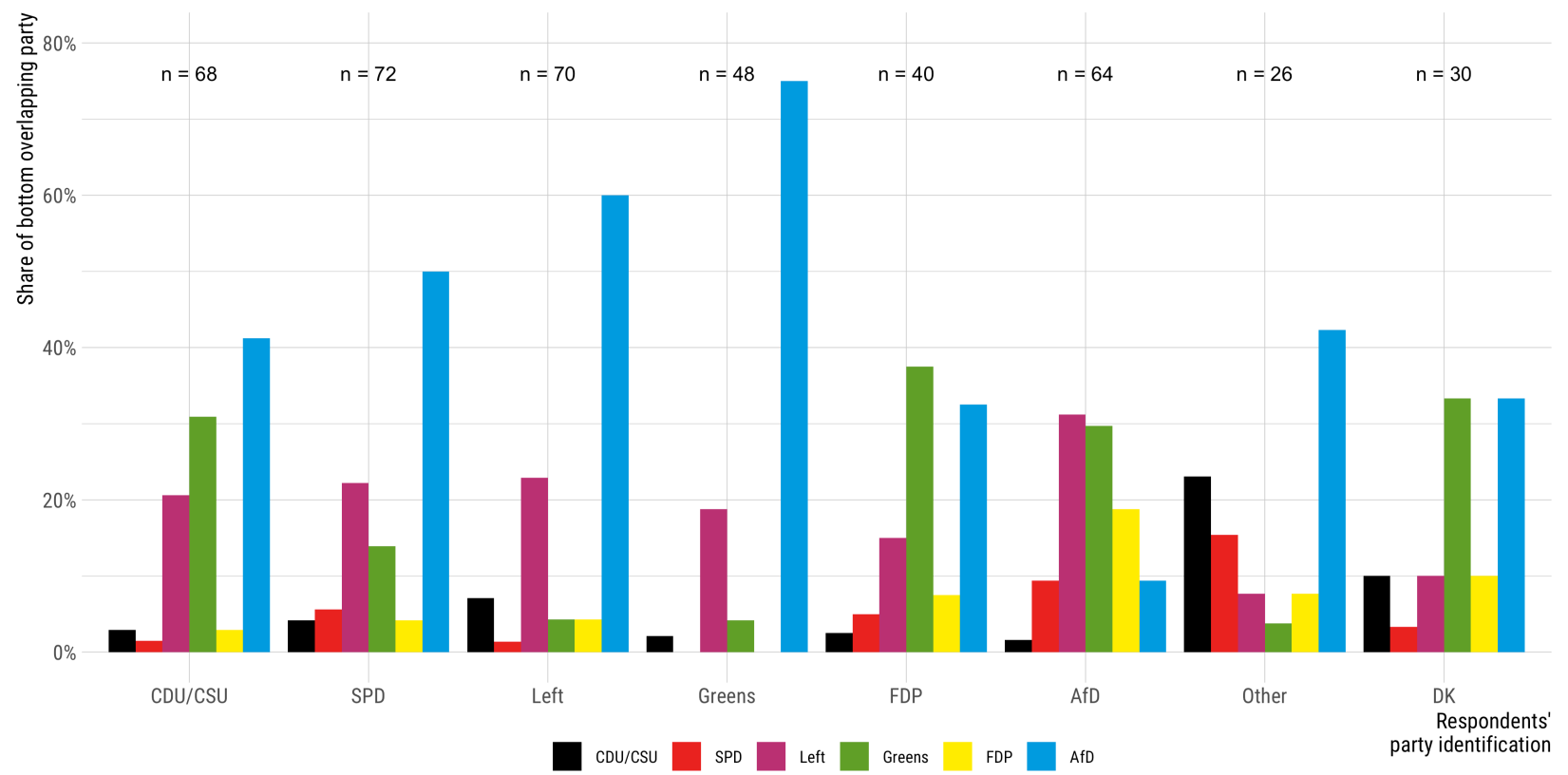


Table B1: First-stage effects of VAA encouragement and covariates on VAA usage

\begin{tabular}{lc}
\hline & Wahlomat Use \\
\hline (Intercept) & $-0.031(0.132)$ \\
Gender & $-0.001(0.031)$ \\
Age & $0.001(0.001)$ \\
Education & $0.050(0.021)^{*}$ \\
Household Income & $-0.001(0.005)$ \\
Political Interest & $0.022(0.015)$ \\
Left-Right Ideology & $0.003(0.007)$ \\
Wahlomat Encouragement & $0.355(0.031)^{* * *}$ \\
\hline $\mathrm{R}^{2}$ & 0.129 \\
Num. obs. & 979 \\
RMSE & 0.469 \\
\hline
\end{tabular}

${ }^{* * *} p<0.001,{ }^{* *} p<0.01,{ }^{*} p<0.05$

Table B2: Effect of VAA usage/encouragement on turnout.

\begin{tabular}{lccr}
\hline & Observed & ITT & \multicolumn{1}{c}{ CACE } \\
\hline Intercept & $0.545(0.071)^{* * *}$ & $0.555(0.072)^{* * *}$ & $0.555(0.086)^{* * *}$ \\
Gender & $0.005(0.017)$ & $0.006(0.017)$ & $0.006(0.018)$ \\
Age & $0.002(0.001)^{* *}$ & $0.002(0.001)^{* *}$ & $0.002(0.001)^{* *}$ \\
Education & $0.018(0.011)$ & $0.021(0.011)$ & $0.021(0.014)$ \\
Household Income & $0.000(0.003)$ & $-0.000(0.003)$ & $-0.000(0.003)$ \\
Political Interest & $0.064(0.008)^{* * *}$ & $0.065(0.009)^{* * *}$ & $0.065(0.011)^{* * *}$ \\
Left-Right Ideology & $-0.007(0.004)$ & $-0.007(0.004)$ & $-0.007(0.004)$ \\
Wahlomat Use & $0.048(0.016)^{* *}$ & & $-0.009(0.048)$ \\
Wahlomat Encouragement & & $-0.003(0.017)$ & \\
\hline$R^{2}$ & 0.089 & 0.081 & 0.078 \\
Num. obs. & 979 & 979 & 979 \\
RMSE & 0.256 & 0.258 & 0.258 \\
\hline
\end{tabular}

${ }^{* * *} p<0.001,{ }^{* *} p<0.01,{ }^{*} p<0.05$ 
Table B3: Effect of VAA usage/encouragement on switched vote choice.

\begin{tabular}{lcrr}
\hline & Observed & \multicolumn{1}{c}{ ITT } & \multicolumn{1}{c}{ CACE } \\
\hline Intercept & $0.315(0.113)^{* *}$ & $0.305(0.114)^{* *}$ & $0.303(0.111)^{* *}$ \\
Gender & $0.089(0.027)^{* * *}$ & $0.088(0.027)^{* * *}$ & $0.088(0.027)^{* *}$ \\
Age & $-0.004(0.001)^{* * *}$ & $-0.004(0.001)^{* * *}$ & $-0.004(0.001)^{* * *}$ \\
Education & $-0.005(0.018)$ & $-0.006(0.018)$ & $-0.009(0.018)$ \\
Household Income & $-0.001(0.004)$ & $-0.001(0.004)$ & $-0.001(0.004)$ \\
Political Interest & $-0.000(0.014)$ & $0.000(0.014)$ & $-0.000(0.014)$ \\
Left-Right Ideology & $-0.005(0.006)$ & $-0.005(0.006)$ & $-0.006(0.006)$ \\
Wahlomat Use & $-0.004(0.026)$ & & $0.047(0.073)$ \\
Wahlomat Encouragement & & $0.017(0.026)$ & \\
\hline $\mathrm{R}^{2}$ & 0.037 & 0.037 & 0.033 \\
Num. obs. & 923 & 923 & 923 \\
RMSE & 0.388 & 0.388 & 0.389 \\
\hline
\end{tabular}

${ }^{* * *} p<0.001,{ }^{* *} p<0.01,{ }^{*} p<0.05$

Table B4: Effect of VAA usage/encouragement on issue knowledge.

\begin{tabular}{lccr}
\hline & Observed & ITT & \multicolumn{1}{c}{ CACE } \\
\hline Intercept & $0.587(0.022)^{* * *}$ & $0.582(0.022)^{* * *}$ & $0.583(0.022)^{* * *}$ \\
Gender & $-0.020(0.005)^{* * *}$ & $-0.020(0.005)^{* * *}$ & $-0.020(0.005)^{* * *}$ \\
Age & $-0.000(0.000)$ & $-0.000(0.000)$ & $-0.000(0.000)$ \\
Education & $0.018(0.003)^{* * *}$ & $0.018(0.003)^{* * *}$ & $0.016(0.003)^{* * *}$ \\
Household Income & $0.001(0.001)$ & $0.001(0.001)$ & $0.001(0.001)$ \\
Political Interest & $0.016(0.003)^{* * *}$ & $0.016(0.003)^{* * *}$ & $0.015(0.003)^{* * *}$ \\
Left-Right Ideology & $-0.006(0.001)^{* * *}$ & $-0.006(0.001)^{* * *}$ & $-0.006(0.001)^{* * *}$ \\
Wahlomat Use & $0.015(0.005)^{* *}$ & & $0.036(0.014)^{*}$ \\
Wahlomat Encouragement & & $0.013(0.005)^{*}$ & \\
\hline R & 0.129 & 0.127 & 0.113 \\
Num. obs. & 979 & 979 & 979 \\
RMSE & 0.078 & 0.078 & 0.079 \\
\hline
\end{tabular}

${ }^{* * *} p<0.001,{ }^{* *} p<0.01,{ }^{*} p<0.05$ 
Table B5: Effect of VAA usage/encouragement on news consumption (news urls visited).

\begin{tabular}{lccr}
\hline & Observed & ITT & \multicolumn{1}{c}{ CACE } \\
\hline Intercept & $0.291(0.602)$ & $0.500(0.615)$ & $0.508(0.630)$ \\
Gender & $-0.420(0.142)^{* *}$ & $-0.428(0.144)^{* *}$ & $-0.435(0.146)^{* *}$ \\
Age & $0.002(0.005)$ & $0.005(0.005)$ & $0.007(0.005)$ \\
Education & $0.072(0.097)$ & $0.103(0.099)$ & $0.111(0.100)$ \\
Household Income & $0.026(0.022)$ & $0.015(0.022)$ & $0.012(0.023)$ \\
Political Interest & $0.269(0.072)^{* * *}$ & $0.271(0.073)^{* * *}$ & $0.279(0.071)^{* * *}$ \\
Left-Right Ideology & $0.035(0.032)$ & $0.040(0.033)$ & $0.043(0.034)$ \\
Wahlomat Use & $0.643(0.137)^{* * *}$ & & $-0.440(0.412)$ \\
Wahlomat Encouragement & & $-0.157(0.142)$ & \\
\hline $\mathrm{R}^{2}$ & 0.082 & 0.055 & 0.000 \\
Num. obs. & 712 & 1.838 & 712 \\
RMSE & 1.811 & & 1.890 \\
\hline$* * * p<0.001 * p<0.01 *<0.05$ & & \\
\hline
\end{tabular}

${ }^{* * *} p<0.001,{ }^{* *} p<0.01,{ }^{*} p<0.05$

Table B6: Effect of VAA usage/encouragement on 1+ political posts on facebook.

\begin{tabular}{lrrr}
\hline & \multicolumn{1}{c}{ Observed } & \multicolumn{1}{c}{ ITT } & \multicolumn{1}{c}{ CACE } \\
\hline Intercept & $0.028(0.114)$ & $0.017(0.116)$ & $0.020(0.122)$ \\
Gender & $-0.032(0.027)$ & $-0.032(0.027)$ & $-0.032(0.027)$ \\
Age & $0.002(0.001)^{*}$ & $0.002(0.001)^{*}$ & $0.002(0.001)^{*}$ \\
Education & $-0.035(0.018)$ & $-0.033(0.019)$ & $-0.037(0.019)$ \\
Household Income & $0.006(0.004)$ & $0.007(0.004)$ & $0.006(0.004)$ \\
Political Interest & $0.038(0.014)^{* *}$ & $0.040(0.014)^{* *}$ & $0.038(0.014)^{* *}$ \\
Left-Right Ideology & $-0.011(0.006)$ & $-0.011(0.006)$ & $-0.011(0.008)$ \\
Wahlomat Use & $0.052(0.026)^{*}$ & & $0.089(0.072)$ \\
Wahlomat Encouragement & & $0.033(0.027)$ & \\
\hline $\mathrm{R}^{2}$ & 0.058 & 0.054 & 0.055 \\
Num. obs. & 549 & 549 & 549 \\
RMSE & 0.303 & 0.304 & 0.303 \\
\hline
\end{tabular}

${ }^{* * *} p<0.001,{ }^{* *} p<0.01,{ }^{*} p<0.05$ 
Figure B3: Descriptive statistics of outcome variables, by subgroup. Means reported.

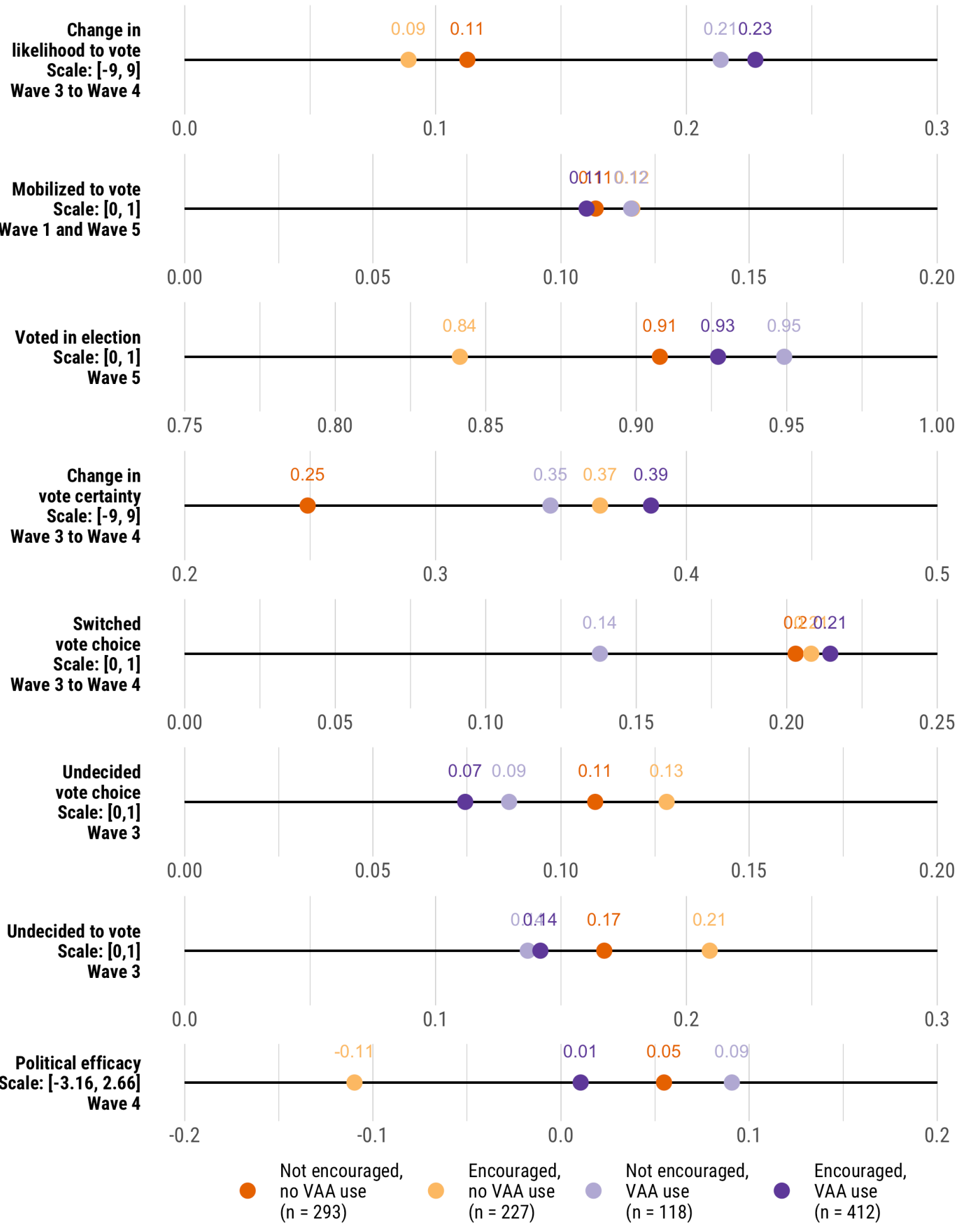


Figure B4: Descriptive statistics of outcome variables, by subgroup. Means reported.

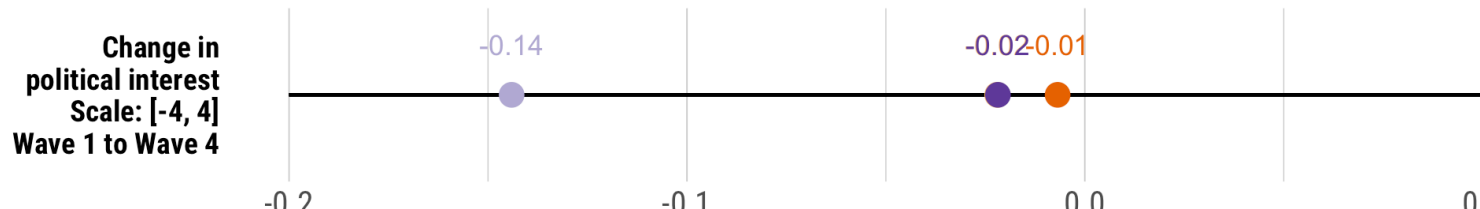

Issue knowledge

Scale: $[0,1]$

Wave 4

$-0.2$

$-0.1$

0.0

0.1

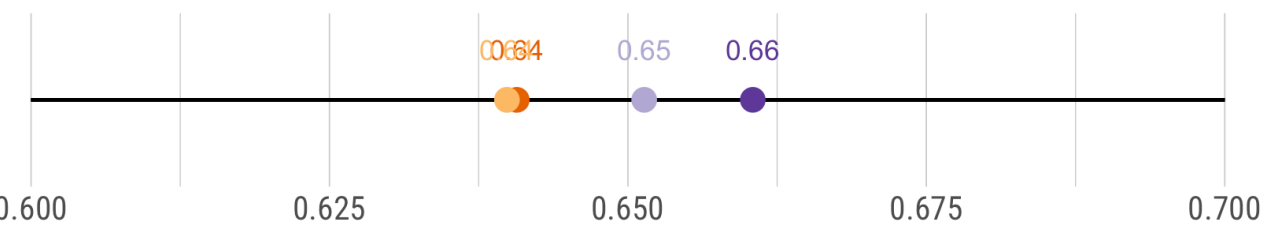

Change in civic knowledge

Scale: $[-2,2]$

Wave 2 to Wave 5

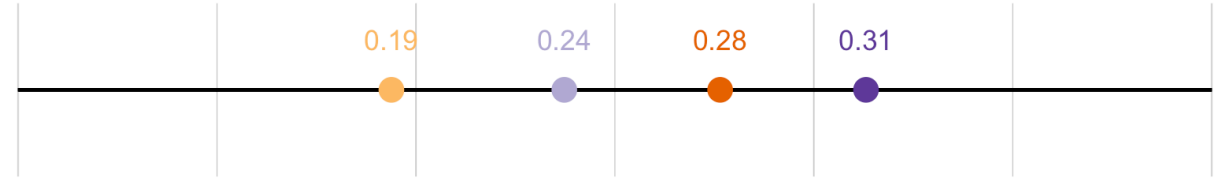

0.1

0.2

0.3

Change in candidate recognition Scale: $[-9,9]$

Wave 2 to Wave 5
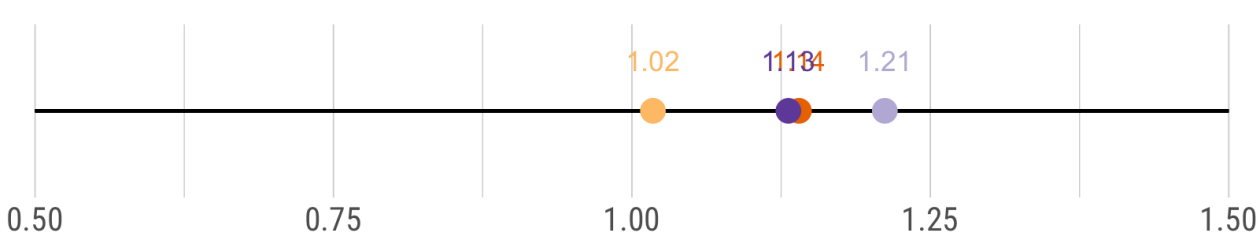

Event knowledge Scale: $[0,10]$

Wave 4

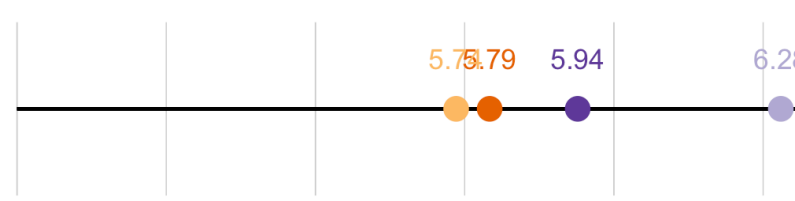

5.0

5.5

6.0

6.5

7.0

News consumption

Scale: $[0+]$

Tracking data

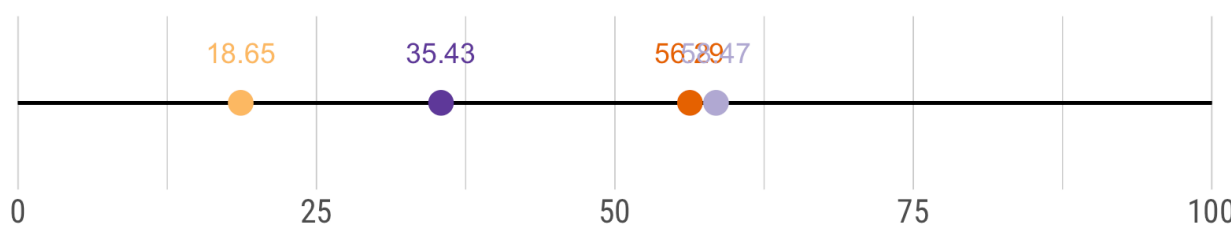

Political use,
Facebook
Scale: $[0+]$
Social media data

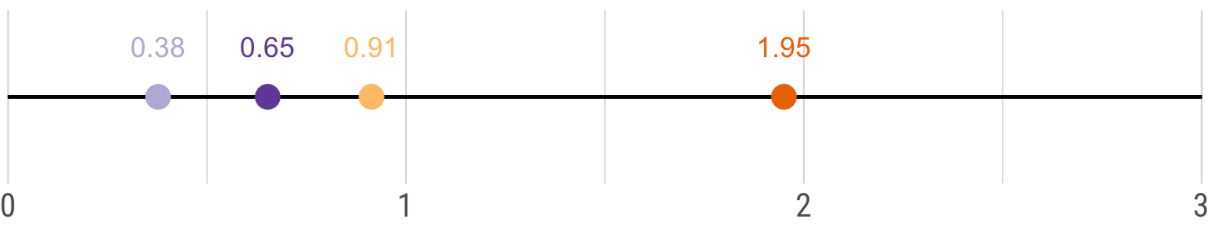

Political use

Twitter

Scale: $[0+$

Social media data

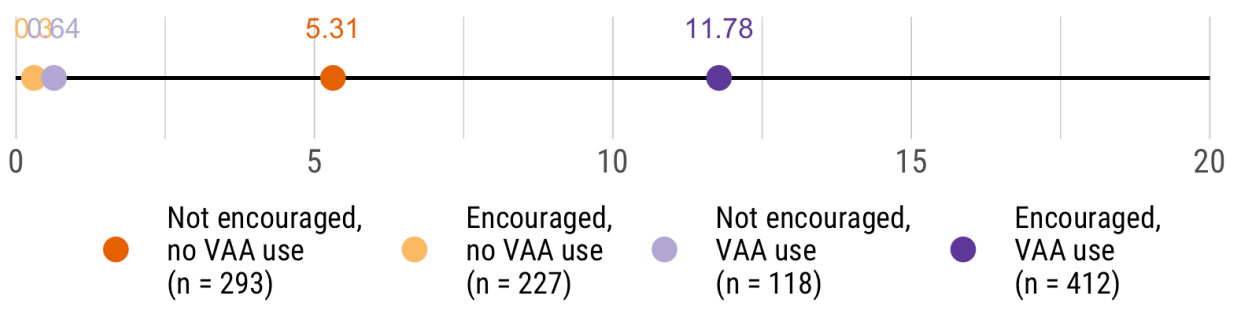


Figure B5: Descriptive statistics of outcome variables, by subgroup. Means reported.

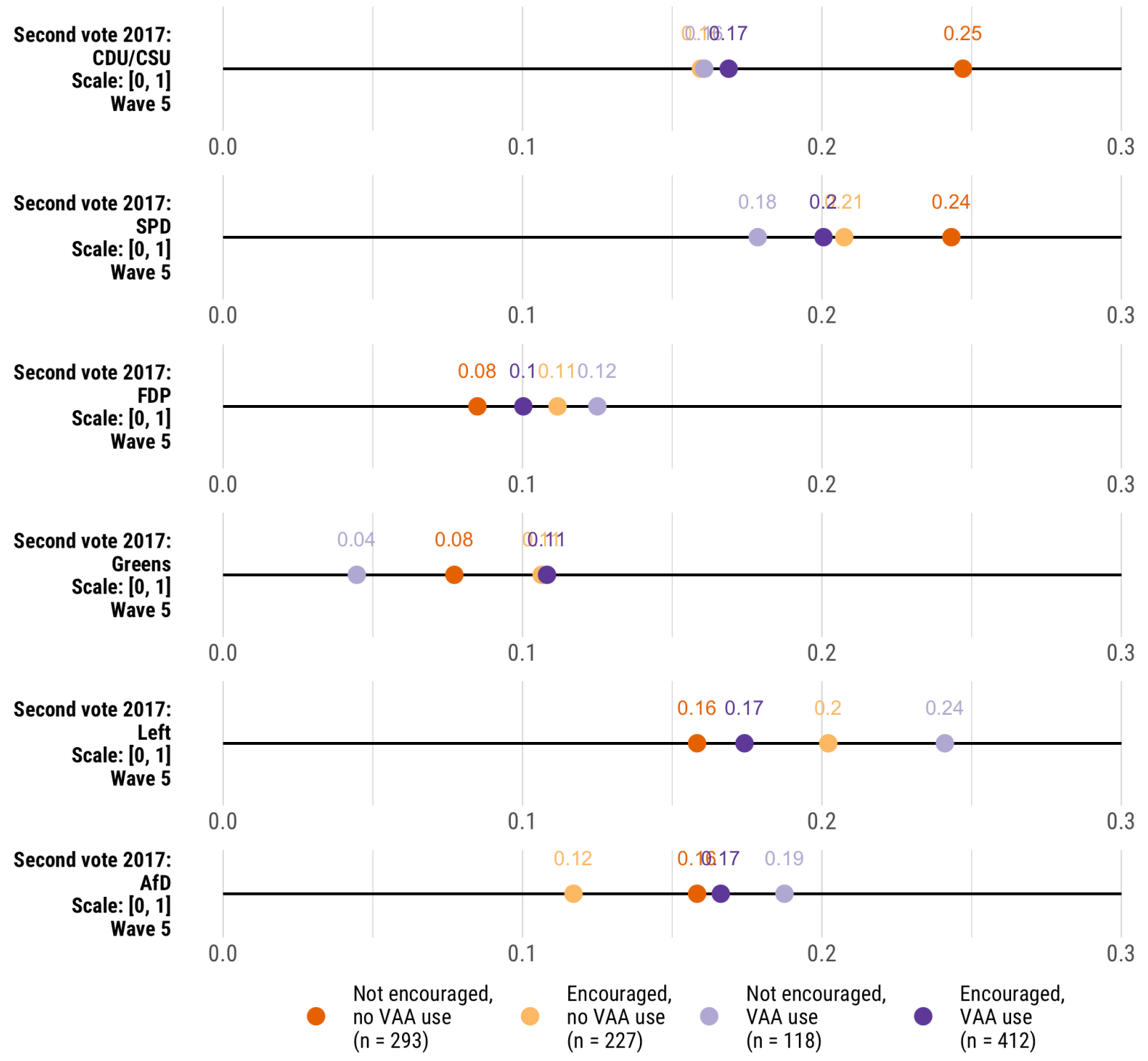


Figure B6: Descriptive statistics of outcome variables, by subgroup. Means reported.

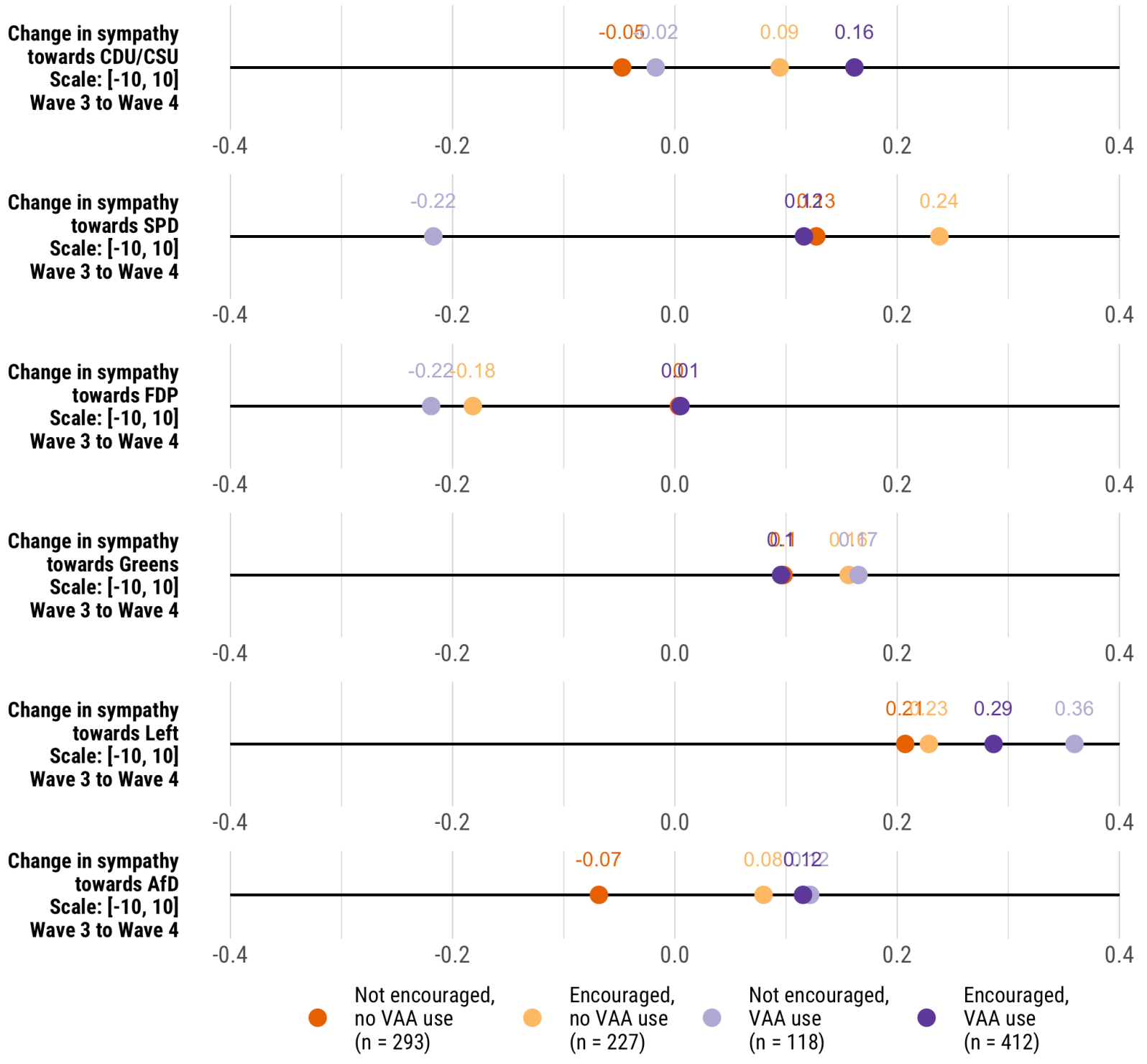


Table B7: Effect of VAA usage/encouragement on 1+ political tweets on twitter.

\begin{tabular}{lrrr}
\hline & Observed & \multicolumn{1}{c}{ ITT } & \multicolumn{1}{c}{ CACE } \\
\hline Intercept & $-0.195(0.369)$ & $-0.154(0.389)$ & $-0.170(0.356)$ \\
Gender & $0.105(0.107)$ & $0.084(0.106)$ & $0.098(0.103)$ \\
Age & $0.006(0.003)$ & $0.006(0.004)$ & $0.006(0.003)$ \\
Education & $-0.063(0.060)$ & $-0.052(0.060)$ & $-0.060(0.060)$ \\
Household Income & $0.006(0.015)$ & $0.007(0.016)$ & $0.006(0.017)$ \\
Political Interest & $0.042(0.047)$ & $0.045(0.047)$ & $0.043(0.038)$ \\
Left-Right Ideology & $-0.000(0.021)$ & $-0.004(0.021)$ & $-0.001(0.024)$ \\
Wahlomat Use & $0.125(0.098)$ & & $0.088(0.265)$ \\
Wahlomat Encouragement & & $0.034(0.102)$ & \\
\hline $\mathrm{R}^{2}$ & 0.083 & 0.066 & 0.081 \\
Num. obs. & 9.42 & 92 & 92 \\
RMSE & 0.451 & 0.455 & 0.452 \\
\hline
\end{tabular}

${ }^{* * *} p<0.001,{ }^{* *} p<0.01,{ }^{*} p<0.05$

Figure B7: Effects of VAA use on self-reported turnout, change in vote choice, and knowl-edge on parties' issue positions. Respondents with missing tracking data and reported VAA use $(n=147)$ excluded from the analysis.

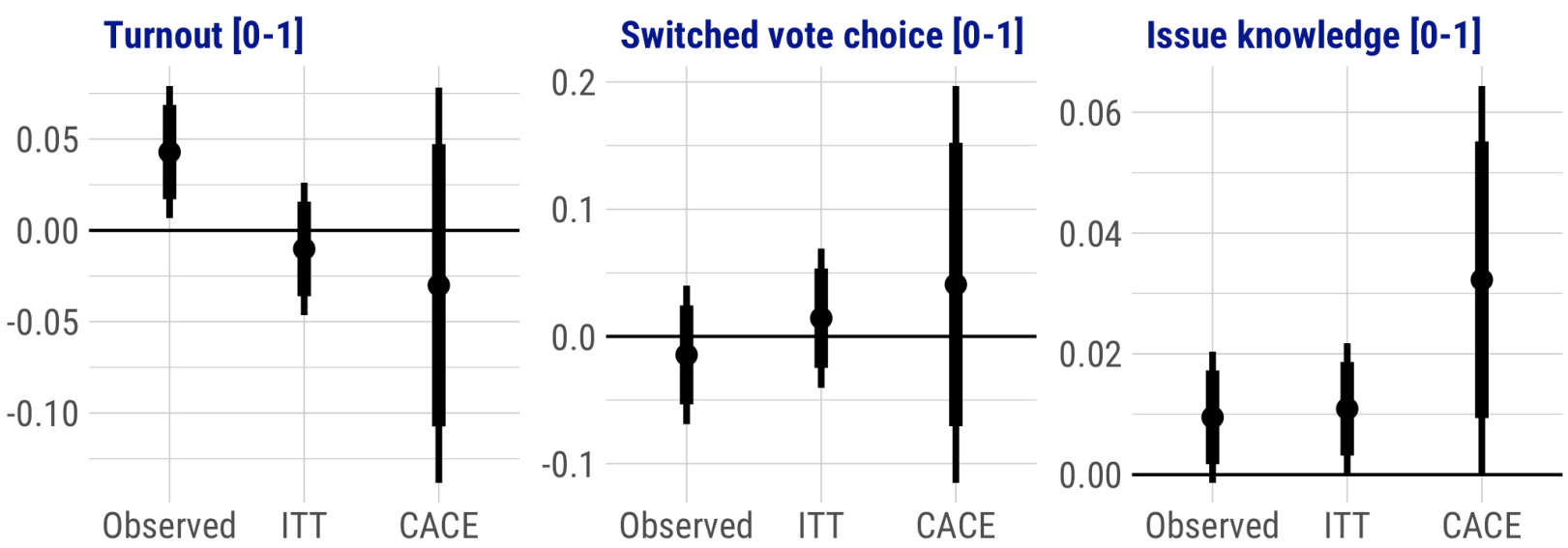


Figure B8: Effects of VAA use on alternative outcomes. Observed = VAA users vs. VAA non-users, ITT = Intent-to-Treat, CACE = Complier Average Causal Effect.

Change in likelihood

to vote [1-10]

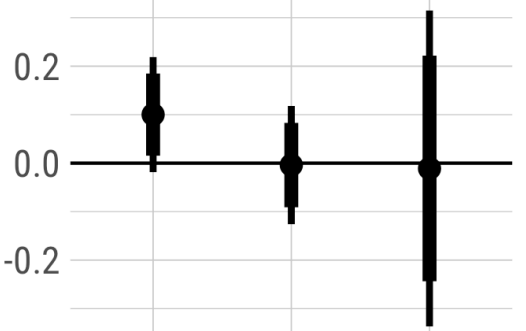

Observed ITT CACE

Change in political

interest [1-4]

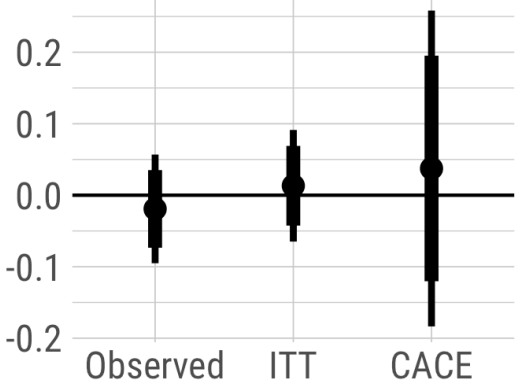

Change in sympathy towards SPD [1-11]

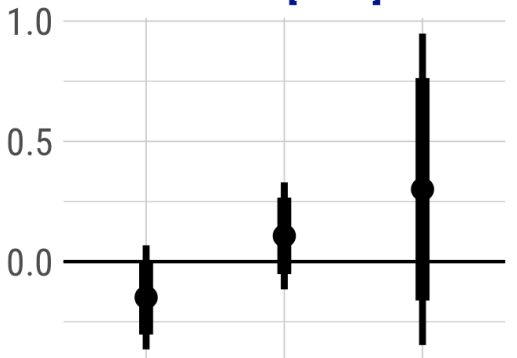

Observed ITT CACE

Change in sympathy

towards Left [1-11]

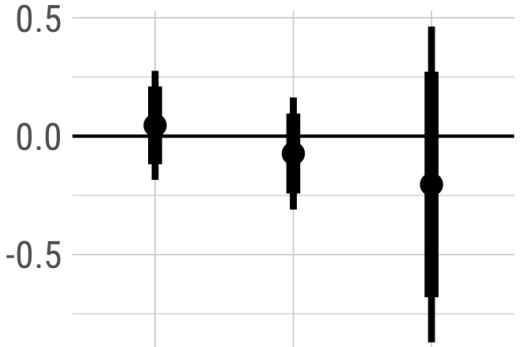

Observed ITT CACE
Change in vote

certainty [1-10]

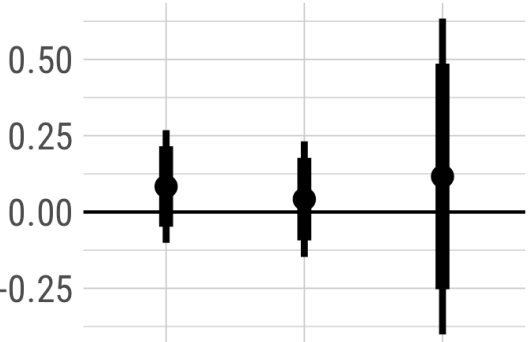

Observed ITT CACE

Political efficacy $[s d=1]$

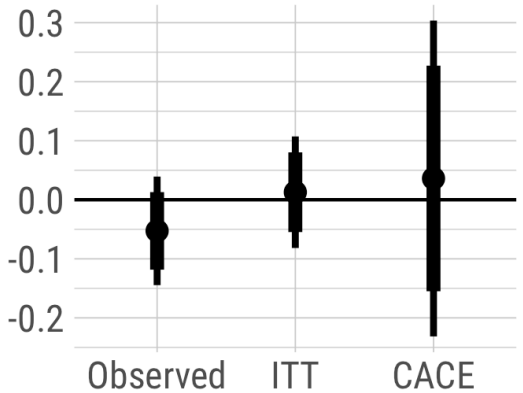

Change in sympathy towards FDP [1-11]

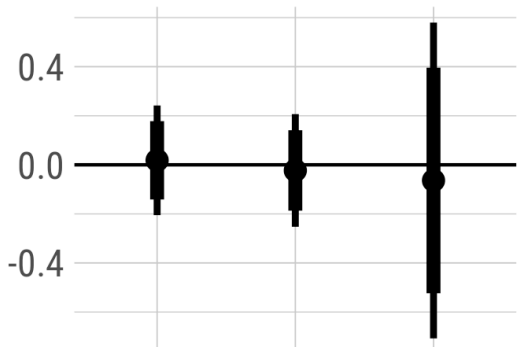

Observed ITT CACE

Change in sympathy towards AfD [1-11]

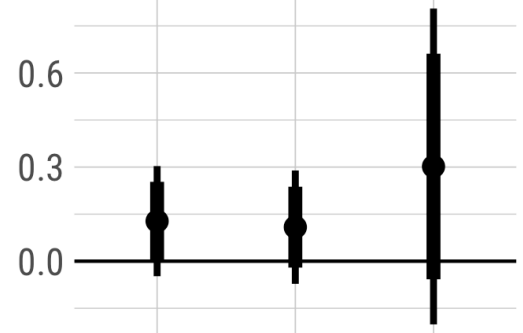

Observed ITT CACE
Mobilized to vote [0-1]

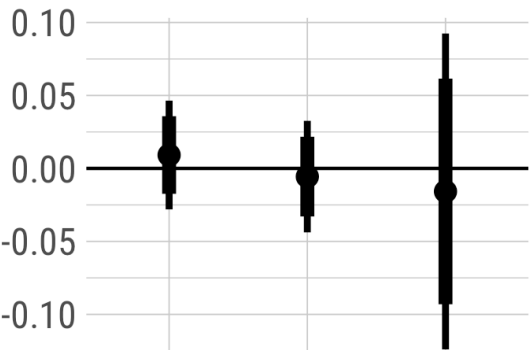

Observed ITT CACE

Change in sympathy towards CDU/CSU [1-11]

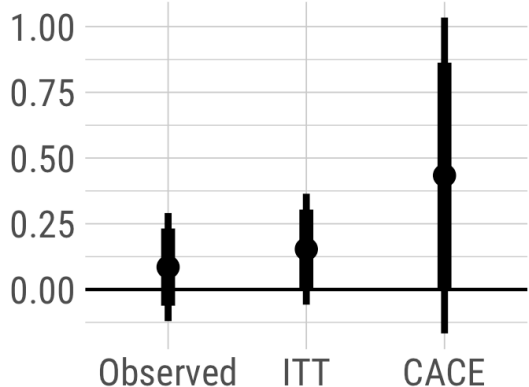

Change in sympathy towards Greens [1-11]

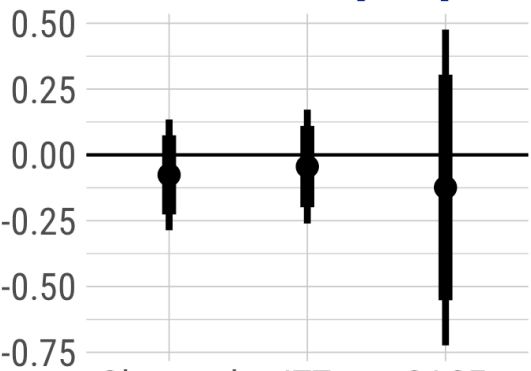

-0.75 observed ITT CACE 
Figure B9: Effects of VAA use on civic knowledge, candidate recognition, and event knowledge. Observed $=$ VAA users vs. VAA non-users, ITT $=$ Intent-to-Treat, CACE $=$ Complier Average Causal Effect.

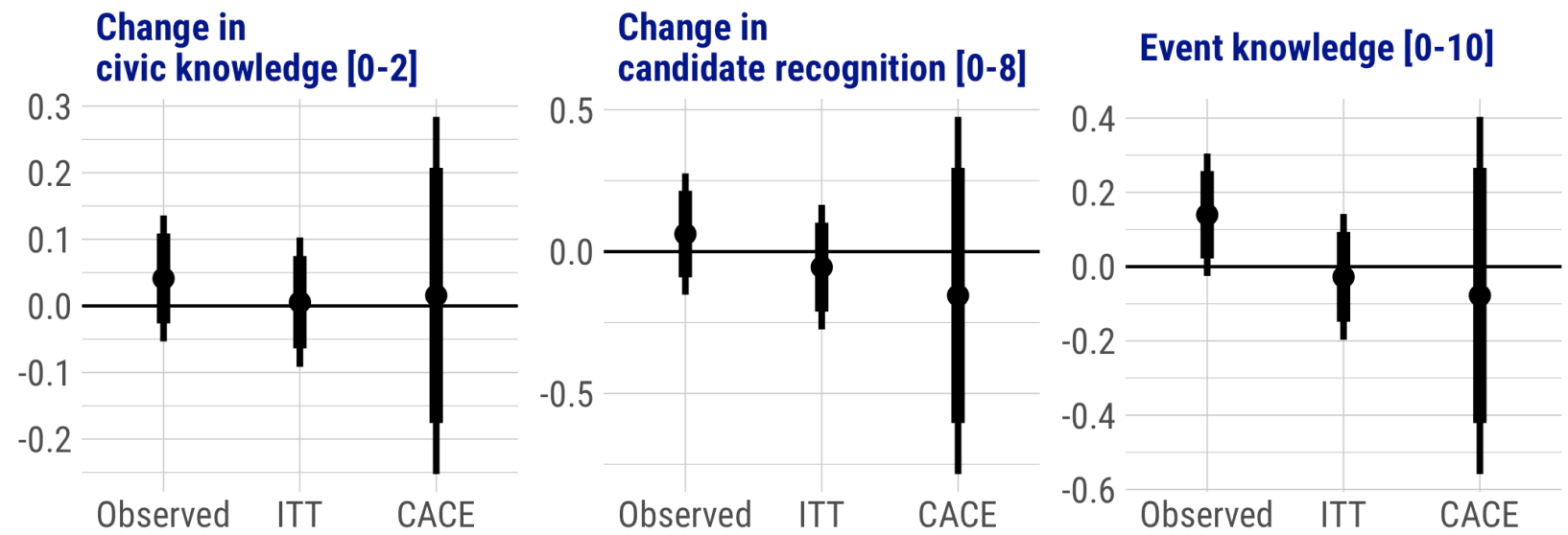

Figure B10: Effects of VAA use on knowledge on parties' issue positions, separated by item. Observed $=$ VAA users vs. VAA non-users, ITT = Intent-to-Treat, CACE $=$ Complier Average Causal Effect.

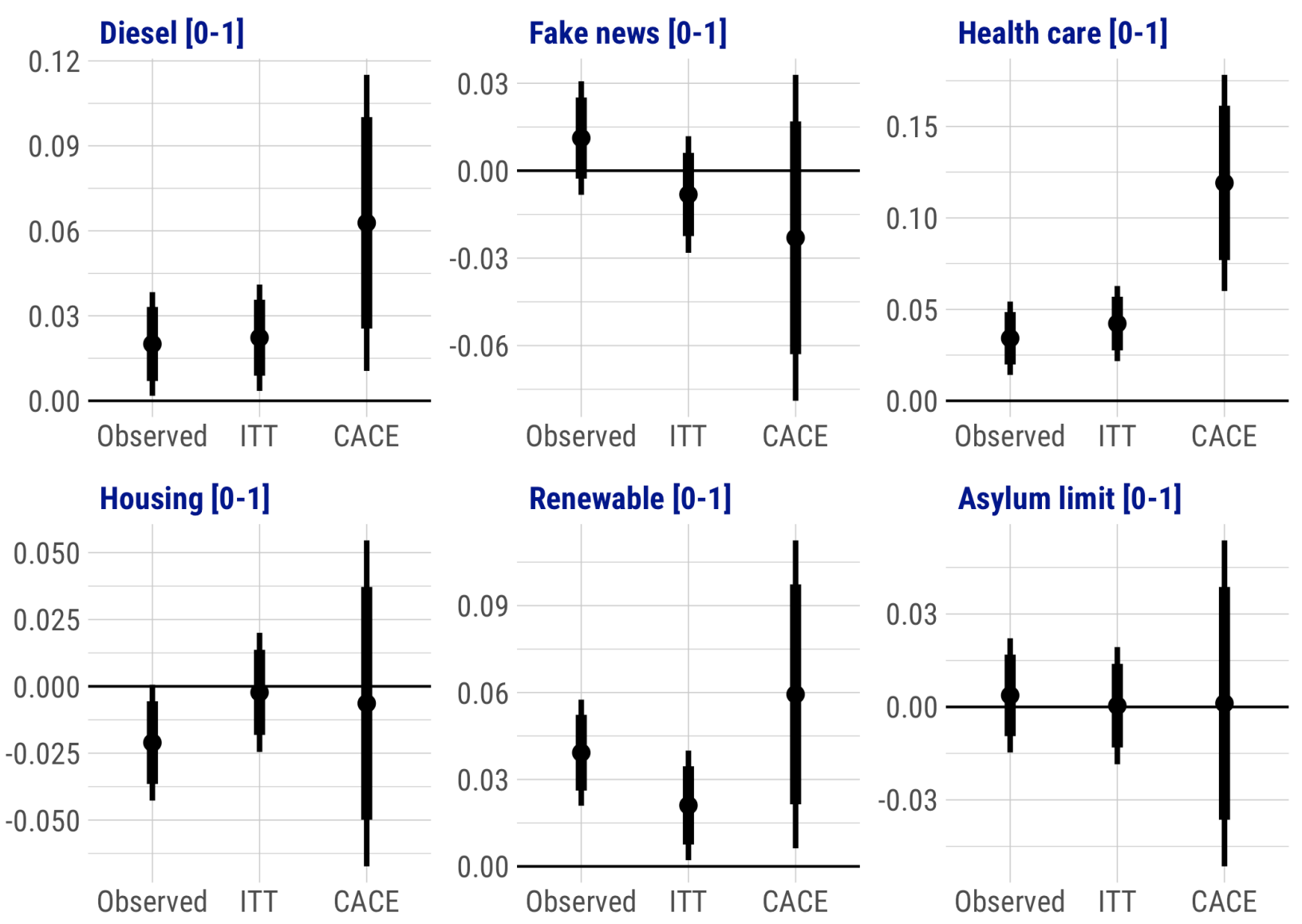


Figure B11: CACE effects of VAA use on self-reported turnout, change in vote choice, and knowledge on parties' issue positions, by age groups.

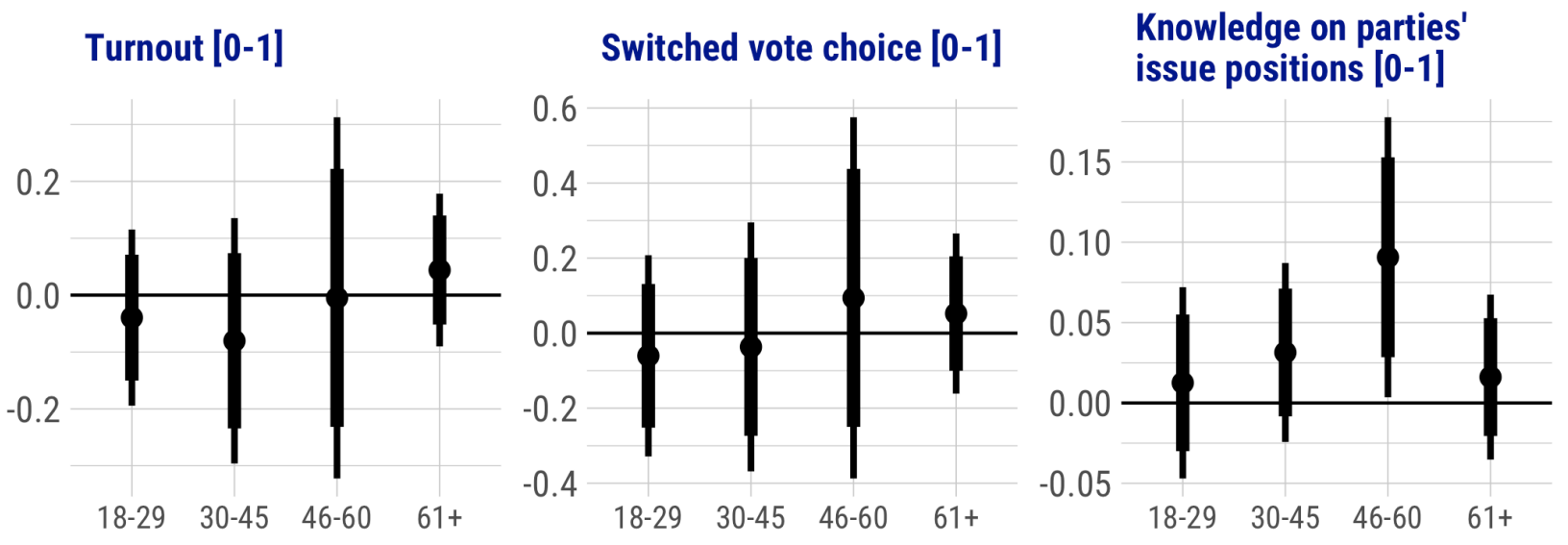

Figure B12: CACE effects of VAA use on self-reported turnout, change in vote choice, and knowledge on parties' issue positions, by education.

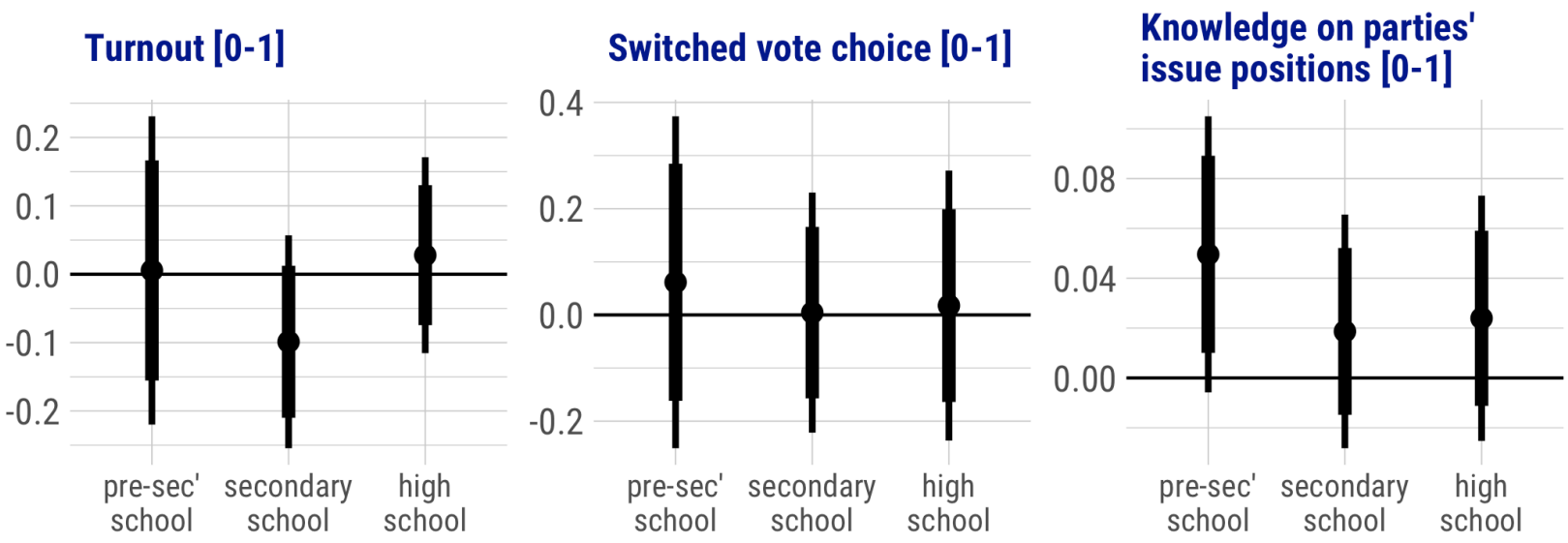

Figure B13: CACE effects of VAA use on self-reported turnout, change in vote choice, and knowledge on parties' issue positions, by gender.
Turnout [0-1]
Switched vote choice [0-1]

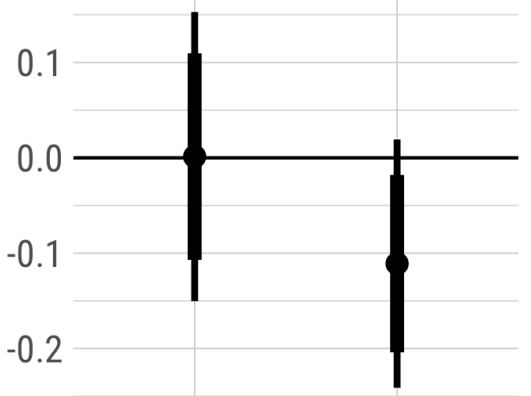

female

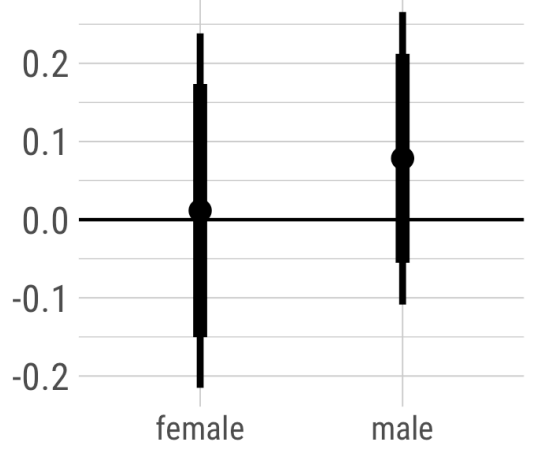

Knowledge on parties' issue positions [0-1]

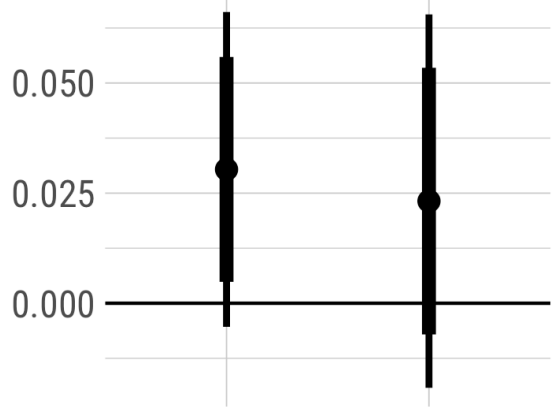

female

male 
Figure B14: CACE effects of VAA use on self-reported turnout, change in vote choice, and knowledge on parties' issue positions, by political ideology.

Turnout [0-1]

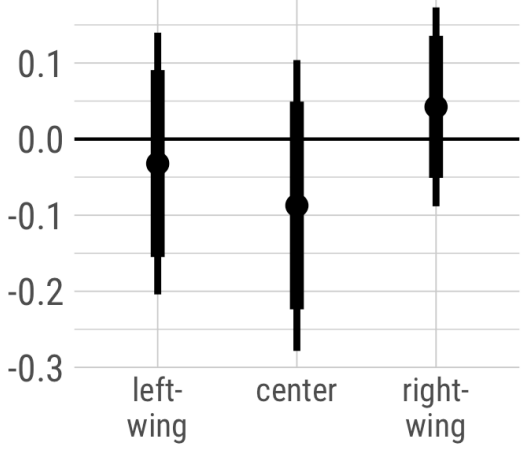

Switched vote choice [0-1]

0.25

0.00

$-0.25$

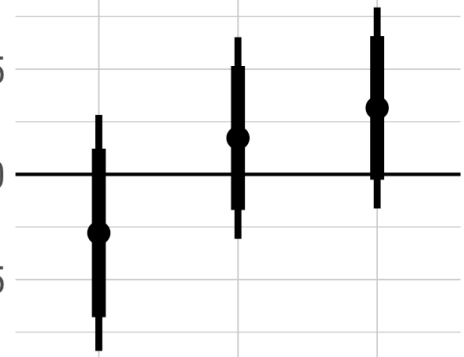

$\begin{array}{ll}\text { left- } & \text { right- } \\ \text { wing } & \text { wing }\end{array}$
Knowledge on parties' issue positions [0-1]

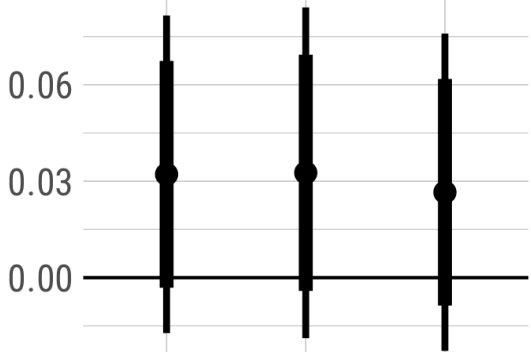

$\begin{array}{ll}\begin{array}{l}\text { left- center right- } \\ \text { wing }\end{array} & \text { wing }\end{array}$

Figure B15: CACE effects of VAA use on self-reported turnout, change in vote choice, and knowledge on parties' issue positions, by political interest.

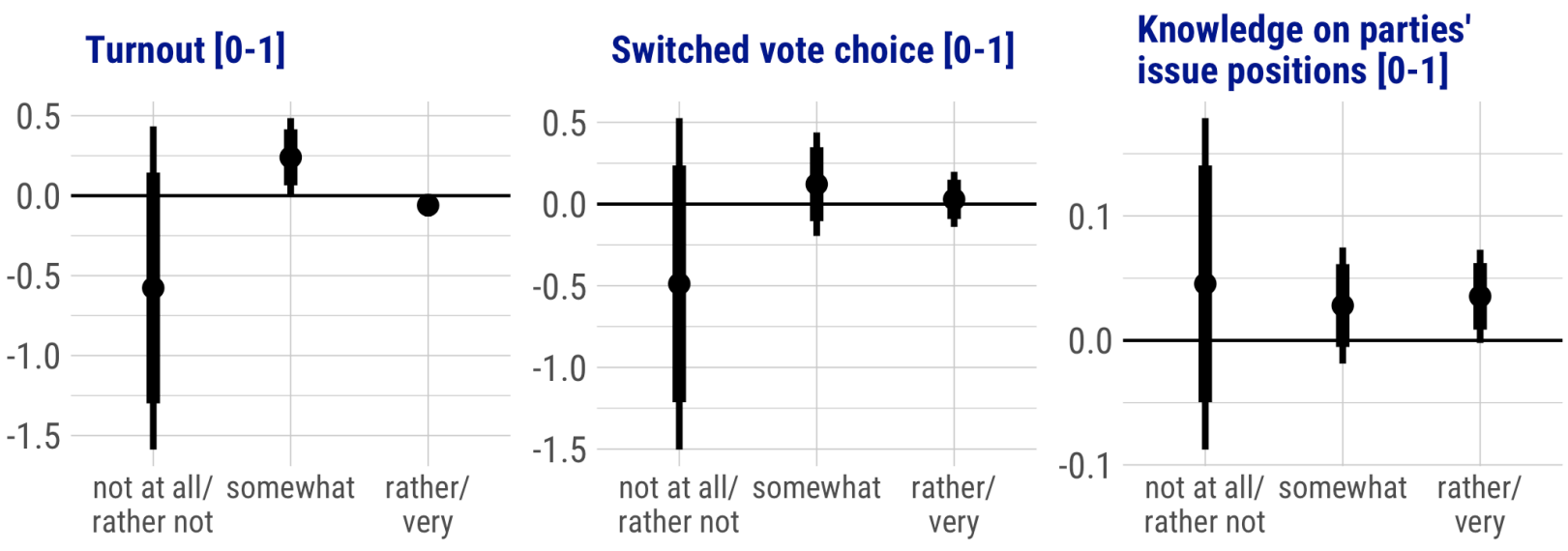

Figure B16: CACE effects of VAA use on self-reported turnout, change in vote choice, and knowledge on parties' issue positions, by civic knowledge.

Turnout [0-1]

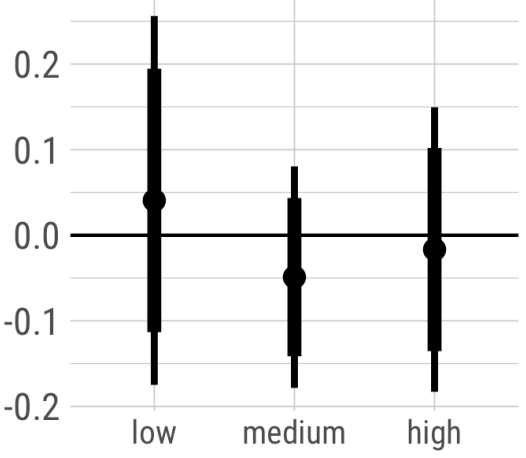

Switched vote choice [0-1]

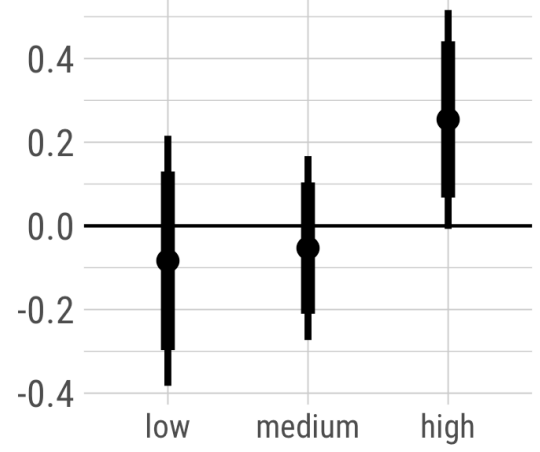

Knowledge on parties' issue positions [0-1]

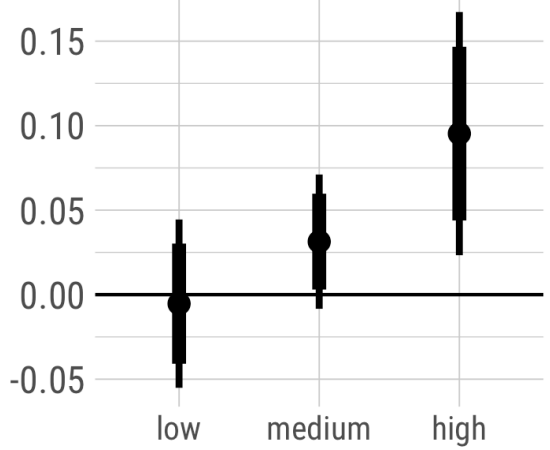


Figure B17: CACE effects of VAA use on self-reported turnout, change in vote choice, and knowledge on parties' issue positions, by candidate recognition.

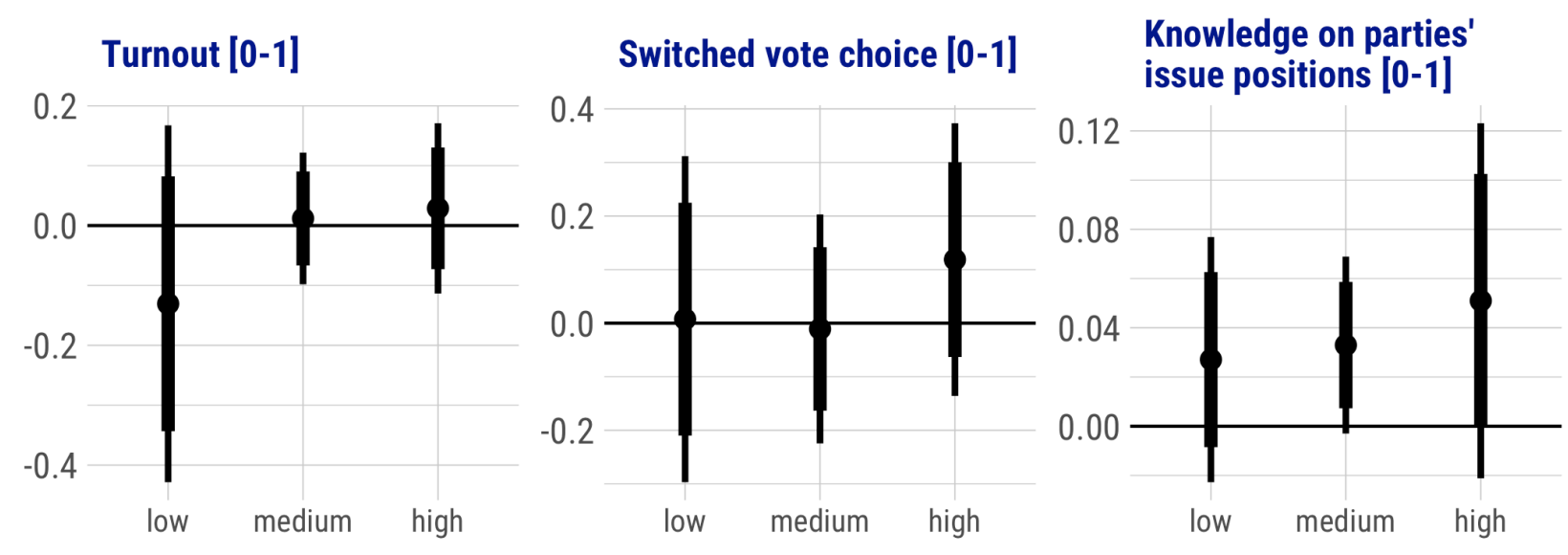

Figure B18: CACE effects of VAA use on self-reported turnout, change in vote choice, and knowledge on parties' issue positions, by pre-treatment party preference.

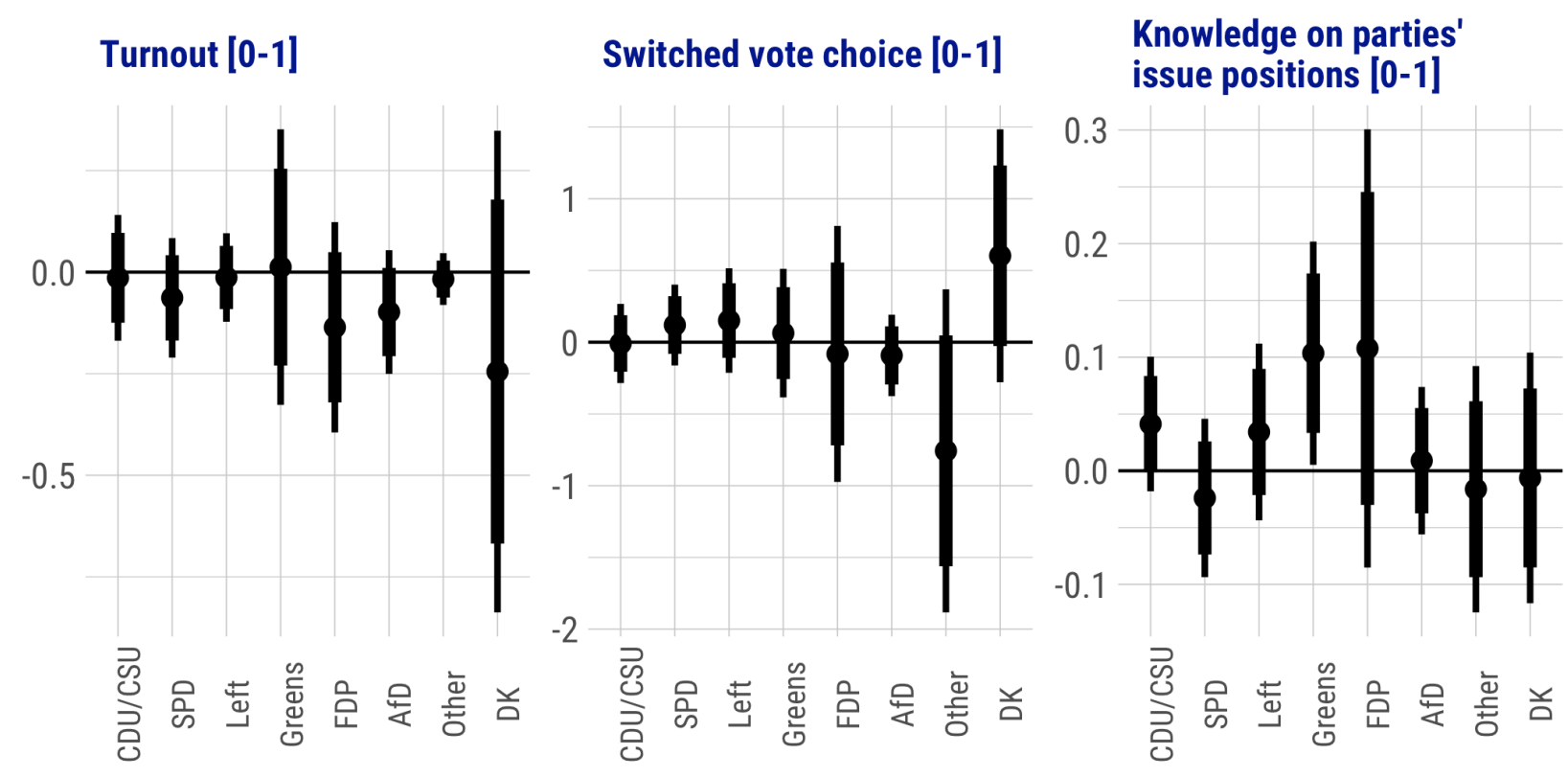




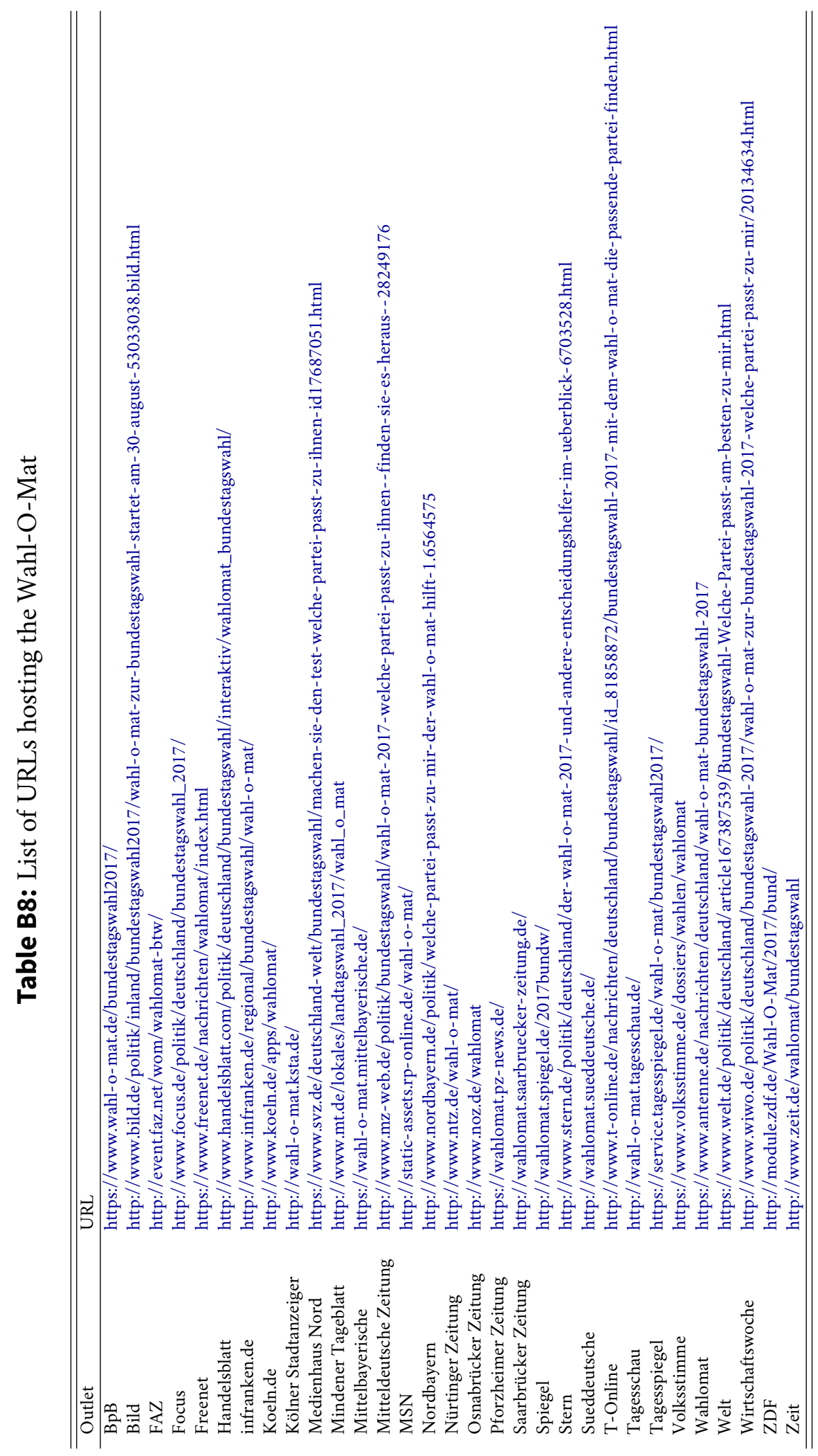




\section{Appendix C Wahl-0-Mat screenshots}

Figure C19: Wahl-O-Mat application: start screen

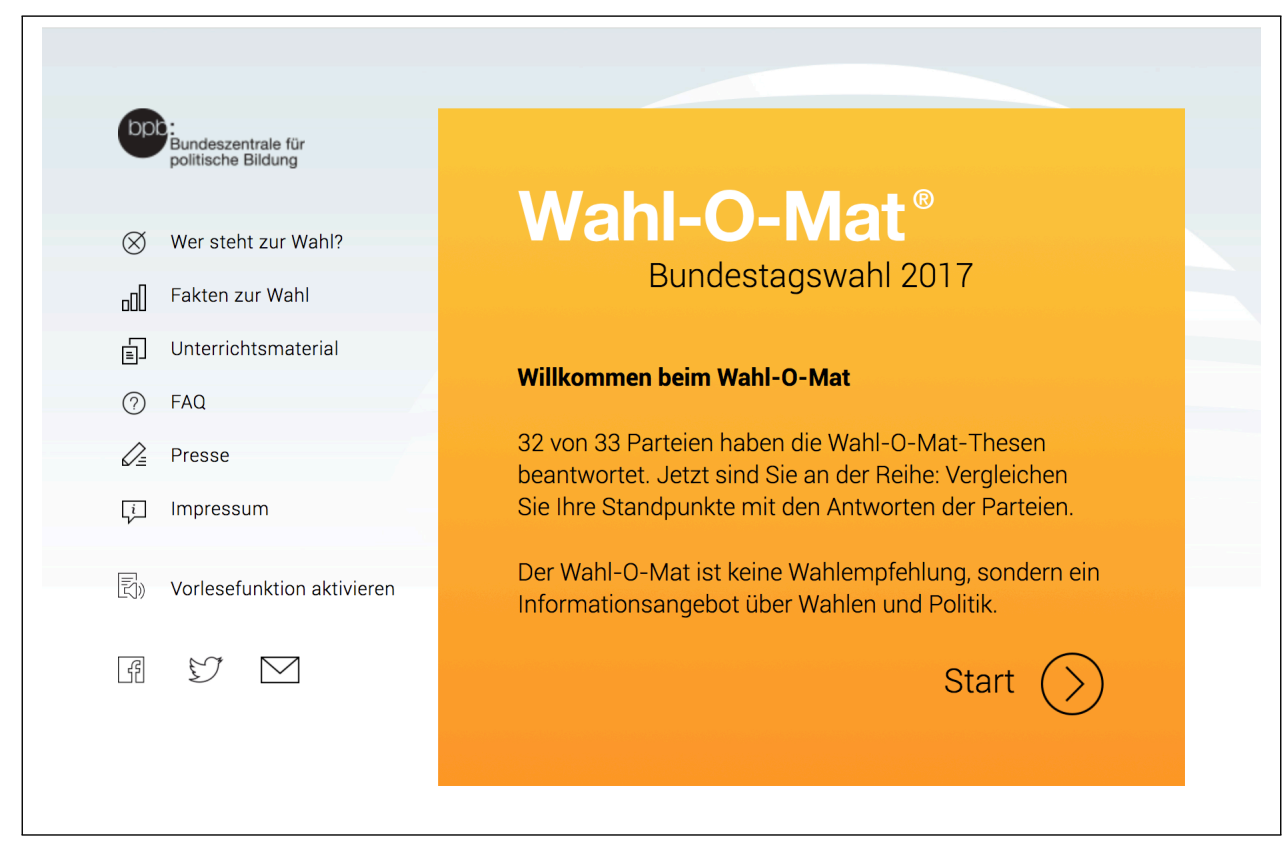

Figure C20: Wahl-O-Mat application: example item

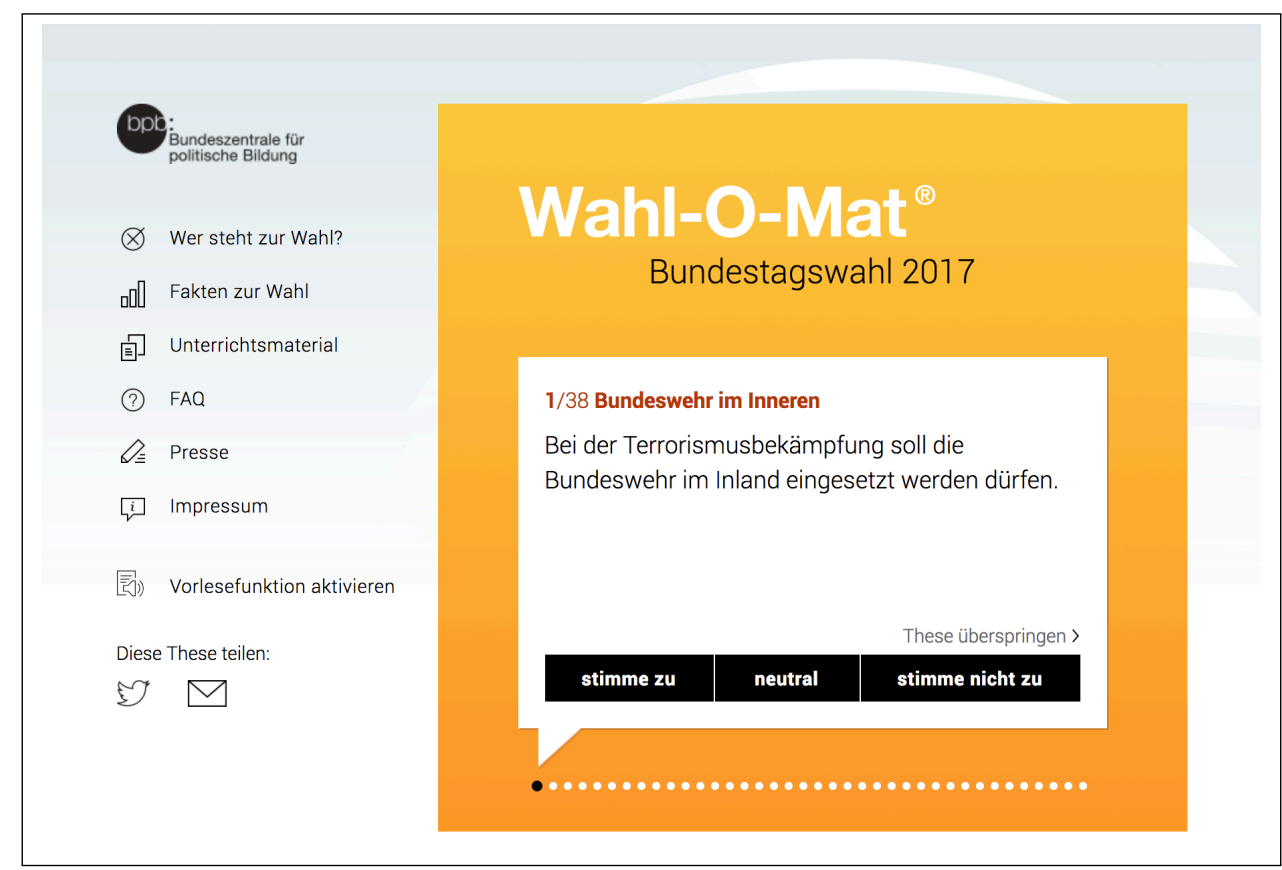


Figure C21: Wahl-O-Mat application: selection of parties for comparison

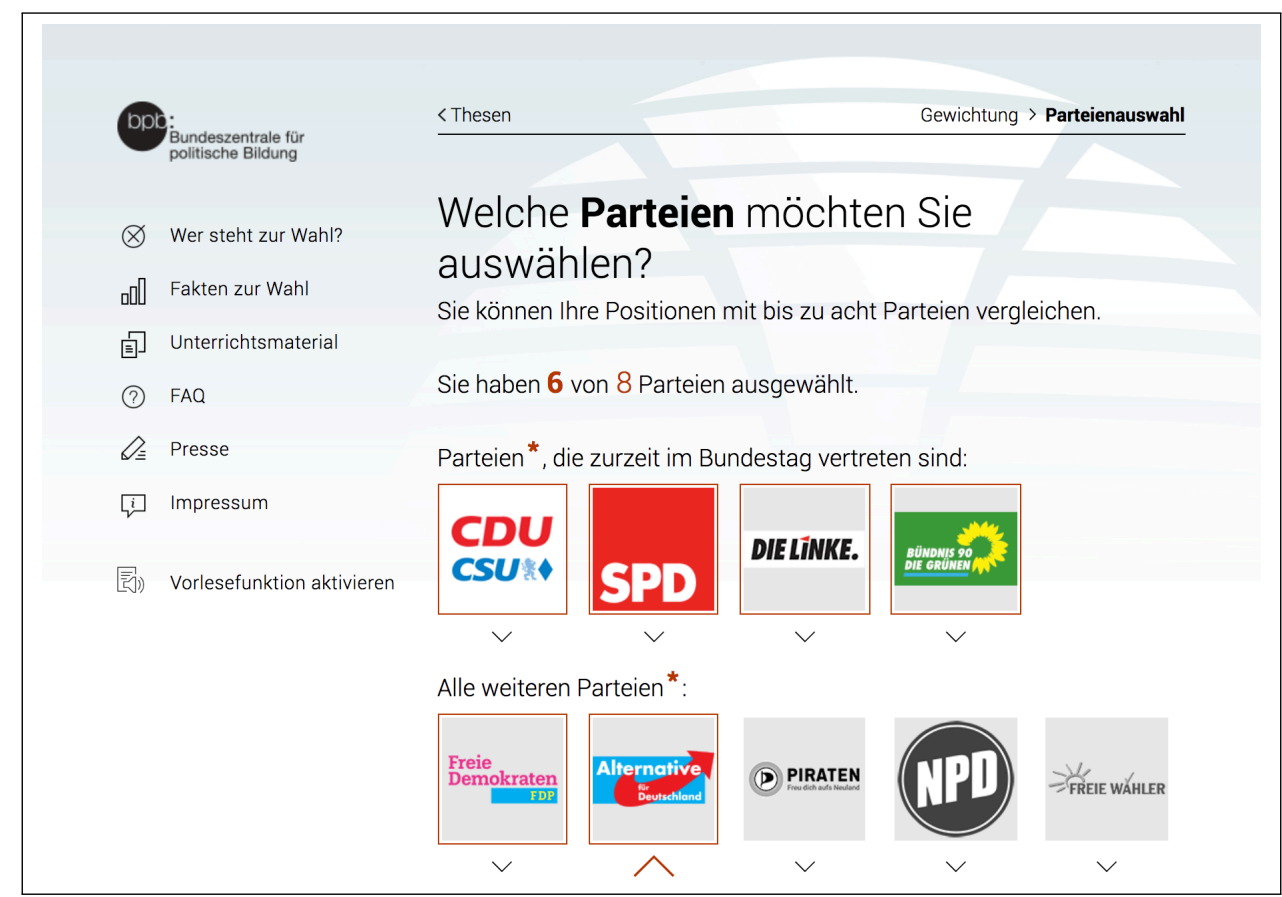

Figure C22: Wahl-O-Mat application: example result

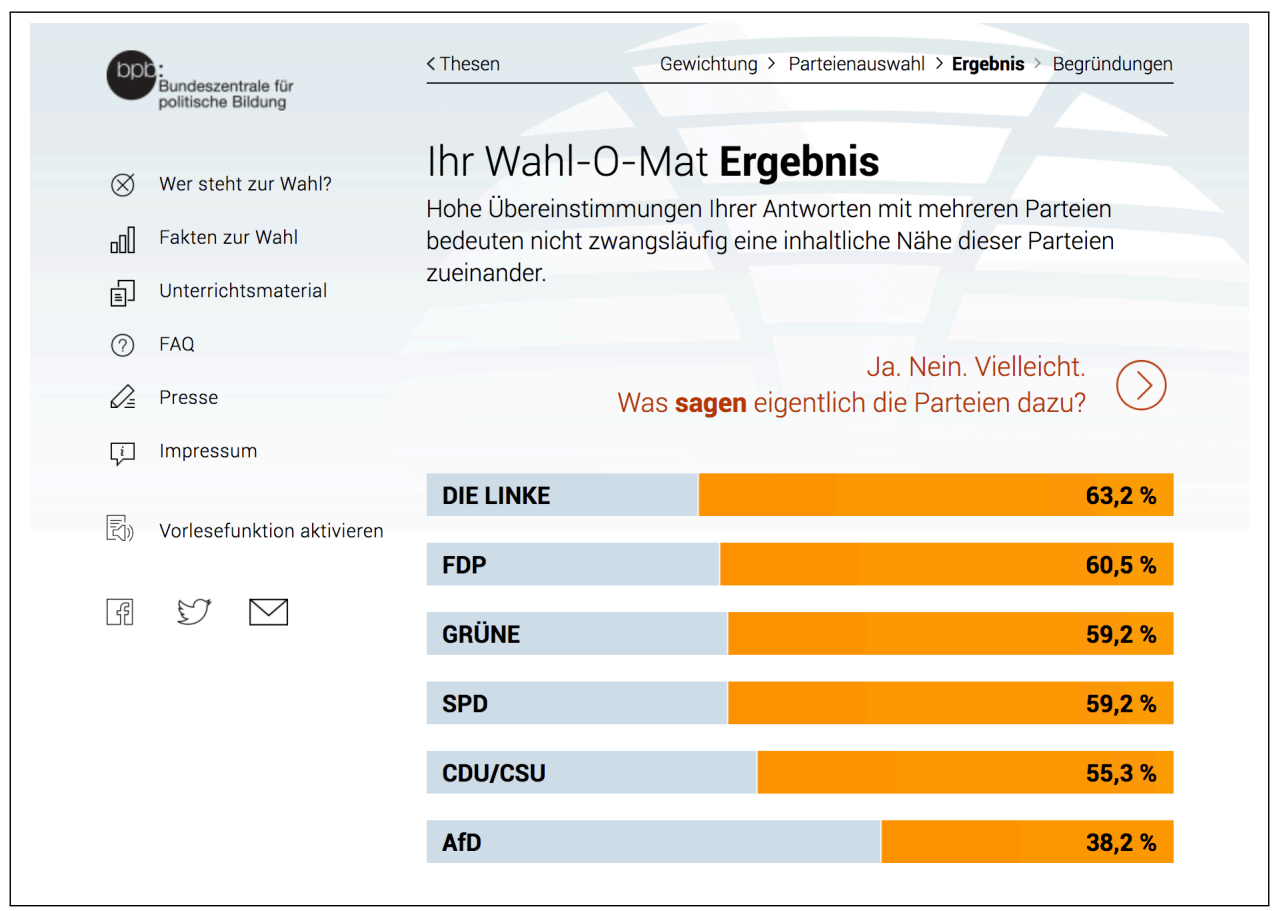


Figure C23: Wahl-O-Mat application: party positions explained

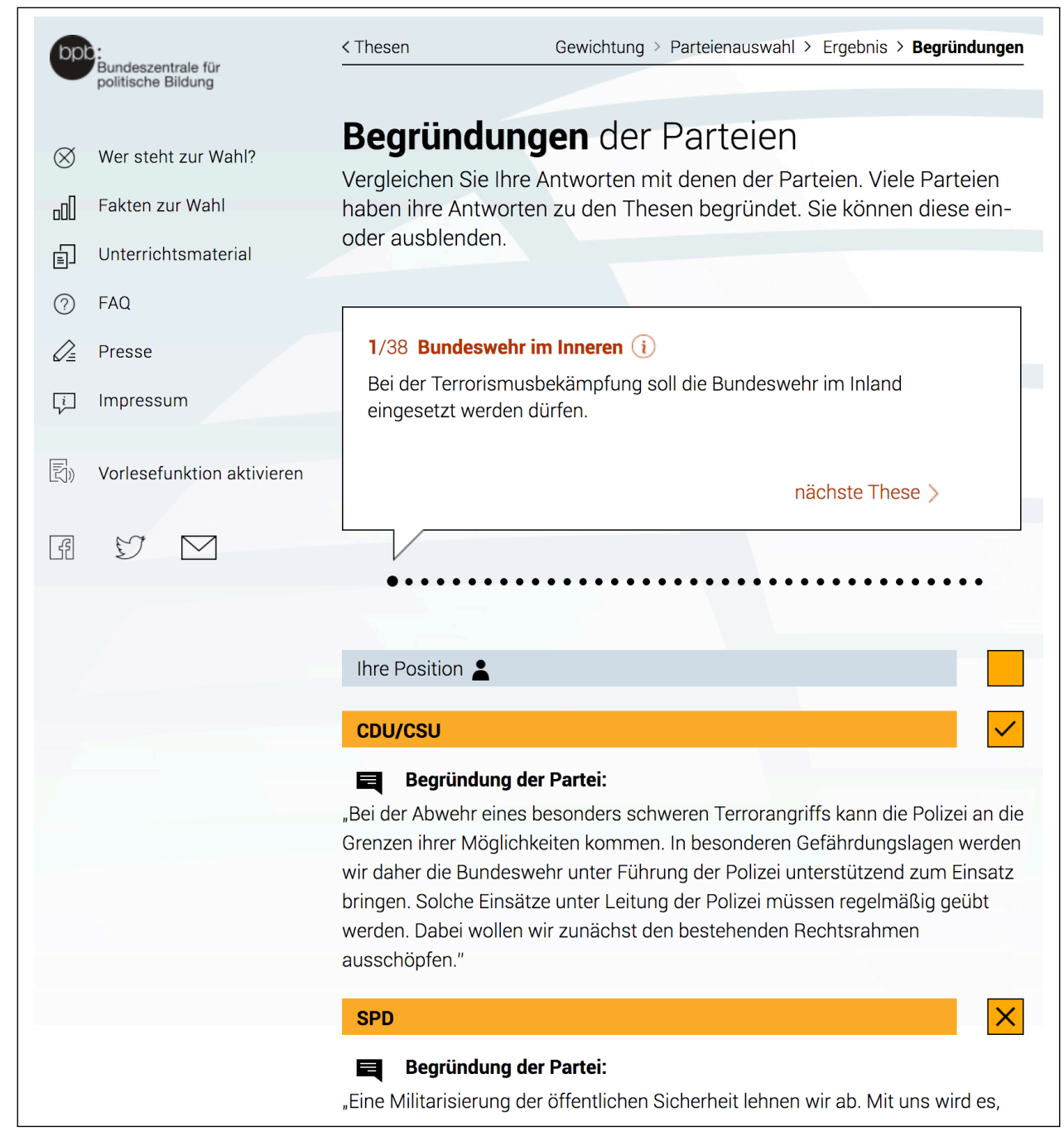


Figure C24: Wahl-O-Mat application: party positions listed

\begin{tabular}{|c|c|c|c|c|}
\hline \multicolumn{5}{|l|}{ Wahl-O-Mat ${ }^{\oplus}$ Bundestagswahl 2017} \\
\hline Vergleich der Positionen & $\underset{\text { CSU }}{\text { CDU }}$ & SPD & DIE LINKKE. & mastion \\
\hline 1. Bei der Terrorismusbekämpfung soll die Bundeswehr im Inland eingesetzt werden dürfen. & $\checkmark$ & $x$ & $\times$ & $x$ \\
\hline 2. Dieselkraftstoff für Pkw soll höher besteuert werden. & $x$ & $\times$ & $\checkmark$ & $\checkmark$ \\
\hline 3. Für die Aufnahme von neuen Asylsuchenden soll eine jährliche Obergrenze gelten. & - & $x$ & $\times$ & $\times$ \\
\hline 4. Der Ausbau emeuerbarer Energien soll vom Bund dauerhaft finanziell gefördert werden. & $x$ & $\checkmark$ & $\checkmark$ & $\checkmark$ \\
\hline 5. Der Bund soll mehr Mittel für den sozialen Wohnungsbau bereitstellen. & $\checkmark$ & $\checkmark$ & $\checkmark$ & $\checkmark$ \\
\hline 6. BAföG soll generell unabhängig vom Einkommen der Eltern gezahlt werden. & $\mathrm{x}$ & - & $\checkmark$ & $\checkmark$ \\
\hline 7. Die Videoüberwachung im öffentlichen Raum soll ausgeweitet werden. & $\checkmark$ & $\checkmark$ & $x$ & $x$ \\
\hline 8. Deutschland soll einem Schuldenschnitt für Griechenland zustimmen. & $x$ & - & $\checkmark$ & $\checkmark$ \\
\hline 9. Generelles Tempolimit auf Autobahnen! & $x$ & $x$ & $\checkmark$ & $\checkmark$ \\
\hline 10. Die Verteidigungsausgaben Deutschlands sollen erhöht werden. & $\checkmark$ & - & $\times$ & $\mathrm{x}$ \\
\hline $\begin{array}{l}\text { 11. Betreiber von Internetseiten sollen gesetzlich dazu verpflichtet sein, Falschinformationen ("Fake News") zu } \\
\text { löschen, auf die sie hingewiesen wurden. }\end{array}$ & $\checkmark$ & $\checkmark$ & $\times$ & $\checkmark$ \\
\hline 12. Ökologische Landwirtschaft soll stärker gefördert werden als konventionelle Landwirtschaft. & - & $\times$ & $\checkmark$ & $\checkmark$ \\
\hline 13. Kindergeld soll nur an deutsche Familien ausgezahlt werden. & $\times$ & $\times$ & $\times$ & $\times$ \\
\hline 14. Arbeitsverträge sollen weiterhin ohne Angabe von Gründen befristet sein dürfen. & $\checkmark$ & $x$ & $\times$ & $\times$ \\
\hline 15. Kinder sollen gegen ansteckende Krankheiten geimpft werden müssen. & $\checkmark$ & $\times$ & $\times$ & $\times$ \\
\hline 16. Alle Banken sollen verstaatlicht werden. & $\times$ & $\times$ & $\times$ & $\times$ \\
\hline $\begin{array}{l}\text { 17. Der Völkermord an den europäischen Juden soll weiterhin zentraler Bestandteil der deutschen } \\
\text { Erinnerungskultur sein. }\end{array}$ & $\checkmark$ & $\checkmark$ & $\checkmark$ & $\checkmark$ \\
\hline 18. Haushaltsüberschüsse sollen überwiegend zum Abbau von Staatsschulden verwendet werden. & - & $x$ & $x$ & $x$ \\
\hline $\begin{array}{l}\text { 19. Die Gesamtzahl der Nutztiere in den landwirtschaftlichen Betrieben einer Gemeinde soll begrenzt werden } \\
\text { können. }\end{array}$ & - & $\checkmark$ & $\checkmark$ & $\checkmark$ \\
\hline 20. In Deutschland soll auch zukünftig Braunkohle abgebaut werden dürfen. & - & $\checkmark$ & $x$ & $x$ \\
\hline
\end{tabular}




\title{
Appendix D Questionnaire items
}

Figure D1: Request for Wahl-O-Mat use (encouragement); wave 3

\section{YouGov}

\begin{abstract}
Wir möchten Ihnen in der nächsten Befragung ein paar Fragen zu den Positionen der Parteien und auch Ihre eigenen Positionen zu bestimmten politischen Themen stellen. Dazu möchten wir Sie bitten, bis zur nächsten Befragung das WahlinformationsTool der Bundeszentrale für politische Bildung "Wahl-O-Mat" zu nutzen, das unter www.wahl-o-mat.de zur Verfügung steht. Wären Sie bereit, dieses Tool bis zur nächsten Befragung, die etwa in zwei Wochen stattfinden wird, zu nutzen?

Hinweis: Wir würden Sie im Falle Ihrer Einwilligung vor Beginn der nächsten Befragung nochmals per Email erinnern. Für Ihre Bereitschaft würden wir Ihnen außerdem 50 YouGov-Punkte gutschreiben
\end{abstract}

Ja, ich bin bereit, bis zur nächsten Befragung den Wahl-O-Mat zu nutzen, und habe es bis jetzt noch nicht genutzt.

Ja, ich bin bereit, bis zur nächsten Befragung den Wahl-O-Mat zu nutzen, und habe es bereits genutzt.

Nein, ich bin nicht bereit, den Wahl-O-Mat zu nutzen.

[Translated] In the next survey, we would like to ask you some questions on positions of parties as well as your own attitudes towards certain political topics. For this purpose, we would like to ask you to use the voting advice application "Wahl-O-Mat", offered by the Federal Agency for Civic Education [Bundeszentrale für Politische Bildung] at www.wahl-o-mat.de until the next wave. Would you be willing to use this tool until the next survey, which will take place in about two weeks?

Please note: If you agree, we would remind you of using the tool by e-mail before the next survey starts. In compensation of your consent, you would be reimbursed with 50 YouGov points.

Yes, I am willing to use the Wahl-O-Mat until the next survey, and I have not used it so far.

Yes, I am willing to use the Wahl-O-Mat until the next survey, and I have already used it.

No, I am not willing to use the Wahl-O-Mat 
Figure D2: Reported Wahl-O-Mat use (encouragement group); wave 4

In der letzten Befragung hatten Sie sich dazu bereiterklärt, das Wahlinformations-Tool „Wahl-O-Mat“ zu verwenden. Hatten Sie Gelegenheit, den „Wahl-O-Mat" zu nutzen?

Ja, ich habe den Wahl-O-Mat genutzt.

Nein, ich habe den Wahl-O-Mat nicht genutzt.

[Translated] In the last survey, you agreed to use the voting guide tool "Wahl-O-Mat". Did you have the opportunity to use the "Wahl-O-Mat"?

Yes, I did use the Wahl-O-Mat.

No, I did not use the Wahl-O-Mat.

Figure D3: Reported Wahl-O-Mat use (control group); wave 4

YOUGOV
\& Medien
Poit kurzem steht online das Wahlinformations-Tool „Wahl-O-Mat“ zur Verfügung, mit dem man die eigenen Einstellungen mit
diese Bundestagswahl schon genutzt?
Ja, ich habe den Wahl-O-Mat genutzt.
Nein, ich habe den Wahl-O-Mat nicht genutzt.

[Translated] As of late the voting guide tool "Wahl-O-Mat" is available online, which can be used to compare own preferences with parties' positions on various issues. What about you: Did you have the opportunity to use the "Wahl-O-Mat" yet?

Yes, I did use the Wahl-O-Mat.

No, I did not use the Wahl-O-Mat. 
Figure D4: Reported Wahl-O-Mat advice (encouragement group); wave 4

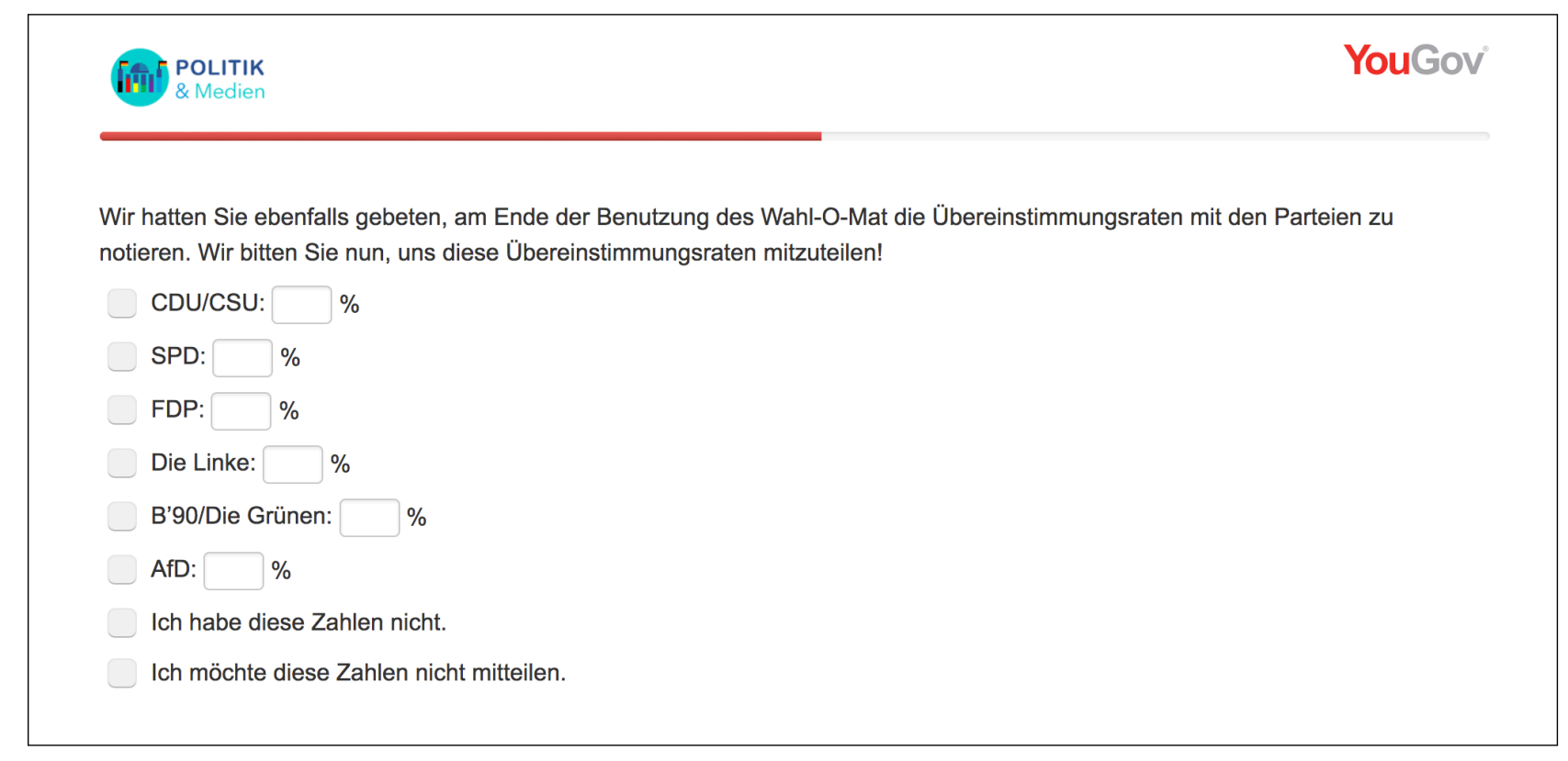

[Translated] We also asked you to write down the overlap rates with the parties after using the WahlO-Mat. We now ask you to tell use these overlap rates!

- ...

I do not have these numbers.

I do not want to share these numbers. 
Figure D5: Reported Wahl-O-Mat advice (control group); wave 4

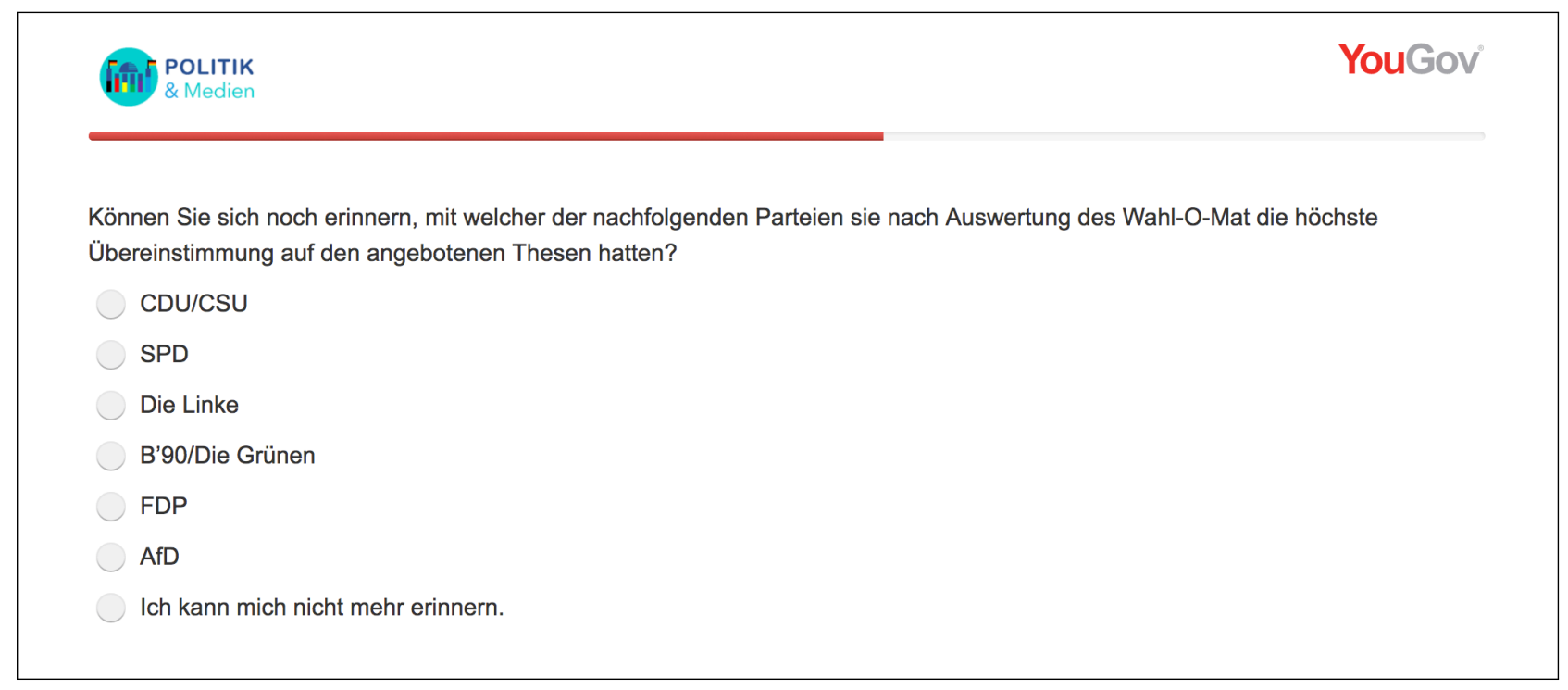

[Translated] Can you still remember with which of the following parties you had the highest overlap on the presented issues according to the Wahl-O-Mat evaluation?

- ...

I cannot remember anymore. 
Figure D6: Perceived party positions on Wahl-O-Mat items; wave 4

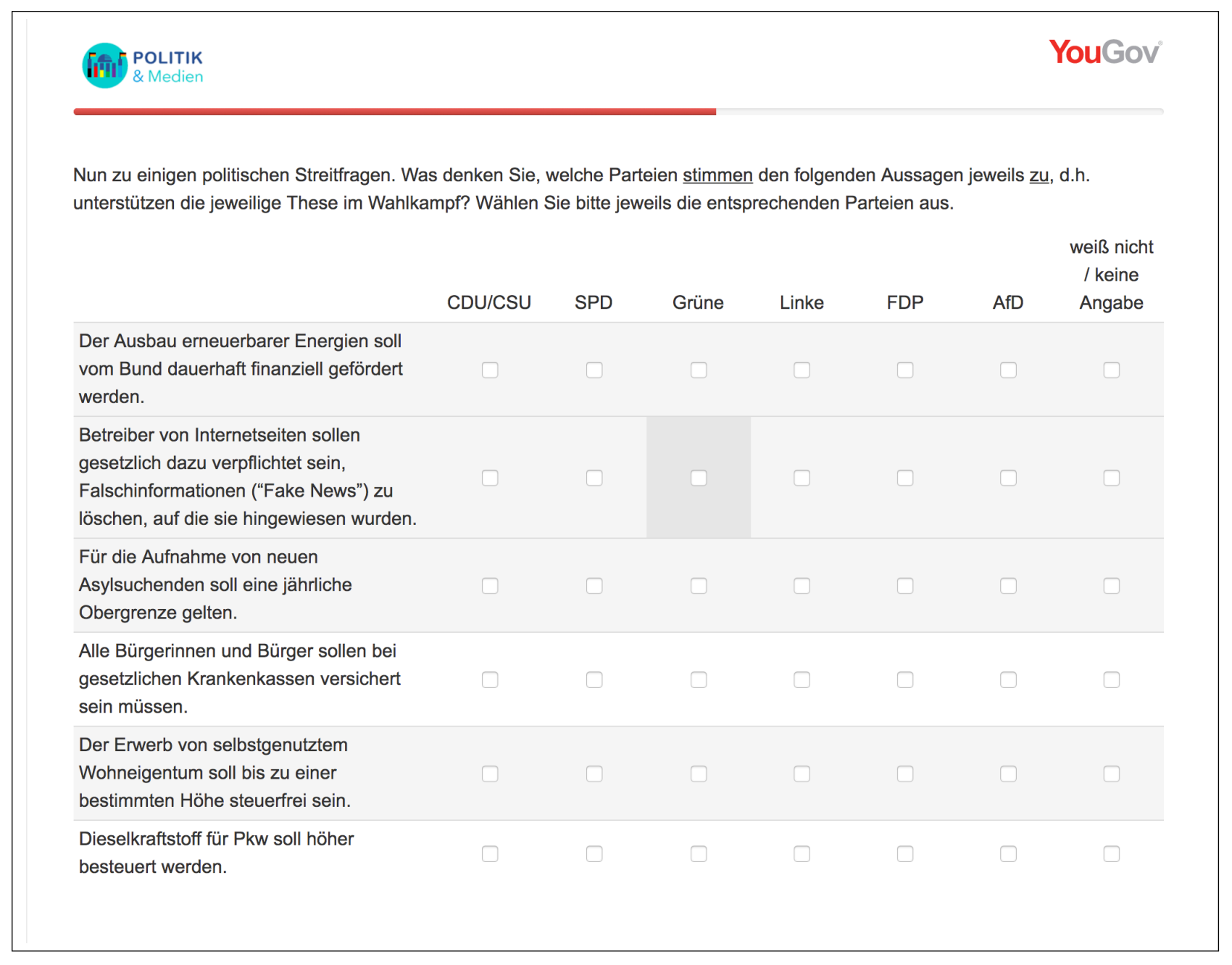

[Translated] Now for some politically contested issues. What do you think, which parties agree with the following statements, i.e. support the corresponding statement in the campaign? Please select the respective parties!

- The expansion of renewable energies should be permanently subsidized by the federal state.

- Internet platform providers should be obliged by law to delete false information ("Fake News") which they are made aware of.

- There should be a yearly upper limit for accepted news asylum seekers.

- All citizens should be under statutory health insurance.

- Acquiring owner-occupied property should be tax-free up to a certain extent.

- Diesel fuel for cars should be taxed higher. 
Figure D7: Reported turnout at election; wave 5

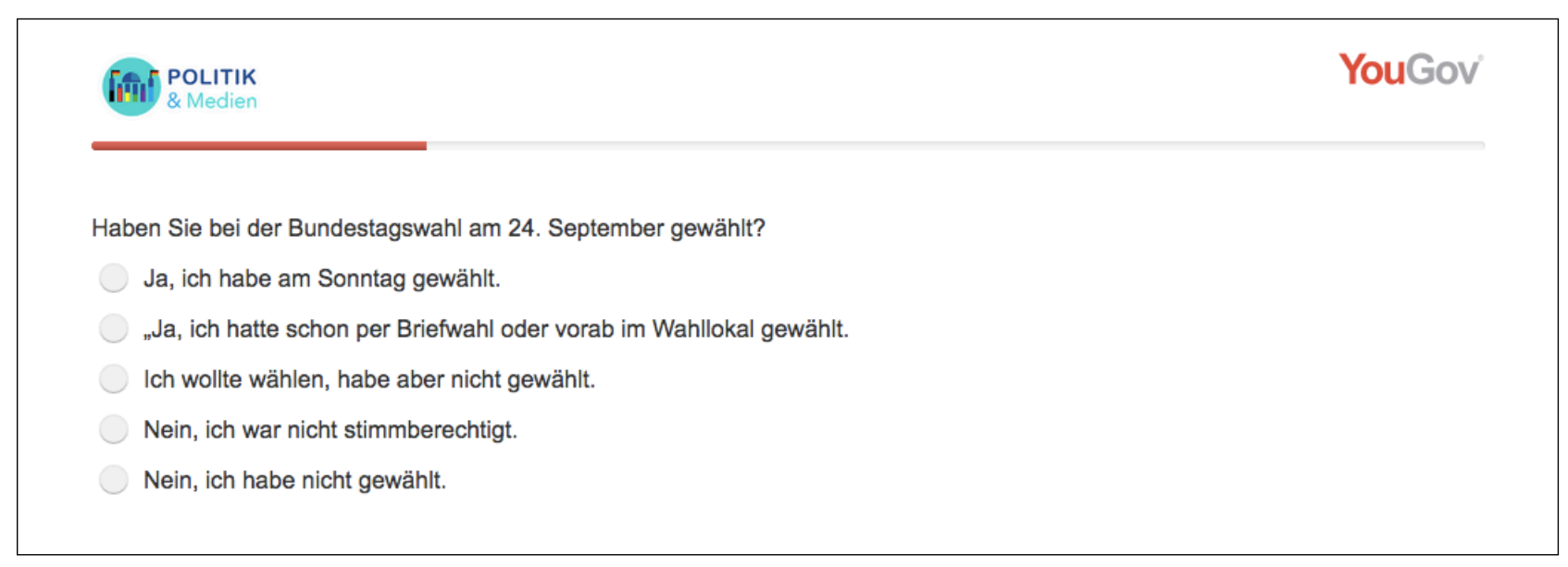

[Translated] Did you vote at the Federal election on September 24?

Yes, I voted on Sunday.

$\bigcirc$ Yes, I had previously voted by mail or at the polling station

I planned to vote, but I did not.

No, I was not entitled to vote.

No, I did not vote. 
Figure D8: Vote intention; waves 3 and 4

\begin{tabular}{|l|l|l|l|}
\hline POLITIK \\
\& Medien \\
Wahlkreis und die Zweitstimme für eine Partei. Was werden Sie auf Ihrem Stimmzettel ankreuzen? \\
Zweitstimme für
\end{tabular}

[Translated] You have two votes at the federal election in September 2017. The first is for a candidate in your constituency, the second for a party. What will you choose on the ballot - $\ldots$

I don't know yet. 
Figure D9: Political interest; waves 1, 3, and 4

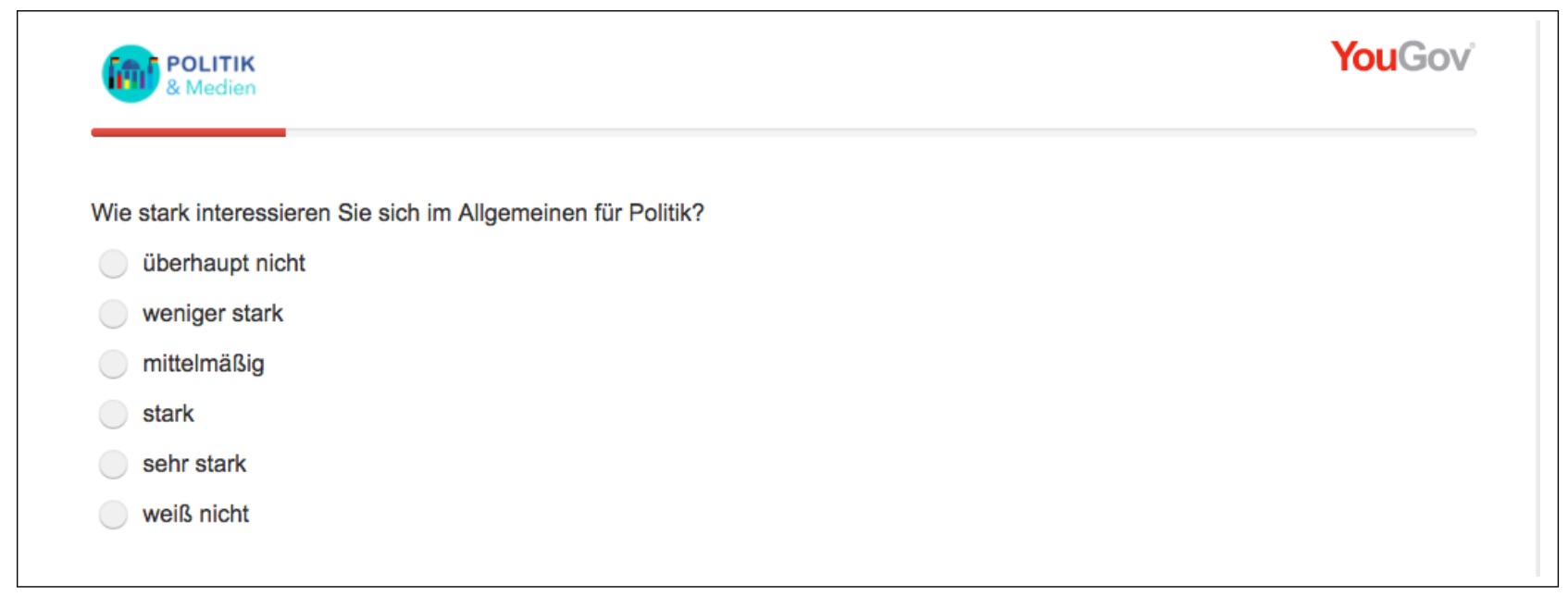

[Translated] How interested are you in politics in general
$\bigcirc$ not at all
$\bigcirc$ not very
$\bigcirc$ moderately
strongly
very strongly
don't know 
Figure D10: Political ideology; wave 1

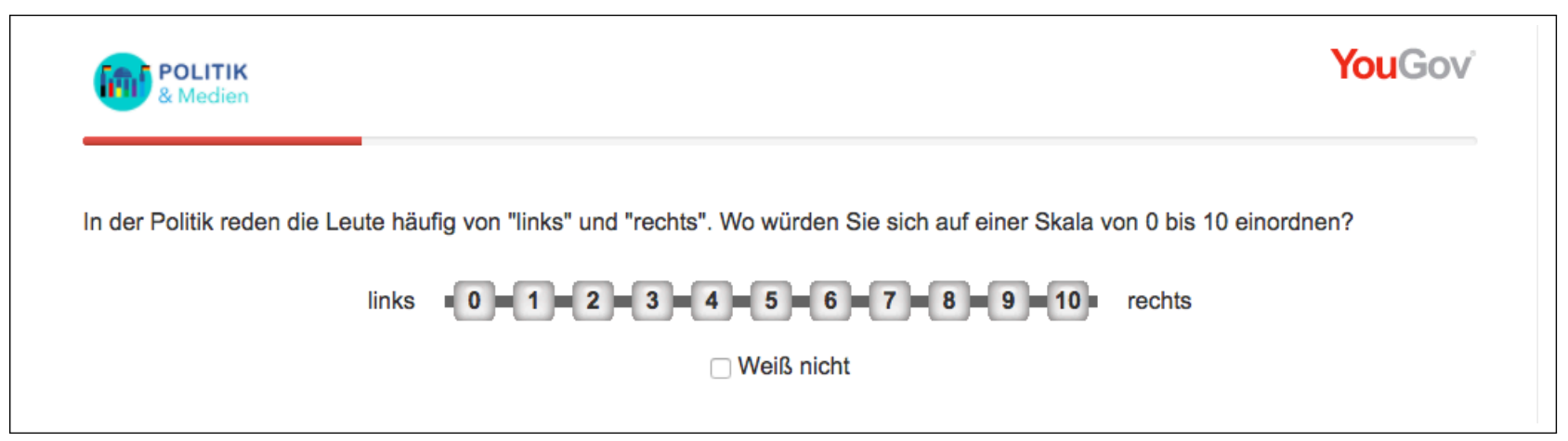

[Translated] In politics, people often speak of "left" and "right". Where would you place yourself on a scale from 0 to 10 ?
$\bigcirc$ left
$\cdot \ldots$
right
don't know

Figure D11: Likelihood to vote; waves 3 and 4

Bei Wahlen nehmen viele Leute teil. Andere schaffen es nicht, ihre Stimme abzugeben, oder nehmen aus anderen Gründen nicht teil. Auf einer Skala von 1 bis 10, wie wahrscheinlich ist es, dass Sie an der Bundestagswahl am 24. September teilnehmen werden?

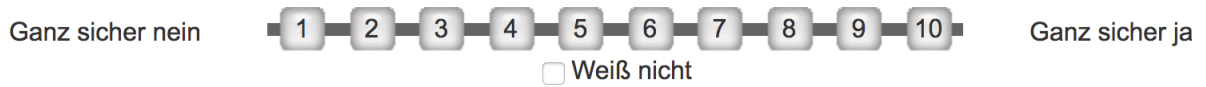

[Translated] Many people participate in elections. Some do not manage to cast a vote or do not partic-
ipate for other reasons. On a scale from 1 to 10 , how likely is it that you will participate at the federal
election on September 24?
Certainly not
-...
Certainly yes
Don't know


Figure D12: Political efficacy; waves 3 and 4

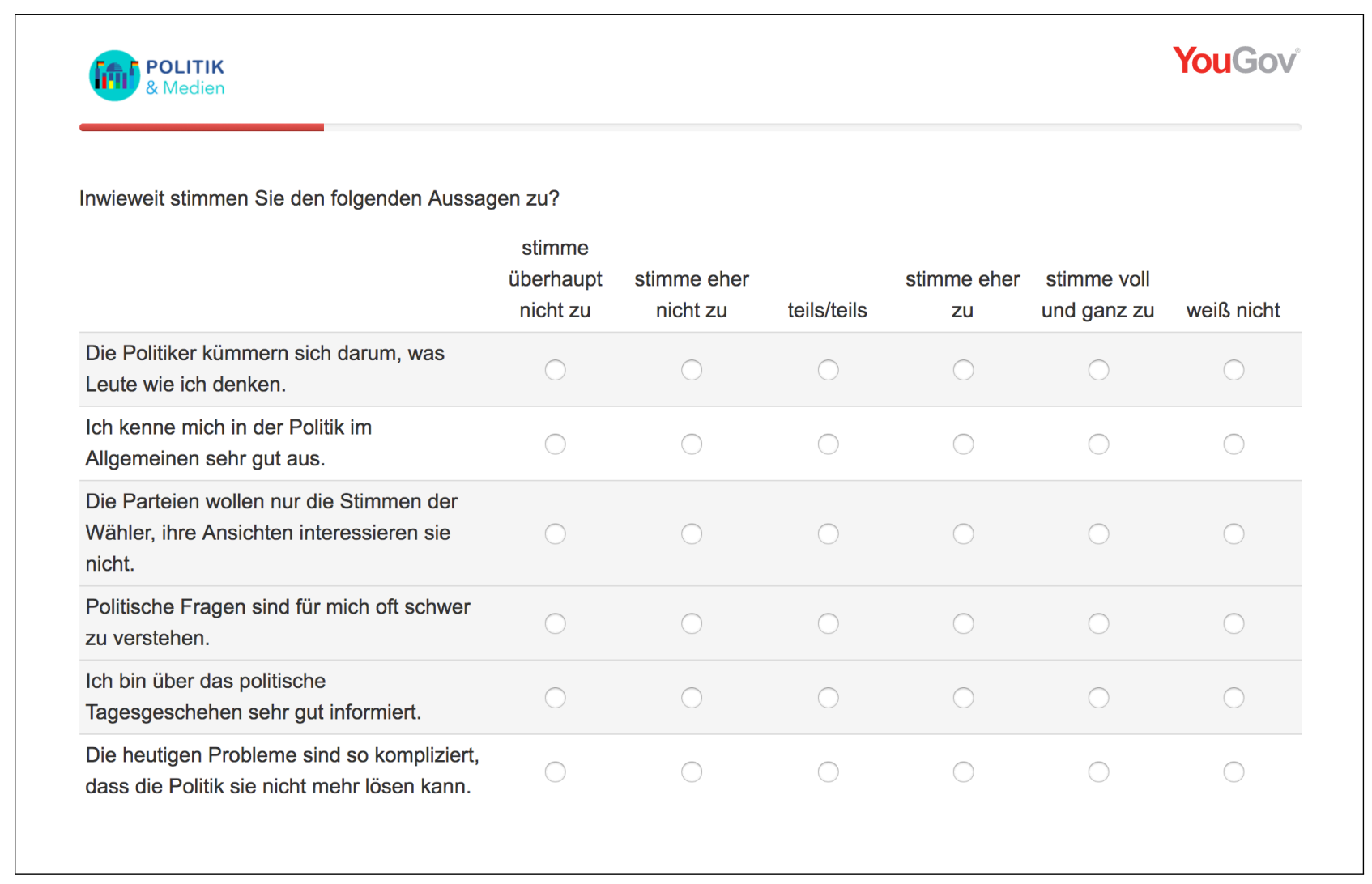

[Translated] To what extent do you agree with the following statements?

Politicians care about what the people think.

$\bigcirc$ I am generally very well informed about politics.

Parties only want to get people's votes; they don't acre about their opinion.

It is often difficult for me to understand political questions.

$\bigcirc$ I am generally very well informed about daily political events.

The problems are so complex today that politics cannot solve them anymore. 
Figure D13: Vote certainty; waves 3 and 4

$\begin{aligned} & \text { YouGov } \\ & \text { \&OLITIK }\end{aligned}$
Wie sicher sind Sie sich bei Ihrer Wahlentscheidung, was die Zweitstimme betrift?
Sehr unsicher
[Translated] How certain are you regarding your decision whom to vote for with your second vote?
Very uncertain
....
Very certain
Don't know


Figure D14: Party scalometers; waves 3 and 4

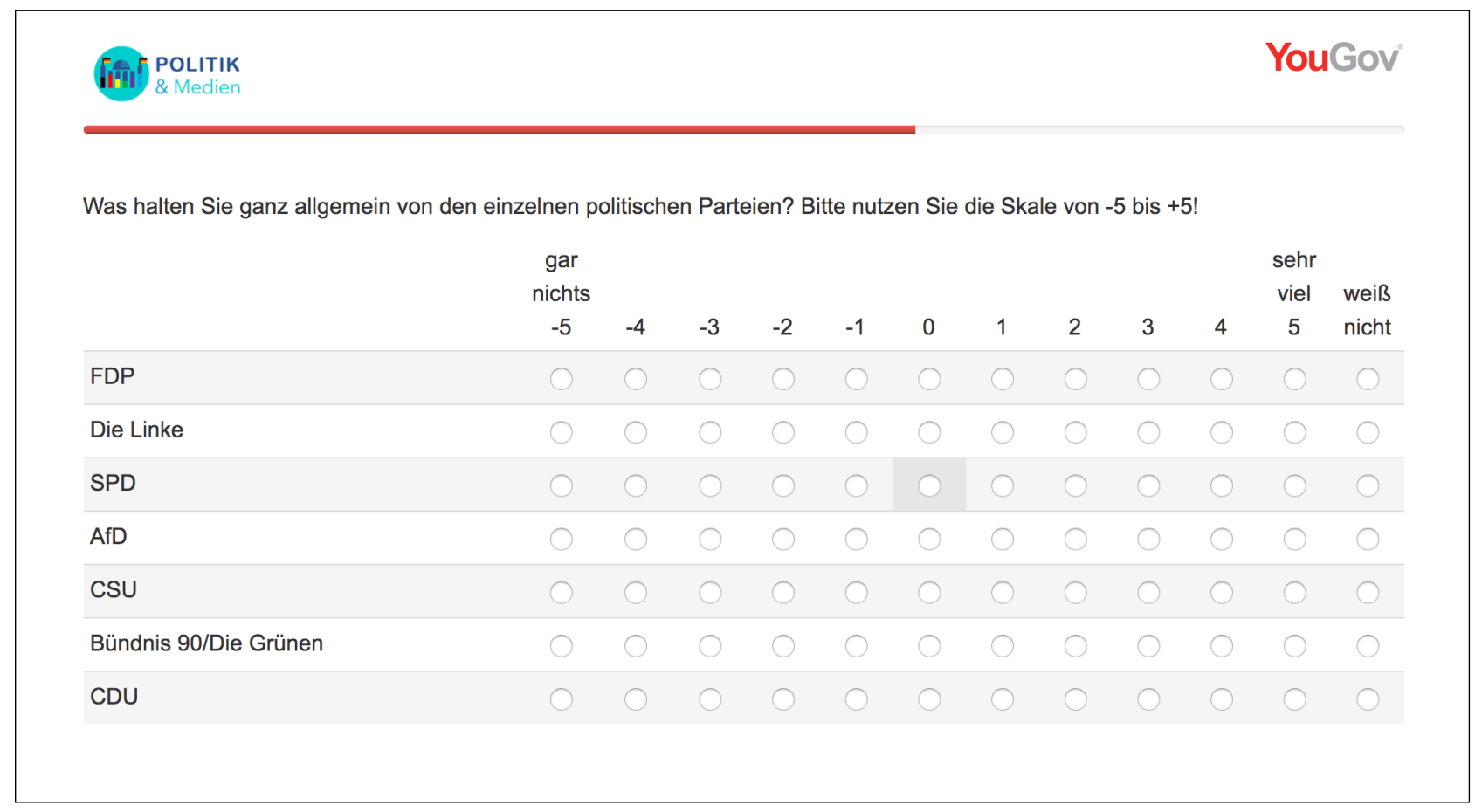

[Translated] Generally, what do you think of the individual political parties? Please use the scale from -5 to +5 !

Nothing at all

- ...

Very much

Don't know 


\section{References}

Best for Planning. 2017. Berichtsband b4p 2017. Gesellschaft für integrierte Kommunikationsforschung.

Menchen-Trevino, Ericka. 2013. "Collecting vertical trace data: Big possibilities and big challenges for multi-method research.” Policy er Internet 5(3):328-339.

Rivers, Douglas. 2006. “Sample matching: Representative sampling from internet panels.” Polimetrix White Paper Series .

Stier, Sebastian, Johannes Breuer, Pascal Siegers and Kjerstin Thorson. 2019. "Integrating Survey Data and Digital Trace Data: Key Issues in Developing an Emerging Field.” Social Science Computer Review p. 0894439319843669. 